\title{
Race, Obesity, and the Puzzle of Gender Specificity
}

\section{Mary A. Burke and Frank Heiland}

\begin{abstract}
:
Obesity is significantly more prevalent among non-Hispanic African-American (henceforth "black") women than among non-Hispanic white American (henceforth "white") women. These differences have persisted without much alteration since the early 1970s, despite substantial increases in the rates of obesity among both groups. Over the same time period, however, we observe little to no significant differences in the prevalence of obesity between black men and white men. Using data from the National Health and Nutrition Examination Surveys (NHANES) and the Behavioral Risk Factor Surveillance System (BRFSS) pertaining to the past two decades, we evaluate an extensive list of potential explanations for these patterns, including race and gender differences in economic incentives, in body size ideals, and in biological factors. We find that the gaps in mean BMI and in obesity prevalence between black women and white women do not narrow substantially after controlling for educational attainment, household income, occupation, location, and marital status-nor do such controls eliminate the gender-specificity of racial differences in obesity. Following these results, we narrow down the list of explanations to two in particular, both of which are based on the idea that black women (but not also black men) face weaker incentives than white women to avoid becoming obese; one explanation involves health-related incentives, the other, sociocultural incentives. While the data show qualified support for both explanations, we find that the sociocultural incentives hypothesis has the potential to reconcile a greater number of stylized facts.
\end{abstract}

\section{JEL Classifications: D11, I12, J15, Z13}

Mary A Burke is a senior economist at the Federal Reserve Bank of Boston. Frank Heiland is an assistant professor of economics at Florida State University. Their email addresses are, respectively, mary.burke@bos.frb.org and fheiland@fsu.edu.

This paper, which may be revised, is available on the web site of the Federal Reserve Bank of Boston at http://www.bos.frb.org/economic/wp/index.htm.

The views expressed in this paper are those of the authors and do not necessarily represent those of the Federal Reserve Bank of Boston or the Federal Reserve System.

We are grateful for the comments of seminar and session participants at the Brookings Institution, Florida State University, Clark University, the Southern Economic Association meetings, the Western Economic Association International Meetings, and the North American Econometric Society summer meetings. In particular, we want to thank Peyton Young, Carol Graham, Ethan Cohen-Cole, Damon Centola, and Robin Simon for helpful discussions and suggestions. For research assistance we thank Carl Nadler, Sarita Frattaroli, and the staff of the research library at the Boston Federal Reserve. All errors are our own.

This version: October 29, 2008 


\section{Introduction}

Since at least the early 1970s, obesity has been significantly more prevalent among non-Hispanic African-American (henceforth "black") women than among non-Hispanic white American (henceforth "white") women. ${ }^{1}$ Table 1 gives age-adjusted obesity rates for white women and black women, ages 20 to 74, over various time intervals between 1976 and 2004, based on the National Health and Nutrition Examination Surveys. ${ }^{2}$ In the 1976-80 data, the rate of obesity among black women exceeds that among white women by 15.6 percentage points; in the 1988-94 data the difference is 15.8 percentage points, and in the 1999-2004 data the excess is 20 percentage points. In these same surveys, the respective differences between black women and white women ages 20 years and older in the mean values of the body mass index (BMI) are 2.5, 2.95, and 3.6 units (not shown). ${ }^{3}$ However, as also shown in Table 1, obesity prevalence does not differ significantly between black men and white men in either the 1988-1994 data or the 1999-2004 data. Obesity was significantly more prevalent among black men as of NHANES II but by a much smaller margin than among women in the same survey.

In this paper, we propose a number of explanations for these surprising race-by-gender patterns in BMI and obesity. The explanations can be grouped loosely into three broad categories: economic incentives, health incentives, and sociocultural incentives. By economic incentives, we mean constraints, such as household income, food prices, and the opportunity cost of time, that bear on decisions influencing weight (and, therefore, BMI). By health incentives, we mean the elevated morbidity and mortality risks associated with obesity. By sociocultural incentives, we mean the rewards and punishments that individuals receive from social contacts for conforming to or deviating from a cultural standard of ideal size. To explain the stylized facts, a given set of incentives must exhibit gender-specific variation between blacks and whites in America, and the incentives must influence BMI in the predicted manner.

\footnotetext{
${ }^{1}$ The definition of obesity employed by the Centers for Disease Control (CDC) is a body mass index (BMI) value of 30 or greater. BMI is the ratio of weight, measured in kilograms, to squared height, measured in meters.

${ }^{2}$ The surveys on which these findings are based are NHANES II, which covers 1976-1980, NHANES III (1988-1994), and NHANES 1999-2004. Age-adjusted data by race and sex are not available in surveys prior to NHANES II.

${ }^{3}$ Prior to NHANES III, 74 was the maximum age of survey respondents. Hence, depending on which surveys are being compared, figures may be limited to the 20-to-74-year-old age group rather than the more inclusive 20-and-older group.
} 
Ours is the first paper in the economic literature to address this puzzle and, within the broader literature on obesity, the first to consider such a comprehensive set of explanations for the puzzle.

To evaluate the candidate explanations, we first undertake multivariate analysis of the determinants of BMI and obesity, employing both the National Health and Nutrition Examination Surveys (NHANES) and the Behavioral Risk Factor Surveillance System (BRFSS). ${ }^{4}$ This analysis shows that standard socioeconomic factors do not resolve the puzzle. For example, in the 1999-2004 data, adding controls for educational attainment, household income, occupation, residential location, and marital status reduces the black-white female BMI gap by just 0.71 units, from 4.04 to 3.33; adding the same controls to a model of obesity risk reduces black women's relative risk (compared with white women's) by 0.22 units, from 1.72 to 1.5 . We find quantitatively similar effects in earlier NHANES data and in the BRFSS data.

We then consider whether there might be gender-specific differences between blacks and whites in either the health incentives or the sociocultural incentives to avoid becoming obese. We focus on these types of incentives because previous research in such diverse literatures as public health, biology, and sociology has found evidence of black-white differences-in some cases gender-specific - in each of these dimensions. For example, there is evidence that differences in potentially exogenous physiological factors, such as body composition and fat distribution, result in gender-specific differences between blacks and whites in the health consequences of elevated body weight and, therefore, in the health-related incentives to avoid becoming overweight. In addition, the sociology and public health literatures have found evidence that aesthetic standards of ideal body size, as well as the severity of social punishments for being overweight, differ between black women and white women, and between women and men across racial groups. ${ }^{5}$ We can assess each of these explanations based on data contained in the NHANES III and 1999-2004 surveys.

\footnotetext{
${ }^{4}$ The BRFSS is a separate CDC survey that measures weight and height, desired weight, numerous health-related behaviors, and demographic information, based on telephone interviews of very large random samples (repeated cross sections) of the non-pregnant resident population aged 18 years and older in participating states of the United States.

${ }^{5}$ We reference this literature extensively below.
} 
Concerning health incentives, we find that the marginal effect of BMI on black women's risk of hypertension is smaller than the marginal effect of BMI on white women's hypertension risk. We also find evidence, although less robust, that similar racial differences apply to the association between BMI and diabetes and between BMI and heart failure among women. This difference in BMI-associated health risk accords with findings-from NHANES and other sources-that black women have a lower percentage of body fat than white women at the same BMI value, as fat has been found to be a stronger predictor of hypertension and diabetes than has BMI. ${ }^{6}$ Therefore, our findings indicate that black women may have weaker health-related incentives to avoid weight gain. While the health incentives story seems promising based on these findings, we find that black men also have a lower percentage of body fat than white men do at the same BMI. Therefore they, too, might have weaker incentives to avoid excess BMI. However, the NHANES data exhibit ambiguity as to whether black men's health is less negatively affected than white men's health is as a result of being overweight or obese. Carroll et al. (2008) also find mixed evidence concerning the gender-specificity of black-white differences in BMI-related health risks. Bacha et al. (2003) find that obese black adolescents have lower levels of dangerous visceral fat than obese white adolescents do, but the samples sizes are too small to discern gender-specific effects.

Concerning sociocultural incentives, the BRFSS data reveal that black women state significantly higher values for "desired" BMI than white women do, and NHANES data show that they are less likely to consider themselves overweight, and more likely to feel underweight, than white women at the same BMI. Black men, too, state higher desired BMI values than white men and are less likely to consider themselves overweight than are comparable white men, but the male differences in these indicators are smaller than the female differences. Further, the race and gender differences in selfclassification are qualitatively robust even after controlling for percentage of body fat. These findings agree with the hypothesis that there are race-and-gender-specific social norms governing body size. Furthermore, there is evidence that marriage-market and labor-market penalties for obesity follow race-

\footnotetext{
${ }^{6}$ See, for example, Cawley and Burkhauser (2006) and Carroll et al. (2008).
} 
and-gender-specific patterns consistent with such norms. ${ }^{7}$ If social norms of body size influence weight aspirations, such norms may also influence BMI outcomes. While the direction of causality between individual goals and individual outcomes, and between social norms and group outcomes, are legitimate concerns, we show that individual goals cannot be explained solely on the basis of individual size and that group norms are not fully explained by mean group BMI.

Either of these explanations-differential health incentives or differential social incentives-may hold unorthodox policy implications. For example, the health-risk story implies that official concern and focus on reducing obesity among black women may be excessive. Official BMI recommendations may need to be tailored to different demographic groups, or replaced with body fat recommendations and greater access to fat measurement. If the outcomes are driven largely by social incentives, the policy implications are less straightforward. The disconnect between individual perceptions of weight status and official standards suggests that public health institutions have a limited influence over body weight goals. To the extent that governments and other institutions attempt to affect outcomes by promoting particular size norms, they should take heed of an apparent tradeoff between strict norms-which may contribute to white women's lower obesity levels—and psychological well-being. For example, white women who become obese despite strict social standards appear to suffer more than obese women in other ethnic groups do in terms of low self-esteem and depression. In addition, the prevalence of eating disorders such as anorexia and bulimia appears significantly greater among white women than among black women (see, for example, Rucker and Cash 1992, Molloy and Herzberger 1998, Parker et al. 1995, and Powell and Khan 1995).

The current inquiry is the first to evaluate a broad set of explanations drawn from diverse literatures and using large representative surveys. We do not claim to fully resolve the empirical puzzle, but we hope to convince the reader that sociocultural factors reconcile the stylized facts more consistently than the alternative hypotheses we consider. At the same time, we hope to raise awareness of the complexity of the relationships between BMI, fat, and health, a complexity that may call for reforms

\footnotetext{
${ }^{7}$ See, for example, Averett and Korenman (1996) and (1999), Cawley (2004), and Baum and Ford (2004).
} 
in the criteria for obesity. The remainder of the paper is organized as follows: Section 2 describes the background. Section 3 briefly describes the data sources and sample selection. Section 4 presents the results, including the multivariate analysis of BMI and obesity, as well as the empirical evaluation of the competing hypotheses of health-related incentives and sociocultural incentives. Section 5 provides a summary of our findings and discusses policy implications. Detailed descriptions of the variables used in the empirical analysis are provided in the Appendix.

\section{Conceptual Background}

\subsection{Determinants of BMI}

Racial and ethnic differences in rates of obesity have been studied by researchers in the fields of public health, medicine, social psychology, and sociology. The public health and medical literature on the topic has been, for the most part, purely descriptive. Various explanatory factors have been proposed, including racial differences in socioeconomic status and in physiological factors such as resting metabolism, but none have been found to account conclusively for racial differences in BMI distributions. Furthermore, the mechanisms by which socioeconomic status-most often measured using individual or parental educational attainment—might influence the risk of obesity are not well articulated in this literature. ${ }^{8}$

The social psychology, cultural studies, and sociology literatures, as well as some research in the field of public health, have suggested that cultural factors may contribute to racial differences in BMI, although such suggestions have not been tested rigorously. Consistent with the NHANES evidence, prior researchers have identified racial differences in conceptions of body size, in subjects' perceptions

\footnotetext{
${ }^{8}$ Purely descriptive papers include Ogden et al. (2006), Flegal et al. (1998), and Dawson (1988); articles examining cultural and socioeconomic factors include Stevens, Kumanyika, and Keil (1994) and Kumanyika, Wilson, and GuilfordDavenport (1993); those citing physiological differences include Martin et al. (2004), Sharp et al. (2002), Weyer et al. (1999), Carpenter et al. (1998), Foster et al. (1997), and Yanovski et al. (1997). Kumanyika (1987, 1994, and 1999) consider multiple hypotheses.
} 
of their own size, and in attitudes towards dieting and exercise. For example, black women tend to point to larger images for ideal size than white women do. ${ }^{9}$ In addition, the black community at large has been characterized as more accepting of overweight, among women in particular, perhaps as a rejection of white female body ideals perceived as oppressive (see, for example, Thompson, Sargent, and Kemper 1996). To this mix of forces, other researchers have added the fact that identity prescriptions within the black community tend to cast black women as selfless nurturers, prescriptions that have resulted in black women's neglecting their own health needs (see hooks 1981, Beauboeuf-LaFontant 2003, and Lynch et al. 2007). Less research has been devoted to black male body image, but evidence suggests that the idealized physique is hypermasculine, characterized by extreme muscularity (Brown 1999, hooks 1992). The male-specific emphasis on athleticism in this ideal, combined with the female-specificity of the "nurturer" identity, may limit obesity among black men relative to black women.

The economic literature on obesity to date has focused more on explaining society-wide secular trends in obesity than on explaining cross-sectional variation in BMI. Thus, examination of possible economic explanations for racial patterns in obesity remains quite scarce. ${ }^{10}$ Nonetheless, the existing literature implies that economic factors used to explain secular trends in obesity—such as food prices and food production technology, income, labor force participation, and the nature of work-may also help to explain cross-sectional variation in BMI and obesity. ${ }^{11}$ The economic literature has also found evidence of significant labor and marriage-market penalties for overweight and obesity, penalties that are also found to vary by race and sex (see below for citations).

An individual's "choice" of weight, which is effectively a choice of BMI since height is exogenous,

\footnotetext{
${ }^{9}$ For a survey of this literature, see Flynn and Fitzgibbon (1998); more recent studies include Lovejoy (2001) and Fitzgibbon, Blackman, and Avellone (2000).

${ }^{10}$ Cawley and Burkhauser (2006) discuss the gender-specific differences in obesity rates between African-Americans and whites, but their analysis deals with measurement error in obesity rates rather than with explaining the racial patterns. However, their analysis strongly informs our investigation of racial differences in body fat and disease risks.

${ }^{11}$ Lakdawalla and Philipson (2002) and Philipson and Posner (1999) use declines in food prices and in the physical requirements of labor to explain long-term secular increases in obesity; Cutler, Glaeser, and Shapiro (2003) emphasize declines in the time cost of food preparation to explain the particularly sharp increase in obesity since the early 1980s. Chou, Grossman, and Saffer (2004) identify smoking and fast-food restaurant density as factors in obesity incidence. Burke and Heiland (2007) argue that social interactions on body weight magnified the effects of lower food prices on obesity.
} 
represents a complex problem. ${ }^{12}$ In the proximate or structural sense, weight is a stock that reflects lifetime "energy balance," which is just lifetime energy intake net of lifetime energy expenditure. ${ }^{13}$ The interesting questions pertaining to weight variation, however, are not merely matters of accounting. Ultimately, we want to know why some individuals eat more than others or burn fewer calories than others. These are difficult questions because caloric intake and caloric expenditure are determined by an array of complex human choices and biological processes, surrounding which there is considerable scientific uncertainty. The human choices depend on preferences concerning food and physical activity, preferences as to the weight outcome itself, and on constraints such as prices, income, information, technology, and the environment. The "environment" includes not just physical constraints but also social norms concerning ideal and acceptable body weight, factors that may in turn depend on aggregate outcomes in a society or group (see Burke and Heiland 2006 and Burke and Heiland 2007). To add even greater complexity, the contributions of BMI to health, longevity, and social and economic well-being may vary across individuals and are not known with certainty.

In order to analyze the determination of BMI in a manner that is useful for empirical work, we have to abstract considerably from such complexity. First, we assume that the choice problem results in a unique, (non-path-dependent) optimal, "equilibrium" value of BMI (for the given preferences, endowments, and constraints) that is stable over time, and that individuals are observed in equilibrium. (While it is more realistic to think of a life-cycle path of BMI, we abstract from age in the discussion immediately following. However, we control for age differences in the empirical analysis.) We assume that for the given optimal BMI for a given individual, there is a unique combination of choices of food intake and elective physical activity that maximizes utility, subject to achieving that stable BMI. Beginning with the physiological or structural relationship, we describe stable BMI as follows:

\footnotetext{
${ }^{12}$ Because we are focusing on adults, we assume height is fixed so that only changes in weight can induce changes in BMI.

${ }^{13}$ Technically speaking, if we consider energy intake and expenditure since birth (rather than since conception), birth weight must be added to lifetime energy balance to get final weight.
} 


$$
B M I_{i}^{*}=B M I\left(F_{i}^{*}, E_{i}^{*}\left(P A L_{i}^{*}, B M I_{i}^{*}, \varepsilon_{i}, g_{i}\right) ; H_{i}, N_{i}\left(B M I_{i}^{*}, \varepsilon_{i}, g_{i}\right)\right) .
$$

In the above equation, $B M I_{i}^{*}$ refers to the individual's optimal (and stable) BMI. The equation requires that this BMI be physiologically consistent with the (simultaneously chosen) optimal choices of food consumption, $F_{i}^{*}$, and voluntary energy expenditure, $E_{i}^{*}$, and with $i$ 's height, $H_{i}$, and involuntary or resting energy expenditure, $N_{i}$. Voluntary energy expenditure depends on the selected physical activity level (PAL), the individual's current BMI, a fixed idiosyncratic physiological endowment, $\varepsilon_{i}$, and on gender, $g_{i}$. Involuntary expenditure or resting metabolism refers to the expenditure required to support involuntary bodily functions in a resting state, and this also depends on current BMI, the idiosyncratic endowment, and gender. ${ }^{14}$ The dependence of caloric expenditure on current BMI reflects the fact that a larger body requires more energy to perform work. The idiosyncratic endowment reflects the fact that there is individual variation around the relationship between BMI and calorie-burning, both at rest and during physical activity. (As discussed below, however, the physiological endowment refers not just to the metabolic rate but to a broad set of phenotypic traits, such as sensitivity to hormonal signals, that contribute to BMI and related health outcomes.) In addition, the parameters of the relationship between BMI and calorie-burning differ between men and women, as may the distribution of endowments.

By physiologically consistent we mean that, beginning from any initial BMI value, when individual $i$ consumes the specified number of calories $\left(F_{i}^{*}\right)$ per day and expends energy per day equal to the sum of voluntary $\left(E_{i}^{*}\right)$ and involuntary $\left(N_{i}\right)$ calorie-burning, her BMI will stabilize at the value $B M I_{i}^{*}$. While there may be multiple physiologically consistent vectors $(B M I, F, E)$ for a given individual, we assume that only one such vector maximizes (lifetime) utility, given preferences, technology, and constraints. In equilibrium, the stable BMI can be reduced to a function of exogenous parameters, including the idiosyncratic endowment, food prices, income, and preference parameters. A parameterized structural

\footnotetext{
${ }^{14}$ Because of its dependence on BMI, the realized level of involuntary expenditure is, of course, endogenous. However, the function that maps BMI onto resting metabolism can be considered exogenous, as can the idiosyncratic shock. We abstract from the fact that resting metabolism is subject to individual control to the extent that one can alter one's level of fat-free mass through weight-training and other physical activity.
} 
model of BMI is given in Burke and Heiland (2007), which gives necessary and sufficient conditions for the existence of equilibrium BMI and characterizes the relationship between BMI and various exogenous factors.

The structural model (1) indicates that the caloric expenditure implied by a given level of physical activity depends on BMI. Based on what we found in Burke and Heiland (2007), the equilibrium relationship in (1) is highly non-linear. This suggests that empirical models in which BMI is linearly separable in food intake and physical activity level are misspecified. Moreover, the assumption that the observed caloric expenditure and exercise levels represent individuals' behaviors at their respective steady-state weights is difficult to verify empirically. To the extent that individuals are not observed in their steady state, estimated effects of behaviors will be attenuated. In addition, food intake and physical activity are likely to be measured with considerable error because they are self-reported and therefore subject to imperfect recall and/or self-reporting bias. Consequently, while it is natural to ask whether the race-by-gender patterns in mean BMI can be accounted for by patterns in caloric intake, patterns in caloric expenditure, or some combination thereof, an empirical strategy that focuses exclusively on the variation in behaviors proximate to BMI is likely to provide unsatisfactory results. Nevertheless, we do provide an estimate, however imperfect, of the contribution of these structural factors, using the available measures in the NHANES surveys below. ${ }^{15}$

Ultimately, we are interested in identifying the underlying factors that influence both the choice of an intended BMI value and the proximate determinants of BMI such as caloric intake and physical activity level. That is, we are interested in reduced-form models. These underlying factors, such as educational attainment, occupation, income, and location, are likely to be relatively stable among adults in the age group we select (25-74), and likely to be measured with less error than structural factors such as food intake. A reduced-form specification is also less likely to suffer from complications, such as

\footnotetext{
${ }^{15} \mathrm{~A}$ recent attempt to estimate structural models of BMI from NHANES data is Rashad (2007). She finds no evidence of an effect of caloric intake (activity-adjusted) or smoking after instrumenting with state-level data on restaurant prices, cigarette taxes, average temperatures in January and July, and clean indoor air laws. More importantly, she finds that the black-white gap for women is reduced only marginally (from 2.47 to 2.36 BMI units in pooled NHANES I, II, III data) in the IV model compared with OLS.
} 
endogenous or random coefficients, than is a model based on structural factors. To this end, we propose a reduced form expression for optimal BMI as follows:

$$
B M I_{i}^{*}=B M I\left(P_{f}, Y_{i}, H_{i}, \varepsilon_{i}, \delta_{i}, \beta_{i}, g_{i}, \theta_{T}, \theta_{S}, \theta_{C}\right)
$$

The expression indicates that the optimal BMI is a function of the relative money price per calorie of (undifferentiated) food, $P_{f}$; individual income, $Y_{i}$; individual height, $H_{i}$; the idiosyncratic physiological endowment, $\varepsilon_{i}$; a vector of idiosyncratic taste parameters, $\delta_{i}$, pertaining to food consumption, physical activity, and related life choices that may affect weight (such as smoking, labor force participation, and child-bearing); individual beliefs, $\beta_{i}$, about the health consequences of different BMI outcomes and about the relationship between BMI and behaviors such as smoking and exercise; a vector of technology parameters, $\theta_{T}$, that affect the time cost of food preparation and acquisition, the physical requirements of home and market labor, and the state of medical technology; a vector of social incentive parameters, $\theta_{S}$, consisting of a socially preferred weight (or BMI) or weight/BMI range and social penalties for deviating from the preferred range; and a vector of parameters, $\theta_{C}$, that captures relevant aspects of the physical environment such as climate, air quality, access to public transportation as well as access to various types of food. The last three parameters are held in common at higher levels of demographic or geographic aggregation, although the level may differ depending on the type of parameter; therefore, they are not subscripted at the individual level.

\subsection{Hypotheses}

As noted above, the form of the structural relation between body mass index, caloric intake, and physical activity is non-linear, a fact that arises because caloric expenditure depends on BMI, physical activity, and idiosyncratic metabolic shock. Qualitatively, however, the expectation is that equilibrium BMI is increasing in per-period caloric intake and decreasing in per-period physical activity level, holding all else constant. The relationships between body mass and the reduced-form variables are less intuitive 
and require some discussion. The discussion below describes a set of proxy variables for the theoretical determinants listed above and provides hypotheses relating these variables to BMI and to the race-BMI relationships of interest.

In terms of the reduced form model described above, educational attainment can be seen as a proxy for beliefs, $\beta_{i}$, about how behavior influences BMI, and about how BMI influences health. A healthdemand model along the lines of Grossman (1972) would predict that more educated individualshaving better information and resources with which to "produce" optimal health-should be more likely than less educated individuals to achieve a BMI in the medically optimal range, other things being equal. However, the health-demand model offers no clear prediction as to whether less educated people will tend to exhibit BMI values below the optimal range or above it, since health is non-monotonic in BMI. In the contemporary United States, people are at greater risk of being overweight, on average, than of being underweight. If we take the "default" condition to be overweight, then the effect of additional schooling on BMI is likely to be negative, provided we assume that a "normal" BMI is better, from an overall health standpoint, than is an "overweight" or "obese" BMI. According to this reasoning, racial differences in female educational attainment are expected to account for at least some portion of the black-white differences in female mean BMI and obesity rates.

Because household income imposes a budget constraint on consumption, it seems natural to expect income to have an influence on food consumption, although the resulting marginal effect on BMI is not obvious. Individuals may use added income to purchase a greater quantity of food, or to purchase higher-quality foods. In the latter case, calorie consumption could move either up or down, or stay constant, depending on the quality-quantity tradeoff. Additional income may also influence the demand for calorie-burning activities such as leisure-time exercise. Because the net effect on BMI of such changes in consumption is ambiguous, one might posit that individuals have an ideal BMI (exogenously given), and that closeness to the ideal constitutes a normal good. ${ }^{16}$ Starting from below the ideal, added income

\footnotetext{
${ }^{16}$ Lakdawalla and Philipson (2002) adopt this assumption to explain the observed non-monotonicity of BMI in income, although they do not discuss the origins of ideal BMI nor its potential variation over time and across individuals.
} 
would tend to increase BMI, and beginning from above the ideal added income would tend to decrease it. Deviation from the ideal reflects the tradeoffs between enjoying the satisfaction of being close to the ideal, the satisfaction of calorie consumption, and the (dis)-satisfaction of calorie-burning activities. In a world in which the average individual runs a high risk of starvation, ideal weights are likely to be above the average weight in the population, and higher-income individuals are likely to achieve higher BMI values than lower-income individuals. Contrariwise, in conditions of abundance, in which it becomes costly — in both psychic and economic terms — to avoid becoming overweight, ideal weights are likely to fall below the average weight in the population, and we would expect higher-income individuals to achieve lower BMI values than lower-income individuals. If the latter relationship holds, on average, among women, then the higher household incomes of white women may help to explain their lower mean BMI and their lower incidence of obesity relative to those prevailing among black women.

In addition to empirical evidence that income influences BMI (Lakdawalla and Philipson 2002, Conley and Glauber 2005) and that the relationship may be non-monotonic, there is also evidence that, among women, higher BMI leads to lower individual wages, lower probability of marriage, and lower spousal income (Baum and Ford 2004, Conley and Glauber 2005, Cawley 2004, Averett and Korenman 1996, 1999, Bhattacharya and Bundorf 2005). Although no consensus exists concerning the causes of such penalties for excess female weight — the penalties have been attributed variously to differences in productivity, differences in health insurance costs, and pure discrimination-the possibility of reverse causality between BMI and household income means that we must be careful in interpreting results of regressions involving income as an explanatory variable. Because we are not interested in estimating the treatment effects of income, however, mutual causality between income and BMI is a concern only to the extent that it could bias our estimate of racial differences. This caveat will be kept in mind throughout the discussion of results.

We include dummies for the calendar year to proxy for the state of technology, $\theta_{T}$, a state that we assume to be constant across individuals in the United States at a given time. Year dummies also proxy for the national food price level, $P_{f}$, and for any other factors affecting BMI at the aggregate level, 
such as a national public-health campaign aimed at reducing obesity. Variation in such global factors will modify measured effects of race only if such factors affect different racial groups differentlyfor example, if some groups tend to learn about or adopt new technologies more readily than others. Although the national level of food prices is directly observable, annual values of the Consumer Price Index (CPI) for food items will be collinear with year dummies, and yet less informative than year dummies. ${ }^{17}$

Age is observed directly, and is included as a proxy for a predictable set of changes in energy metabolism, appetite, and body composition over the life cycle. We also include an age-squared term, based on prior information about the functional form of the age-BMI relationship. Inclusion of age terms controls for the possibility that racial variation in age composition could be contributing to racial patterns in BMI.

An individual's location will be associated with environmental factors such as climate, population density, air quality, access to public transportation, food prices, and access to various types of food. These factors, denoted $\theta_{C}$ above, may impose constraints on the ability to achieve a given BMI, for example, by limiting exercise opportunities or lowering the cost of food acquisition. Because racial composition varies by location, location may help to explain racial differences in BMI. For example, if blacks live disproportionately in neighborhoods where fresh produce is expensive or even unavailable, we expect the residual race effect to fall, once location is controlled for. However, since location may also proxy for other factors, such as preferences over mode of transportation, that also predict BMI, we will be careful not to draw causal inferences concerning the influence of location on BMI. ${ }^{18}$

Like other demographic indicators, an individual's country of origin might predict BMI for a number of reasons. For example, preferred foods may differ between U.S.-born and foreign-born indi-

\footnotetext{
${ }^{17}$ In multivariate analysis using the BRFSS data, we will make use of local food price data to control for differences in price shifts over time in different regions. The geographic indicators in NHANES do not permit the use of localized food prices.

${ }^{18}$ Location may also capture some influence of social incentives, $\theta_{S}$, to the extent that such incentives vary with the data's geographic groupings. Since we want to isolate the influence of racial differences in social incentives, it is desirable to control for location-based social influences.
} 
viduals, as might BMI aspirations, insofar as these are influenced by cultural context. For more recent immigrants, economic constraints such as food prices may have differed from those in the United States over much of an individual's lifetime, possibly leaving a lasting impact on BMI. Depending on how foreign-born individuals identify themselves, failing to separate this category may introduce biases in estimated racial differences between blacks and whites born in the United States.

In the reduced-form equation above, we referred to preferences, technologies, and constraints that affect the costs and benefits of choices such as food consumption (both quality and quantity) and physical exercise. Some observable proxies for these underlying factors include marital status, occupation type, employment status, and, for women, the number of live births. Taken together with household income, these factors affect the benefits and costs of activities such as home cooking and leisure-time exercise. Since these factors vary by race and sex, they should be included in the multivariate analysis. Concerning marital status, a number of potential relationships are predicted. There is evidence that married people devote more time to home production (including meal preparation) than single people do (Cutler, Glaeser, and Shapiro 2003), presumably because housework produces greater value for a couple than for an individual. Consequently, married people face a higher opportunity cost of exercise than singles do, all else being equal, but they may also eat more home-cooked meals, a practice that has been linked to lower BMI (Cutler, Glaeser, and Shapiro 2003). Among women, the fact that obesity reduces the chances of getting married would predict a negative correlation between female BMI and female marital status (Averett and Korenman 1996). The presence of children in the household is likely to further raise the opportunity cost of leisure-time exercise and may also raise the household's demand for convenience foods. In addition, the experience of pregnancy may affect a woman's weight beyond the period of pregnancy itself.

Labor force participation may matter for several reasons. Ignoring selection issues, wage-earners will have a higher opportunity cost of leisure-time activities than non-earners. Among married or cohabiting individuals, the impact of household income may depend on whether it is self-earned or earned by the spouse. Empirically, women's (but not men's) increasing labor force participation has 
been linked to rising aggregate obesity and rising childhood obesity, one explanation being that working women rely more heavily on calorically dense convenience foods than non-working women do (Bleich et al. 2007, Anderson, Butcher, and Levine 2003) and that this leads to higher BMI for the children and possibly for the entire family. Among the employed, we might predict that individuals with more sedentary jobs would tend to have greater BMI than those with more physically demanding jobs, ignoring issues of selection into jobs. ${ }^{19}$ Job selection could yield various relationships: for example, if individuals chose sedentary jobs as a result of a general distaste for physical exertion, we would also expect a negative association between on-the-job activity and BMI. On the other hand, among women at least, there is evidence that high-wage, high-status jobs, which may be relatively sedentary, select for women with lower BMI (Conley and Glauber 2005). In addition, wage, job-status, and marriage penalties for higher-body-mass women may apply primarily to white women (Averett and Korenman 1999). This last result suggests that we should test for interactions between the race categories and the employment and marital status variables.

The reduced-form model also refers to a vector of sociocultural incentives, denoted $\theta_{S}$, consisting of an ideal weight and associated costs and benefits that depend on one's distance from the ideal. Such incentives are sociocultural in the sense that they apply to all members of a social group, or to a set of individuals identifying with a common culture, and in the sense that the benefits (or costs) of conforming to (or deviating from) the ideal are delivered in the course of social interactions. For example, rewards may include having more friends and romantic partners, and punishments may include ostracism and stigmatization. Punishments and rewards may also be self-imposed if individuals internalize the prevailing norms, and these punishments and rewards may extend into the realm of monetized costs and benefits, for example, if hiring decisions depend on conformity to a sociocultural weight standard. If such sociocultural incentives are salient, then we expect group-level ideals to influence the individual weight aspirations of group members; hence, to the extent that individual

\footnotetext{
${ }^{19}$ The increasingly sedentary nature of work has been cited as an important factor in rising obesity rates during the past century (Lakdawalla and Philipson 2002).
} 
aspirations influence individual outcomes, group ideals will influence individual outcomes. However, the degree of conformity of outcomes to the ideal will depend on the strength of the incentives for conformity/deviation, where these may be asymmetric relative to the ideal, depending on whether the deviation is above or below the ideal. To the extent that individuals do not choose gender and racial affiliations, variation in sociocultural incentives by race and sex will contribute to predicting variation in mean BMI in these dimensions. In Section 4.4.2, we discuss how we use available measures in the NHANES and BRFSS data to evaluate variation in physical ideals and associated incentives by race and gender, and the potential contribution of these ideals to variation in body mass by race and gender.

The model also includes influences of fixed idiosyncratic biological traits. The hypothesis is that racial variation in such traits, which may be gender-specific, either leads directly to gender-specific racial variation in BMI or results in gender-specific racial differences in the relationship between elevated BMI and associated health risks and therefore in the incentives to avoid elevated BMI. This hypothesis is relevant to our study because there is evidence that blacks, both men and women, tend to have a lower proportion of fat mass than their white counterparts of the same sex at the same BMI, where elevated adiposity or fatness is linked more strongly to the onset of diseases such as diabetes and hypertension than is elevated body mass, which does not differentiate between fat and fat-free mass (see, for example, Carroll 2008). ${ }^{20}$ In addition, blacks have been observed to have a lower amount of visceral (inner belly) fat than their white counterparts, and visceral fat is an even stronger predictor of heart disease and diabetes than is overall adiposity. ${ }^{21}$ Because we do not observe the exogenous genetic determinants of body composition and associated disease risks, we cannot test this hypothesis directly. However, as described in Section 4.4.1, the NHANES data do allow us to determine whether

\footnotetext{
${ }^{20}$ Although men are genetically predisposed to having a lower percentage of body fat than women, the threshold value of body fat percentage at which men's risks of diabetes and other disorders become elevated is lower than the corresponding threshold for women. Therefore, "excess" adiposity is a relative value, rather than an absolute.

${ }^{21}$ The evidence on racial differences in body composition comes from studies such as Bacha et al. (2003), Carroll et al. (2008), and from the NHANES data itself. Racial differences in body fat percentage in the NHANES data derive in part from the manner in which the raw examination data (that is, bio-impedance readings) are converted into estimates of body fat percentage. Following Cawley and Burkhauser (2006), we adopt a conversion equation that contains race- and gender-specific error-correction terms. Other studies, such as Gallagher et al. (1996), cast doubt on the validity of such error corrections, and therefore on the extent of racial differences in body fat percentage at a given BMI.
} 
black women (and, separately, black men) face a weaker association than whites of the respective sexes between elevated BMI and the risk of diseases such as Type II diabetes, hypertension, and heart disease.

\section{Data and Sample Selection}

As mentioned above, the bulk of the empirical analysis is conducted using data from the National Health and Nutrition Examination Survey (NHANES), a nationally representative series of cross-sectional studies conducted by the Centers for Disease Control (CDC). We also make use of data from the Behavioral Risk Factor Surveillance System (BRFSS), which we describe in section 4.3 and in the Appendix. The NHANES data include observations of weight, height, and other physical features measured by direct examination, as well as information about demographic and socioeconomic characteristics, life circumstances, behavioral choices, and health conditions, collected via in-person interviews. We examine data from each of NHANES I (1971-1974), NHANES II (1976-1980), NHANES III (1988-1994), and NHANES 1999-2004. However, our reported regression results are drawn from the latter two survey waves, which are more current and include more observations as well as a greater number of relevant factors than either of the first two surveys. ${ }^{22}$

We restrict the NHANES samples to individuals 25 to 74 years of age who had their height and weight measured by direct examination. ${ }^{23}$ The minimum age of 25 is selected in order to avoid mismeasurement of educational attainment, and the maximum age of 74 enables us to use identical age ranges across survey waves. We do not exclude any racial categories from the analysis, although our study focuses on the discrepancies between just two groups: non-Hispanic whites and non-Hispanic

\footnotetext{
${ }^{22}$ Since 1999, the survey has been conducted annually, with statistics reported in two-year increments. Reported figures for NHANES 1999-2004 refer to the combined data, but figures can be broken out for 1999-2000, 2001-2002, and 20032004. Data are available from NHANES 2005-2006, but we limit most tests to the 1999-2004 data in order to include the most comprehensive set of control variables.

${ }^{23}$ In interview sessions conducted prior to the physical examinations, individuals gave self-reports of weight and height. Some individuals were not subsequently examined and these individuals are excluded. This exclusion minimizes measurement error and does not affect representativeness, since survey weights are provided that pertain to use of the examinationonly sample.
} 
blacks. We calculate individual BMI as weight in kilograms divided by the square of height in meters. For detailed definitions of the variables used in the empirical analysis, refer to the Appendix.

\section{Results}

\subsection{Direct behavioral influences on BMI and obesity}

We noted above that estimating a structural model of BMI using our food intake and physical activity measures is not straightforward and also that measurement error is likely to blunt the contribution of these factors. Nonetheless, it is useful—both for policy purposes and for evaluating different explanatory hypotheses - to get at least a rough estimate of the contribution of behaviors proximate to BMI to the race-by-gender patterns in BMI and obesity. The raw data indicate that differences between blacks and whites in physical activity levels, smoking, and caloric intake are gender-specific (Table 3). For example, in the 1999-2004 data, the gap in exercise intensity between blacks and whites, while negative for both sexes, is smaller among men than among women. Also, black women and white women are about equally likely to be current smokers, whereas black men are significantly more likely than white men to be current smokers. Black men consume fewer total calories than white men, while black women and white women report consuming about the same number of total calories.

To determine whether these behavioral patterns can provide a proximate explanation of the racial and gender patterns in BMI, we estimate a model, using the NHANES 1999-2004 data, in which BMI is linear in caloric intake, physical activity level, smoking behavior, and dietary composition. We add age, race, and interactions between race and behavior in subsequent specifications. Smoking has been found to be strongly negatively associated with BMI and may be used as a means of weight control by some individuals. Because the exact mechanism by which smoking acts on weight is not fully understood, smoking behavior may show up as significant in determining BMI, either because it captures smokinginduced metabolic differences or because it proxies for measurement error in reported caloric intake. 
Similarly, dietary composition may help to explain BMI, either because different types of calories (for example, fat calories versus protein calories) influence weight differently-a claim that is subject to dispute—or because the composition measures proxy for measurement error in total caloric intake.

Assuming individuals are at their respective stable weight values consistent with their respective caloric intakes and physical activity levels, we expect BMI to increase in caloric intake, to decrease in physical activity level, and to decrease with cigarette intake (proxied by discrete smoking categories), in each case holding all else constant. The expected impact of dietary composition, such as percentage of calories from fat, is unknown. As Table 4 shows, for women we find that the expected relationships hold, and are highly significant with respect to vigorous exercise and being a current smoker. Women who reported diets relatively high in the share of either fat or protein as compared with carbohydrates had significantly higher BMI values, while those reporting a greater share of calories from alcohol had significantly lower BMI. However, total caloric intake had no significant effects on BMI in any of the specifications. This last finding could reflect measurement error in the reporting of caloric intake, and/or an omitted variable bias caused by a positive correlation between caloric intake and the (unobserved) idiosyncratic shock to resting metabolism. The table shows that, using a linear probability model, the relationships between the behavior measures and the prevalence of obesity are similar to the relationships between behavior and BMI. Based on the models that omit age and race, we find that the behavioral variables together explain 5.1 percent of the variation in female BMI, and 4.1 percent of the variation in female obesity.

Based on this linearized structural regression, we can estimate how much of the black-white gap in mean female BMI can be accounted for by differences in the observed behaviors. We do this by comparing predicted BMI values, at various ages, for the following: (1) a white woman with average white-female behavior, (2) a black woman with average black-female behavior, (3) and a black woman with average white-female behavior. As Table 5 shows, for women of average age (45.75) in NHANES 1999-2004, these predicted BMI values, respectively, are 27.8, 31.7, and 31.45. Behavioral differences account for .25 BMI units, or 6.4 percent, of the total black-white female BMI difference of 3.9 units. 
Patterns in the raw data (seen in Table 3), together with these regression results, suggest that black women's lower exercise levels figure most prominently among the behavioral factors that contribute to their having higher BMI.

We observe similar patterns for men in terms of the significance of behavior variables on BMI and obesity. However, the impact of exercise appears considerably weaker for men, and the impact of smoking stronger than, the corresponding impacts observed among women, and the share of calories from alcohol has no significant effects on male BMI or male obesity. While no significant blackwhite BMI gaps among men are observed in these regressions, the prediction exercise indicates that, if average-age black males adopted average white-male behaviors, the BMI of black males would increase by .4 BMI units, an increase that would push black male BMI above white male BMI. Therefore, behavioral differences_-and the greater prevalence of smoking among black men in particular-help to account in some measure for the absence of a gap in BMI between black men and white men.

\subsection{Reduced-form estimation of BMI and obesity}

The parametric form of relationship (2) is unknown. To test for robustness of results against model uncertainty, we estimate several different empirical models: those in which the dependent variable is BMI, which is assumed to be linearly separable in its arguments, those in which log BMI is the dependent variable and also linearly separable in its arguments, and those with the same respective dependent variables, but allowing for interactions between the race categories and other included factors such as education or income. ${ }^{24}$ We also estimate Poisson regression models of the risk of the binary outcome, obesity, defined as having a BMI value greater than or equal to 30, involving the same sets of covariates as in the various linear models. ${ }^{25}$

\footnotetext{
${ }^{24}$ The significance and magnitude of the effects are not substantively different between the models with BMI as dependent variable and those with log BMI as dependent variable; for ease of exposition we suppress results from models using log BMI. We also estimated similar models, to the extent that the data allowed, using the earlier NHANES surveys. Since the magnitude of the female race gap in BMI and obesity risk changes little between waves I, II, and III, we report only the findings from NHANES III and NHANES 1999-2004.

${ }^{25}$ While a logistic regression may seem the more natural choice here, the high prevalence of obesity in the subject population means that odds ratios derived from logistic regressions will not (as they do for outcomes with low prevalence)
} 
We estimate the models in stages in order to determine the extent to which inclusion of additional variables alters the magnitude of the race residual. First, we examine the impact of education and income on BMI and on residual race effects in the NHANES data. Then, we expand the list of controls to capture additional factors in the model described above. Complex survey design is accounted for, in all data sets, using Stata's "svy" commands, which weight the data appropriately and account for various levels of clustering in the survey design when producing standard errors. In the NHANES data, we cannot control for individual calendar years. Given the long time span of the data across surveys, we estimate the model separately for each survey wave, pooling the 1999-2004 data as recommended in the NHANES analytical guidelines (National Center for Health Statistics 1996).

Table 6 reports, for women observed in NHANES III, estimated coefficients from linear regressions of BMI against various groups of regressors. The first row in each column (in bold) gives the estimated difference in mean BMI between black women and white women conditional on the other covariates, the estimated coefficients for which are shown in subsequent rows. Table 7 shows the results of the Poisson models of obesity risk for women observed in NHANES III. Here, the first column indicates the estimated ratio of relative obesity risk for black women compared with white women, conditional on the other covariates. Subsequent rows indicate the remaining coefficients of relative risk. Tables 8 and 9 are analogous, respectively, to Tables 6 and 7, for women observed in NHANES 1999-2004. Tables 10 through 13 show the corresponding results for men.

\subsubsection{Educational attainment and household income}

In a baseline specification that includes only the variables age, age squared, and race/ethnicity on the right-hand side, we observe a large and highly significant difference in mean BMI between white women and black women. The estimated difference for NHANES III (Table 6, column 1) is approximately 3.15 BMI units, the equivalent of about 17 pounds for a woman of average height (about 1.62

approximate relative risks of obesity. Poisson regression produces reliable estimates of relative risks, and provides robust confidence intervals via the use of the survey command. We find that the results are qualitatively similar, in terms of the significance and relative magnitudes of race differences, regardless of whether we adopt a logistic or a Poisson model. 
meters or 64 inches, a figure that does not differ significantly between blacks and whites). The difference in mean BMI estimated in the 1999-2004 data is, at 4.04 BMI units, significantly greater (based on standard errors) than that estimated in the earlier data. The Poisson models indicate that the risk of obesity is significantly higher among black women than among white women, but the estimated relative risk ratio of 1.7 does not differ significantly across the survey periods.

Significant black-white gaps remain in mean female BMI and obesity risk after the education and income measures are added to the model. However, as shown in Tables 6 to 9, the estimated gaps narrow somewhat when these controls are included. Consistent with our predictions above, the estimates indicate that women with postsecondary education have lower BMI and lower prevalence of obesity than women who did not complete high school. Across models and data sets, we also find that women in households with high incomes (incomes more than 3.5 times the poverty level) have significantly lower BMI and a lower likelihood of being obese than their counterparts from the lowest-income households. ${ }^{26}$ These findings suggest that differences in educational attainment and household income between black women and white women contribute to, but do not fully account for, the differences in BMI and obesity between these groups.

Turning to the results for men, in the baseline specifications (age, age-squared, and race), we find no significant differences in either mean BMI or risk of obesity between white men and black men. When income and education are added to the models, as shown in Tables 10 to 13, the lack of racial differences holds, with one exception: in the 1999-2004 data only, we observe a slightly higher mean BMI, by 0.54 units (significant at the 10 percent level), among black men compared with white men. The association between educational attainment and BMI (or obesity) is qualitatively similar between men and women, despite appearing weaker for men in the 1999-2004 data. The relationship of BMI to income, however, differs between the sexes. For men, we observe no significant difference in mean BMI (controlling for age, age-squared, race, and education) between the lowest-income group and the

\footnotetext{
${ }^{26}$ Our results are consistent with earlier cross-sectional findings such as Chou, Grossman, and Saffer (2004). Using a pooled sample of men and women in the BRFSS, they report significant negative coefficients for the effects of educational attainment and income on BMI (and obesity), respectively.
} 
highest, while the middle income group has significantly higher mean BMI than the lowest group. This same non-monotonic relationship is observed for relative obesity risks.

Given the income-BMI relationship observed for men, and the fact that a small BMI gap emerges after controlling for income, there is some suggestion that income distribution of black males exerts a net negative effect on black men's mean BMI compared with that of whites, perhaps because there are more middle-class white men than middle-class black men.

\subsubsection{Occupation, marital status, and foreign-born status}

The next stage of the model retains the right-hand-side variables, age, age-squared, race, educational attainment, and household income, and adds the occupation categories (which subsume employment status), the marital status categories, and the status of being either foreign-born or native. In each of Tables 6 to 9, column (4) shows the results of the regressions (either linear or Poisson) that add these factors. The omitted occupation category is "blue-collar," the omitted marital category is "nevermarried," and the omitted foreign-born category is "U.S.-born."

The tables show that the differences between black women and white women in mean BMI and risk of obesity narrow some with the additional controls but remain highly statistically significant. They also show, for the 1999-2004 data, that women in skilled, white-collar jobs are significantly less likely to be obese than women in blue-collar jobs, and that they have marginally lower mean BMI at the 10 percent significance level. There is some suggestion in the 1999-2004 data that obesity is more prevalent among women in blue-collar jobs than among women in each of the other occupation categories, including "unskilled white collar" and the "not employed" group, but these effects are significant only at the 10 percent level and have no parallels in the mean BMI results. These results lend credence to the findings of Conley and Glauber (2005) that women's obesity status (but not men's) influences their job status, since skilled, white-collar jobs are not likely to be more physically demanding than blue-collar jobs; we observe no equivalent relationship in the NHANES data among men (see Tables 6 through 9).

The results from the 1999-2004 data indicate that women who are married or cohabiting, and 
women who are divorced, have significantly lower BMI values and are less likely to be obese than nevermarried, noncohabiting women. ${ }^{27}$ These results are consistent with the prior evidence (Averett and Korenman 1999) that having higher BMI reduces a woman's probability of getting married. However, the NHANES III results for women lend no support to this relationship, as none of the marital status categories have significant coefficients.

We noted above that child-bearing and child-rearing might be expected to increase female BMI for a number of reasons, for example because pregnancy-related weight gain may persist post-partum and/or because children raise the demands on caregivers' time, which might otherwise be devoted to exercise or healthy meal preparation. (Recall that pregnant women are not included in either the NHANES or BRFSS because of the distortion of BMI during pregnancy.) The NHANES data do not indicate whether children are present in the household, but they do report the number of live births a woman has had. We find that neither a binary indicator of whether a woman has had any live births, nor the actual number of births, has a significant impact on female BMI and risk of obesity, for either NHANES III or NHANES 1999-2004. Furthermore, the estimated effects on BMI (and on risk of obesity) of being a black female are unchanged with the inclusion of the live births measures. Given these findings, we do not report the results of regressions in which live births variables are included. These findings seem unsurprising when one considers that the time elapsed since birthing events is not reported and that both marital status and age may proxy for the impact of pregnancy and child-rearing on female BMI. Any impact of child-rearing on men may also be partly captured by men's marital status and men's age.

Being foreign-born is associated with a large and significant negative effect on female BMI, and a sizable and significant lowering effect on risk of obesity, in the NHANES 1999-2004 sample, but has weaker or insignificant effects in the NHANES III estimates.

While we found no significant gaps in mean BMI or risk of obesity between black men and white men in the previous specifications, when we control for the additional factors of occupation, marital sta-

\footnotetext{
${ }^{27}$ The results are weaker for differences in risk of obesity (10 percent significance level) than for differences in BMI (5 percent significance level).
} 
tus, and foreign-born status a significant black-white difference in mean BMI emerges in the NHANES 1999-2004 data (see Table 12, column 4). According to these estimates, the mean BMI of black men exceeds that of white men by 0.75 points, significant at the 5 percent level, conditional on the other included factors. The Poisson model yields a relative risk of obesity estimate of 1.11 for black men compared with whites, but the effect is not significant. As stated above, the occupation indicators have no significant effects for men in either specification (linear or Poisson) or survey period. However, the estimates for 1999-2004 indicate that married men have significantly higher BMI (by 0.89 units, significant at the 5 percent level) than never-married men. The same effect is not significant in the NHANES III data, and, despite point estimates indicating a higher relative risk of obesity of married men in both surveys, no significant differences in obesity by marital status are observed. Like foreign-born women, foreign-born men have significantly lower BMI and obesity prevalence than U.S.-born men in both survey periods, but more so in the more recent data, although the difference is only marginally significant in the earlier survey.

Based on this evidence, the absence of the black-white BMI gap among men in the baseline specification may reflect a larger share of foreign-born men among those identifying as black relative to the share among those identifying as white. For the 1999-2004 data, the absence of a racial gap in BMI for men could also reflect differences in relationship status, since we observe in these data that a smaller share of black men than white men fall in the married/cohabiting group (see Table 3). Given that marital effects on BMI are less likely to represent selection effects for men than for women (Averett and Korenman 1996 find no selection into marriage on the basis of BMI for men), marital status differences could make at least a proximate contribution to gender-specificity in the BMI gap between these races.

\subsubsection{Physical activity, smoking, and food intake}

As an additional exercise, we supplement the reduced-form model with the measures pertaining to smoking behavior, level of physical activity, total calories consumed, and dietary composition. While this model is likely to be misspecified, the point is to determine whether these behavior measures 
are redundant when education, income, and other relatively exogenous factors are accounted for. If behavior were found to be redundant, the suggestion might be that behavioral differences are reducible to the observed constraints and that residual racial differences reflect differences in fixed physiological endowments that influence BMI directly. If behavior were found not to be redundant, however, we would suspect the presence of a racial difference in preferences over BMI-a difference that is not reducible to the other included factors. Of course, such a difference in preferences might derive from racial differences in either sociocultural incentives and/or health-related incentives.

Models (5), (6), and (7), in Tables 6 to 9, show results for models of female BMI and obesity that add, in succession, the exercise, smoking status, and dietary composition variables described above. In the 1999-2004 model of female BMI, adding the exercise indicators ("moderate activity" and "vigorous activity," with an omitted category for individuals reporting no engagement in either moderate or vigorous leisure-time physical activity) reduces the point estimate of the black fixed effect by 0.14 units, from 3.33 to 3.19. (Each of these latter estimates is highly significant, but the standard error of 0.38 on each estimate exceeds their difference.) This reduction roughly equals the reduction that occurs when the occupation, marital status, and foreign-born variables are added simultaneously. Adding exercise augments the R-squared by more than adding the latter set of variables does. (Among the 1999-2004 results, the increase in R-squared from adding the exercise measure is greater than the increase from any of the other model augmentations we undertake.)

While moderate activity has only a marginally significant negative effect on BMI (columns 5 and 6), vigorous activity is associated with a sizable and highly significant reduction in BMI (columns 5, 6, and 7). For comparison, the estimated effect of vigorous activity is greater than one-half the effect, estimated in the baseline regression, of being black (column 1), and close to three-quarters the effect of being black, estimated in the most inclusive model (column 7). For NHANES III, the exercise measure differs, but the impact on the BMI gap of adding the control is quantitatively similar to that observed with the 1999-2004 data, and the coefficient on the exercise index is highly significant. ${ }^{28}$ Concerning

\footnotetext{
${ }^{28}$ The coefficient on the "exercise index" means that a one-point increase in exercise intensity, along the 100-point index
} 
black women's relative risk of obesity, the impact of adding the exercise control is weaker in relation to the impact of adding the income controls than we observed in the linear BMI models. The impacts of vigorous exercise (1999-2004) and of exercise intensity (NHANES III) were again highly significant and associated with sizable reductions in the risk of obesity.

Adding smoking status, with "never smoked" the omitted category, reduces the point estimate of the fixed effect of being black by a further 0.15 units in the 1999-2004 data, and adds another 1 percent to the R-squared. Being a current smoker is associated with significant reductions in BMI in both survey periods. In the 1999-2004 data the estimated effect of (current) smoking on BMI is roughly on par with the effect of vigorous exercise. These results appear to suggest that a greater percentage of white women than black women are current smokers and that this disparity helps explain white women's lower BMI. However, in the raw data (Table 3), the share of current smokers in NHANES 1999-2004 is roughly equal between white women ( 22 percent) and black women ( 23 percent). The simple explanation of this apparent contradiction is that the black fixed effect on BMI in the model with the smoking controls (column 6) is not significantly different from the black fixed effect in the preceding model without such controls (column 5). Consistent with this observation, the point estimates of the black fixed effect in the corresponding models using the NHANES III data are virtually identical (Table 6, columns 5 and $6)$.

Adding the dietary composition variables does not change appreciably the estimated effect of being black on BMI, nor does it change the effect on the risk of obesity. In both survey periods, consuming a higher percentage of calories from either fat or protein relative to the share from carbohydrates is associated with significantly higher BMI. In the 1999-2004 sample only, a greater share of calories from alcohol is associated with significantly lower BMI. The Poisson model results for both surveys indicate that each one-percentage-point increase in the share of fat calories (at the expense of carbohydrate calories) raises the risk of obesity by one percent. The share of calories from alcohol lowers the

scale, is associated with a 0.10 unit reduction in BMI, and a one-standard-deviation increase in exercise intensity would be associated with about a half-unit decrease in BMI, which is close to 3 pounds for a woman of average height. 
risk of obesity significantly only in the later survey and the share of calories from protein raises the risk of obesity significantly only in the earlier data.

The results indicate that higher BMI and greater prevalence of obesity among black women may be partly attributed, in the proximate sense, to their being less physically active than white women. As seen in Table 3, 53 percent of black women reported that they engage in little to no leisure-time exercise, as compared with 31 percent of white women. This difference in behavior is not explained by racial differences in educational attainment, household income, marital status, foreign-born status, or occupation. Our interpretation is that racial differences in unobserved factors affecting a woman's motivation to achieve a given BMI value result in white women's simultaneously targeting lower BMI values and selecting higher physical activity levels, relative to the corresponding choices of black women. We discuss two such motivational factors and their potential explanatory power in the sections below.

We find similar patterns in the effects of the behavioral variables on BMI and risk of obesity for men. Exercising, smoking, and a diet lower in relative fat are associated with lower levels of BMI and risk of obesity. In the NHANES III data, a significantly higher obesity risk for black men appears when the (continuous) exercise level is added to the model (Table 11, column 5), but the same difference in risk does not emerge in the 1999-2004 data when we add the (discrete) exercise categories (Table 13, column 5). The (positive) black fixed effect on BMI in the 1999-2004 data increases from 0.75 units to 0.82 units when the exercise categories are added, but this change is not significant (Table 12, columns 4 and 5). Controlling for smoking behavior does not change the black fixed effect on BMI in either survey period. However, in the 1999-2004 survey, black men's obesity risk becomes significantly higher than white men's when we control for smoking (Table 13, column 6).

We suspect that behavioral differences account for a greater share of the racial differences in BMI than is evidenced by our tests so far, because the measures of behavior are quite coarse and subject to self-reporting error. To the extent that measurement error in the behavioral factors is race-specific, we address this shortcoming in the following section by testing for race-specific impacts of physical activity, smoking, and diet. 


\subsubsection{Interactions between racial categories and control variables}

For a number of reasons, we might expect that factors in the models above could have a different effect on BMI or the risk of obesity within the different racial categories. For example, the content or quality of education could differ across groups for the same level of attainment, as might result from racial segregation in schools. In addition, average educational attainment within the top-coded group "some college or above" could differ between blacks and whites. Similarly, the effect of income may differ as a result of differences in mean income within the top income group, or as a result of racial differences in any reverse effects from BMI to income. ${ }^{29}$ Concerning occupation, prior research has found that labor market and marriage-market penalties for overweight and obesity are weaker among black women than white women (Averett and Korenman 1999, Conley and Glauber 2005). Given the coarseness of the exercise and smoking measures, the average frequency and intensity of exercise, or the average quantity of cigarettes, may differ between blacks and whites within the same category. For any of the included variables, measurement error could be more severe for one group than for the other, resulting in weaker effects for one group due to attenuation bias. ${ }^{30}$

We now describe the results from the obesity models for NHANES 1999-2004, starting with those for which interaction effects appear strongest (Table 14). For women, we find significant interactions (5 percent significance or better) between the dummy variable for being black and the variables "middle income," "high income," "unskilled white-collar job," "vigorous exercise," and "percent of calories from fat.",31

The results indicate that the income-obesity gradient differs significantly between black women and white women. Among white women, being in the middle-income group is associated with 19 percent

\footnotetext{
${ }^{29}$ By using the poverty-income ratio as our income measure, we automatically control for racial differences in household size, since poverty thresholds are household-size-specific.

${ }^{30} \mathrm{We}$ test for interactions one variable at a time. We are unable to include interaction terms for all variables simultaneously because of insufficient degrees of freedom.

${ }^{31}$ Results from NHANES III for women find fewer significant interactions. Only one interaction is significant for NHANES III that is not also significant in the later survey. This result implies that the impact of some college on risk of obesity is considerably weaker for black women than for white women, but we do not highlight this result because it is not robust.
} 
lower risk of obesity relative to that of the lowest-income group. However, being middle-income rather than low-income raises black women's risk of obesity by an estimated 9.8 percent. Being in the highestincome group lowers the risk of obesity for both white and black women, but by a significantly smaller margin among blacks: the relative risk estimates are .69 for high-income white women and .86 for high-income black women, relative to low-income, same-race peers. These results imply, consistent with patterns in the raw data, that the disparity in the risk of obesity between black women and white women is greatest in the high-income group and smallest in the low-income group.

The interactions between black identity and the occupation categories suggest that, among white women, the risk of obesity among unskilled white-collar workers is significantly lower than that among blue-collar workers, while the opposite relationship between risk of obesity and occupation group holds among black women. White women in skilled white-collar jobs also have a significantly lower risk of obesity than white women in blue-collar jobs, and there is evidence at the 7 percent significance level that the reverse relationship holds again for black women. The results also show no significant difference in the risk of obesity (the relative risk estimate is 1.18 , with a p-value of .159), controlling for the other included factors, between black women and white women when both hold blue-collar jobs. Taken together, these findings imply that differences in obesity rates between black women and white women appear to be concentrated among white-collar workers, a fact that is seen already in the raw data on the relative risks of obesity by occupation category (see Table 2).

The interactions between race and income, and between race and occupation, are consistent with prior evidence, based on longitudinal data, that white women suffer greater wage penalties, spousalincome penalties, and job-status costs of being obese than do black women. ${ }^{32}$ Our occupation results suggest a number of potential explanations. We might conclude that job-status penalties for obesity either do not apply to black women or that they are dominated by treatment effects that result in bluecollar workers' having lower BMI than white-collar workers. Alternatively, white women might select

\footnotetext{
${ }^{32}$ Cawley (2004) finds significant wage penalties associated with obesity among white women, but not among black women. Averett and Korenman $(1996,1999)$ find significant negative effects of obesity on white women's marriage prospects and spousal income, but little to no effect of obesity on black women's wages or marriage prospects.
} 
into occupations on the basis of obesity status, or preferences that predict obesity status, even in the absence of employer penalties, while among black women the relationship between job preferences and obesity might differ.

If, for the sake of argument, we interpret the relationships between obesity and occupation among white women as evidence of obesity-related job-status penalties, and if we assume that all women prefer white-collar jobs to blue-collar jobs, then the data patterns suggest that, all else being equal, white women have a stronger incentive than black women to avoid obesity. Although researchers have differed in their views as to the cause of body mass-related labor-market penalties- two prominent explanations include body mass-related differentials in productivity and appearance-based discriminationthe differences in incentives will hold regardless of their cause, provided they are imposed by employers and not merely statistical artifacts of self-selection into occupations. In the discussions below of the potential roles of differences between black women and white women in either the health consequences or the social consequences of BMI, we will consider which set of consequences might better reconcile the various findings on labor-market penalties for obesity by race and sex.

Both moderate and vigorous exercise appear to have a stronger association with a lower risk of obesity among white women than among black women. White women who report moderate exercise had a risk of obesity 0.85 times the risk of women who report no exercise, and those white women who report vigorous exercise had risk only 0.56 times the risk of the reference group. Among black women, however, moderate exercisers had higher risk of obesity, by a factor of 1.14 , than non-exercisers, and vigorous exercisers were 0.79 times as likely to be obese as those in the sedentary group. Based on the wording of the survey questions, there is room for variation within each exercise group in the frequency and intensity with which the "moderate" or "vigorous" activities are performed. Hence, the results may mean that the average intensity and/or frequency of activity within each category is lower among black women than among white women. There may also be racial differences within each group in unobserved behaviors, such as food consumption, that negate the effects of exercise. If so, it may be that white women engage in exercise to a greater extent than black women, in order to maintain a low 
BMI and not just for recreation or to gain fitness and/or muscle mass-reflecting a difference in body goals across groups that we will discuss in more detail below. Of course, these differences may reflect the presence of greater error in measuring the intensity of exercise among black women than among white women - although we see no obvious reason to expect racial differences in measurement error here.

For white women, a 1-point increase in the percentage of calories from fat is associated with a 2-percent increase in the risk of obesity. For black women, however, the significant interaction term implies that the same increase in the share of dietary fat is associated with a 1-percent reduction in the risk of obesity. These results may indicate racial differences in the association between the share of fat calories and total calories consumed, and also suggest that diets higher in fat do not necessarily raise the risk of obesity. When total calories are included in a regression, however, their impact on the risk of obesity is insignificant (results not shown). While dietary composition appears to hold greater explanatory power over obesity than total caloric intake, it is possible that the composition variables are better proxies than measured caloric intake for true caloric intake.

Looking at potential interactions between race and the various right-hand-side variables in models of the male risk of obesity, we find some evidence that, for black men, having a higher income implies having a higher mean BMI relative to lower-income black men, but the same does not hold for white men. (The interaction coefficient is significant at the .07 percent level.) Concerning the risk of obesity, the interaction term between high income and the dummy for being black is not significant, but including the interaction term reduces the significance of the main effect of black identity on risk-the p-value increases from .085 to .578 , suggesting that the marginally significant difference in the risk of obesity in the model without interactions is driven by differences in obesity among high-income men. Similar to the findings for women, in the raw data we find that relative risk of obesity for black men is greatest for the high-income group, in contrast to the risk patterns for women; however, this is the only income group for which black men's relative risk is greater than one-the value is 1.163.

We find no systematic differences in BMI or risk of obesity across occupation types for men of 
either race. We also find, as discussed above, that the risk of obesity is not consistently negatively associated with income among men, for either blacks or whites. Thus, we observe that evidence of obesity-related job-status and wage penalties, and of racial differences in the strength of such penalties, is specific to women. ${ }^{33}$ This gender-specificity does not, on its face, explain the relationships between race, gender, and obesity, but it may provide some clues. As we evaluate below the roles of social incentives and health incentives, respectively, in explaining the stylized facts about obesity, we will consider whether either set of forces also predicts the observed relationships between BMI (or risk of obesity) and occupation, and between BMI and household income by race and sex.

The model with interactions that includes the smoking variables indicates that black male "neversmokers" have 1.36 times the risk of obesity of white male "never-smokers," and that smoking has significantly stronger effects for black men than for white men in reducing the risk of obesity. We note that the gender-specificity of the relative risk of obesity disappears for the never-smoking group: black men and black women in the never-smoker group are estimated to have nearly identical relative risks of obesity ( 1.37 for men, 1.39 for women) compared with never-smoking whites of the same sex, and this risk value is also close to black women's relative risk, estimated at 1.42, on average, across the categories of all the control variables. Consistent with the raw data, these results indicate that black male smokers have particularly low obesity rates, lower than those of black women smokers and also lower than those of white smokers of either sex. Black men are also significantly more likely to smoke than black women. Differences in smoking behavior, then, represent an important proximate cause of male-female differences in the prevalence of obesity among blacks, although these differences in smoking behavior themselves remain to be explained.

Vigorous exercise is associated with a significant reduction in the risk of obesity among white men. However, black men who report vigorous exercise have significantly higher obesity rates, by an estimated 13 percent, than sedentary black men. This perverse-sounding result should not be taken at

\footnotetext{
${ }^{33}$ In the previous literature, evidence of racial differences in penalties for obesity among men is mixed. Averett and Korenman (1996) find a wage penalty for obesity among white men, but not among black men, and no marriage penalty for obesity among men.
} 
face value: black men in the vigorous exercise group classified as obese tend to have significantly lower percentages of body fat than does the average obese male of either race in the other exercise categories.

Of this group, 11.4 percent of black men would be classified as non-obese based on a body fat threshold of 25 percent, whereas only 1.5 percent of white men would be similarly classified. ${ }^{34}$

This positive relationship between vigorous exercise and BMI/obesity is consistent with the notion put forth above that whites may use exercise as a means of weight control to a greater extent than blacks, and blacks who exercise may be more concerned with building muscle and fitness, or at least less concerned with weight control than whites. Judging by point estimates at least, we note also that vigorous exercise is associated with greater reductions in BMI and the risk of obesity among women than among men, within either racial group.

\subsection{Reduced-form estimation of BMI and obesity using the BRFSS}

The BRFSS is a separate CDC survey that contains self-reports of height and weight, desired weight, numerous health-related behaviors, and demographic information, based on telephone interviews of very large random samples (repeated cross-sections) of the non-pregnant resident population 18 years and older in participating states of the United States. ${ }^{35}$ To study the determinants of BMI and obesity, we use BRFSS data from 1998 to 2002, which are roughly comparable to the NHANES 1999-2004 data. In the analysis of weight dissatisfaction, we use data from BRFSS survey years that report desired weights, which include 1989, 1994, 1996, 1998, and 2000.

The BRFSS indicates each individual's MSA of residence, a much finer proxy for the natural and economic environment than is available in the NHANES data. In addition, we link food price measures (specifically, the Consumer Price Index for all food items or "food CPI") to the BRFSS data at the MSA level. Including MSA-level food prices together with MSA fixed effects helps to isolate food price

\footnotetext{
${ }^{34}$ This threshold has been suggested in the public health literature by the National Institutes of Health (for example, NIDDK 2008) and adopted by Cawley and Burkhauser (2006). However, there is no broad scientific consensus as to the proper fat-percentage thresholds for obesity. See Gallagher et al. (1996), among others.

${ }^{35} \mathrm{We}$ correct for self-reporting bias on weight and height. See the Appendix for discussion of methods.
} 
variation within a region over time, while year fixed effects capture aggregate trends in food prices and obesity. Food price variation within a region over time may be important for two reasons: (1) The economic literature has linked the rise of obesity to supply-side-driven declines in food prices, ${ }^{36}$ trends that may have varied regionally, and (2) regional movements in food prices may also reflect regional shifts in demand factors that are simultaneous with changes in BMI. Therefore, including time-specific regional food prices further reduces the chances of attributing influences based on location to influences that are based on race, and this reduction results in conservative estimates of race effects.

In the analysis of BMI and obesity using the BRFSS data, we include the following variables: racial identity (white, black, Hispanic, or other), categorical measures of educational attainment and income, age and age-squared, an indicator of regular vigorous physical activity, an indicator of whether the individual is a smoker, an indicator of labor-force status, the individual's MSA of residence, the year of observation, and MSA-by-year values of the food CPI. ${ }^{37}$ Tables $15-18$ show results of BMI and obesity regressions. (In these tables, coefficients on the MSA variables are suppressed for convenience.) When we include only race, age, and age-squared in the regression (column 1), the risk of being obese for blacks is 1.86 times greater than the risk for white women and is highly significant. As in the NHANES data, the gap declines slightly when we control for socioeconomic status (educational attainment, income, and labor-force status) and behaviors (exercising and smoking). When we include the full list of controls, the estimated relative risk ratio is significantly lower, at 1.55 , which is slightly above the value (1.43) found in the most inclusive model from NHANES 1999-2004. Among the controls, income and exercise have the biggest (negative) impact on the relative risk ratio of interest. Food prices appear to have no effect on the black-white female obesity gap.

Effects of education and income are, for the most part, qualitatively similar to those observed in the NHANES data. However, the income variable is more finely measured in the BRFSS, and we are able to detect a non-monotonic relationship between income and the risk of obesity. Women in the second

\footnotetext{
${ }^{36}$ Food prices played a role in frameworks of Lakdawalla and Philipson (2002), Philipson and Posner (1999), Burke and Heiland (2006, 2007), Cutler, Glaeser, and Shapiro (2003), and Chou, Grossman, and Saffer (2004)

${ }^{37}$ For details concerning these variables, see the Appendix.
} 
and third income groups (corresponding roughly to the second and third octiles of the data's female income distribution) have risks of obesity that are greater than the risks faced by women in the lowest income group, while women in each of the top four income groups have a lower risk of obesity than the poorest women. The very top income group has the lowest risk of obesity. For men, as in the NHANES data, we also observe a non-monotonic relationship between income and the risk of obesity. This risk is greater in each of income categories $4,5,6$, and 7, than in the lowest-income group. However, the risk of obesity for the highest-income group does not differ significantly from that faced by the lowestincome group, as shown in Table 18. The location indicators point to significant regional differences in the risk of obesity that nonetheless do not account for racial differences in obesity. Prices, in both the BMI and obesity models, have significant but small negative effects. Effects of national price changes are embedded in year fixed effects, which are significant and positive.

\subsection{Explaining residual race and gender differences}

Thus far, we have shown that the race and gender patterns in mean BMI and obesity are largely robust to controls for racial variation in age, household income, educational attainment, occupation, marital status, exercise, smoking, and diet. In the analysis of interaction effects, however, we identified some subgroups within which racial differences appear less gender-specific, and we found that differences in smoking rates, and in the impact of smoking on the risk of obesity, between black men and black women, represent an important proximate source of gender-specificity. Among women, we identified a subgroup—blue-collar workers-whose members, on average, experience obesity levels that do not differ significantly between whites and blacks, and other subgroups-such as the high-income group - where the difference in rates of obesity between the two races is significantly greater than in the aggregate. We observed both gender and race specificity in the income-obesity gradient, a finding consistent with the hypothesis that wage (and spousal-wage) penalties for obesity are weaker for black women than for white women, and weaker (or non-existent) for men than for women within each race. 
We also noted important race and sex differences in the relationship between vigorous exercise and $\mathrm{BMI} /$ obesity that suggest corresponding differences in the motivation to exercise.

Any comprehensive explanation of obesity patterns by race and sex must seek to reconcile not just the residual variation in these dimensions but also the gender- and race-specificity in behavior choices and, potentially, in the gender- and race-specificity of relationships between obesity and factors such as income and vigorous exercise. The remaining analysis considers two hypotheses: first, that our data patterns are driven by race and gender differences in underlying physiology that result in differences in the health-based incentives to avoid obesity; second, that the patterns reflect gender-specific differences in social norms of BMI and their salience, where the norms are not reducible to health standards but reflect aesthetic or moral standards.

\subsubsection{Evidence of differences in physiological endowments and related health incentives}

The biomedical and epidemiological research on the prevalence of obesity has sought physiological and genetic explanations for differences in obesity across groups. One factor that has received considerable attention is energy metabolism or calorie burning, an important component of the energy balance equation. Basal metabolism, defined as the energy expended in maintaining basic body functions at rest, is costly to measure, however, and such measurements are relatively scarce. Still, a small group of studies finds evidence that basal metabolic rates among black Americans, both male and female, are significantly lower than the rates among white Americans. The studies control for race and sex differences in the fundamental proximate determinant of basal metabolism, fat-free body mass (Martin et al. 2004, Sharp et al. 2002, Weyer et al. 1999, Carpenter et al. 1998, among others).

However, if we try to explain racial differences in female obesity on the basis of metabolic endowments, we encounter the gender-specificity problem again: in most of the studies that find racial differences in basal metabolism, the metabolic gap is not significantly different between black men and black women (Gannon, DiPietro, and Poehlman 2000 provide a review of these metabolism studies). Furthermore, other studies of basal metabolism find no significant differences between blacks 
and whites (Luke et al. 2000, Nicklas et al. 1997), and recent evidence argues against even the basic premise that idiosyncratic variation in the metabolic endowment helps to explain BMI outcomes (Flatt 2007). Although we cannot directly test the power of this explanation with our data, since NHANES does not include measures of resting metabolism, the relatively scant and conflicting evidence in this direction argues for a cautious assessment. The existence of rapid historical shifts in mean BMI, including shifts in relative BMI and obesity between different racial groups, also counters any argument based on biological determinism.

Overweight and obesity, as defined using BMI, have been associated with significantly greater rates of diabetes, hypertension, heart disease, some types of cancer, and other adverse health conditions (Flegal et al. 2005, Olshansky et al. 2005, Troiano et al. 1996). However, excess adiposity or fatness, rather than excess mass in general, has been identified as the primary causal factor linking high BMI with the aforementioned disorders. The body mass index is considered by many medical professionals to be a weak index of the risk of disease, since it does not differentiate between fat mass and fat-free mass, the latter category encompassing muscle and connective tissue, bone, and water. Despite the significant positive correlation between BMI and percentage of body fat, there is considerable variation in fat mass among individuals at the same BMI. Even among individuals with similar levels of overall fatness, the quantity of visceral (inner belly) fat may vary considerably, and visceral fat has been found to be more strongly linked to disease risks than fat in other parts of the body (Bacha et al. 2003, Carroll et al. 2008). ${ }^{38}$

The NHANES data contain measurements of body fat percentage. ${ }^{39}$ These measurements indicate that the percentage of body fat has a significant racial component: controlling for BMI and age, the

\footnotetext{
${ }^{38}$ One study finds that BMI explains only 25 percent of variation in total fat mass. While BMI has been strongly criticized as an index of risk, there is disagreement as to which, if any, alternative anthropometric criterion should be used, among total fat mass, fat mass percentage, waist-to-hip ratio, and waist circumference, none of which correlates perfectly with visceral fat. Waist circumference appears to be gaining popularity as a supplementary risk indicator, however. For example, the National Heart, Lung, and Blood Institute (a division of the CDC) now gives gender-specific thresholds for waist circumference indicating elevated disease risks.

${ }^{39}$ These measures are indirect and require additional assumptions in order to be converted into actual fat percentages. See the Appendix for more information about the measurement of body fat percentage.
} 
average percentage of body fat is lower among blacks, both male and female, than among their samesex white counterparts. ${ }^{40}$ In addition, a recent study by Carroll et al. (2008) found that the average level of visceral fat (measured using computed tomography) was significantly lower among blacks than among whites, within each sex separately. ${ }^{41}$ They also found that visceral fat levels increased less steeply with either BMI or waist circumference for black women than for white women, and found some evidence that black men's visceral fat increased less sharply with BMI than white men's did. ${ }^{42}$

In light of this evidence, we might expect to find a lower prevalence of diseases linked to excess fat among blacks than among whites, comparing individuals with the same BMI and assuming all else equal. Depending on the form of the relationship between body fat and risk, and on the relationships between BMI, overall body fat, and visceral fat-each of which may differ between the races and/or sexes—we might also expect to find a weaker marginal effect of BMI—or a weaker effect of obesityon certain disease risks among blacks.

If such differences in risk exist, and if they derive from fixed biological factors, then blacks may face weaker health-related incentives than whites to avoid BMI values classified as overweight or obese. ${ }^{43}$ Furthermore, any such difference in incentives could be gender-specific. Although we cannot observe directly the biological factors that might explain differences in body composition, we can examine the relationships surrounding this hypothesis, using measures of BMI, body fat, and prevalence of disease contained in the NHANES surveys, together with the findings of previous studies that examined variation in fat distribution conditional on race and sex.

We begin by describing the racial differences in percentage of body fat, conditional on BMI, observed in the NHANES data. For each survey, and for men and women separately, we regress percentage of body fat against BMI, the dummy for being black, age, and age-squared. (We must omit all

\footnotetext{
${ }^{40}$ Lower fat percentage implies a higher percentage of fat-free mass, but not necessarily a higher percentage of muscle mass, since bone mass and water mass are also included in fat-free mass.

${ }^{41}$ The differences were significant for both sexes based on the directly measured L4-L5 slice of visceral fat, and the difference was significant for men based on the imputed measure of total VAT.

${ }^{42}$ Although these findings are based on a relatively limited sample size, additional evidence from other samples supporting these findings is found Bacha et al. (2003), Okosun et al. (2000), and Hill et al. (1999).

${ }^{43}$ Very low BMI values also involve health risks. For now we are considering just the incentives to avoid high BMI.
} 
except non-Hispanic whites and non-Hispanic blacks because we lack data on fat measures for other groups.) In separate regressions, we add an interaction term between BMI and the dummy for being black. We find that black women have, on average, a significantly lower percentage of body fat than white women at the same BMI and age, by 1.58 and 1.02 percentage points, respectively, for NHANES III and 1999-2004. In the 1999-2004 data only, we observe a significant, negative interaction between being black and BMI: that is, the percentage of fat increases less steeply with BMI among black women than among white women. ${ }^{44}$ Black men are found to have a lower percentage of body fat than white men, by 2.7 and 2.29 percentage points, respectively, in NHANES III and 1999-2004. For men, interactions are significant yet positive for both surveys, indicating that, despite their lower average percentage of body fat, black men's fat ratio increases more steeply with BMI than white men's does. Figure 1 shows plots of body fat against BMI for average-age men and women by race. The plots are generated using the models that include interactions only when these are significant. ${ }^{45}$

The NHANES surveys also contain self-reported information on morbidity, including whether an individual has been diagnosed with diabetes, hypertension, heart failure, or has suffered a heart attack. ${ }^{46}$ Using this information we can test for racial differences by sex in the prevalence of disease, conditional on BMI, in terms of both levels and marginal effects. Despite blacks' lower percentage of body fat at a given BMI, the prevalence of obesity-related disease does not appear to be lower among blacks than among whites at the same BMI. (Therefore, we suspect that differences in unobserved factors offset any risk advantage of blacks' lower body fat at a given BMI.) However, we find that the rate of increase in some disease risks with BMI may be smaller for blacks than for whites, and there appears to be a degree of gender-specificity to this phenomenon.

\footnotetext{
${ }^{44}$ As shown in Figure 1, the plots of body fat against BMI intersect in NHANES 1999-2004, so that among women with BMI values below about 24 , blacks are predicted to have a higher percentage of body fat than whites, while the opposite is true when BMI values exceed 24.

${ }^{45}$ These racial differences in percentage of body fat derive in part from corrections to the models that predict total fatfree body mass (the complement of fat mass). The correction terms are positive for blacks but negative for whites. These corrections are recommended by Sun et al. (2003) and Cawley and Burkhauser (2006), based on observed prediction biases in the former study.

${ }^{46}$ In the examination portion, NHANES also identifies previously undiagnosed cases of diabetes and hypertension. However, adding these cases results in a significant reduction in the sample size, so we do not include them.
} 
To obtain these results, we let each disease or condition be the dependent variable in a Poisson regression. In the simplest model (results not shown), right-hand-side variables include BMI, a dummy for being black, age, and age-squared. ${ }^{47}$ To allow for a non-linear relationship between BMI and the risk of disease, we also estimate alternative models that substitute the binary indicator of obesity in place of BMI. We then add to each disease model an interaction term between the indicator of being black and the anthropometric risk factor (for example, BMI or the dummy for obesity). We test robustness by running models that include the same set of controls as used in the maximal models of BMI discussed in the previous section.

In the 1999-2004 data, the basic models of disease risk indicate that black women experience significantly higher rates of diabetes, heart attack, and hypertension than white women at the same age and BMI. The greatest difference is observed for diabetes, where the relative risk among black women compared with whites is estimated at 1.77 (results not shown). Significantly higher levels of risk are also observed when conditioning on obesity rather than BMI. Risks increase significantly with either BMI or obesity for diabetes, hypertension, and heart failure, but not for heart attack. Black men also experience significantly higher rates of diabetes and hypertension than white men with similar BMI or obesity status - and the magnitude of the risk difference is similar to that for women - but no fixed differences are observed for heart failure and heart attack. The relationships between BMI/obesity and disease among men closely follow those observed among women, in both magnitudes and significance. Adding the additional controls does not eliminate the significance of racial differences in the risk of disease. The results are broadly similar in the NHANES III data. These findings indicate that any risk advantage owing to blacks' lower percentage of body fat is offset by racial differences in unobserved factors that contribute to these disease risks.

Tables 19 and 20 show the results from the models that include interaction terms between race and BMI. We observe-for both survey periods - that an increase in BMI is associated with a sig-

\footnotetext{
${ }^{47}$ Costa-i-font and Gil (2005) suggest using a seemingly unrelated regression approach when estimating disease risks, since unobserved factors may determine both BMI and the disease outcome. We find that such an exercise does not qualitatively affect the findings on racial differences in disease risks.
} 
nificantly smaller (percentage) increase in the risk of hypertension or diabetes among black women than among white women (column 1). The effect is robust to controls for education, income, foreign birth, marital status, occupation, diet, smoking, and exercise (column 2). Among men, the evidence of race-specificity in the relationship between BMI and hypertension and diabetes risk is much weaker: the interaction term is significant only for diabetes risk in NHANES 1999-2004, and the effect is not robust to the inclusion of additional controls.

Since we suspect that differences in marginal risks of disease may reflect underlying differences in percentage of body fat, we add percentage of body fat as an additional right-hand-side variable to the models and check whether significant interaction terms remain between BMI (or obesity) and black identity. As columns 3 and 4 in Tables 19 and 20 show, for women, the racial differences in the effect of BMI on the risk of hypertension are significant and robust in both data sets. That is, black women's risk of hypertension appears to increase less steeply with BMI, and by a smaller percentage among obese subjects, than does white women's risk, by significant margins, even after controlling for differences in percentage of body fat. The race-specificity of the marginal risk of BMI on diabetes also remains significant for women in NHANES III after controlling for body fat, but it is only marginally significant in the more comprehensive models for NHANES 1999-2004. For men, the evidence of race-specificity in the marginal health risks of BMI, controlling for differences in body fat, remains ambiguous. While the coefficients of relative risk on the interaction term between BMI and being black are less than 1 for both NHANES III and 1999-2004, the significance of the estimates is not consistent across model specifications and survey periods, as shown in Table 20, columns 3 and 4.

Given that differences in percentage of body fat do not account for all of the observed racial differences in associations between BMI/obesity and the risk of disease, it seems plausible that the associations between percentage of body fat and the risk of disease may also vary by race and/or sex, as suggested by the evidence that the fat distribution differs between blacks and whites of both sexes. Accordingly, we test for sex-specific racial differences in the prevalence of disease, conditional on percentage of body fat, allowing for interactions between percentage of body fat and race, in models that 
control for age and age-squared, but not also for BMI. We find that increases in body fat percentage are associated with significantly smaller increases in hypertension risk for black women and black men, respectively, than for their white counterparts (results not shown). These results hold for NHANES III as well as in the NHANES 1999-2004 data. For diabetes risk, we observe a significantly smaller impact of body fat for black men in both surveys, and for black women in the 1999-2004 survey.

Taken together, these results support the hypothesis that racial differences in percentage of body fat at a given value of BMI may result in different associations between BMI and risk of disease between blacks and whites within each sex. They also agree with the related hypothesis that racial differences in fat distribution at a given percentage of body fat may result in associations between fat levels (or percentages) and the risk of disease that are race-specific and possibly also gender-specific. Our results exhibit some gender-specificity in that significant interactions (for example, between black identity and BMI) were more common and more robust for women, although it should be recalled that our sample size of black women is larger than our sample size of black men. However, the difference in marginal effects between whites and blacks may simply reflect the fact that non-obese blacks have elevated risks of hypertension and diabetes compared with non-obese whites, perhaps as a result of unobserved differences between these two groups in nutritional quality, access to health care, and/or other risk factors.

The results of Carroll et al. (2008) are also gender-specific: the evidence that visceral fat increases less steeply in blacks than in whites appears stronger among their female subjects than among their male subjects, and similarly the evidence that visceral fat increases less steeply with waist circumference among blacks is stronger for women than for men. However, they also observe significantly lower average visceral fat levels among black men than among white men at the same elevated waist circumference level, and their sample size of black women $(n=45)$ is more than twice as large as their sample size of black men $(n=21) .{ }^{48}$ Given the small, non-representative sample used in that study, we are hesitant to draw sharp conclusions.

\footnotetext{
${ }^{48}$ Respective sample sizes for white women and white men were 32 and 15 .
} 
Other findings complicate the picture further: Hill et al. (1999) find significantly lower visceral fat, controlling for total adiposity, among black men than among white men but not also among black women compared with white women. Bacha et al. (2003) find evidence that visceral fat itself may have different associations with disease among blacks than among whites, and that the association may be either weaker or stronger for blacks than for whites, depending on the disease. Analyzing the relationship between BMI and all-causes mortality by race and sex, Durazo-Arvizu et al. (1998) find no significant black-white differences, for either women or men, in the BMI value associated with minimum mortality, and find that the overall BMI-mortality relationship looks quite similar across black women, white women, black men, and white men.

Consider again the health incentives hypothesis. The claim is that for blacks, and for black women in particular, excess BMI (as defined by the CDC) poses lower morbidity risks than it does for whites. In light of their lower marginal costs in terms of BMI, we expect black women rationally to "consume" more of it than white women do, all else being equal, on the assumption that higher BMI enables benefits in the form of greater calorie consumption and/or lower calorie expenditure. While we find this claim intriguing, it rests on some debatable assumptions: first, the differences in the underlying disease-risk factors, such as visceral fat, must be exogenous; second, the differences in the association between BMI/obesity and morbidity must either be much stronger for women or, if not, must have a stronger impact on female behavior than on male behavior-for example, health risks could be less salient for black men than for black women; third, women must have a decent understanding of the risks they face as a function of elevated body mass, and black women must understand the specific relationship that applies to them.

Each of these conditions is debatable. Based on our findings from NHANES, blacks—both women and men-appear to have a weaker disincentive than whites of the corresponding sex to accumulate body fat. However, the average percentage of body fat is significantly lower among black men than among white men (not controlling for BMI, since controlled differences could reflect exogenous relationships), while the average percentage of body fat is higher among black women than among white 
women. Furthermore, our findings indicate that black women's higher BMI values do not represent the risk-adjusted equivalent of white women's BMI values after taking into account differences in percentage of body fat. That is, if risk levels are chosen through behavior, black women more than consume any risk savings they may have enjoyed.

Public awareness of race- and gender-specific risk relationships is also likely to be limited, even ignoring the scientific uncertainty surrounding them. The CDC's recommendations for BMI are not race-specific, and they are likely to be more representative of morbidity relationships for whites than for blacks, should the relationships genuinely differ. Individuals might make inferences on the basis of casual empiricism, or they could glean information from the medical literature or perhaps via encounters with knowledgeable health care providers. A person who understands that fat is a stronger gauge of risk than BMI, and who has measured her percentage of body fat-for example, by using a scale that measures body fat-may substitute a BMI aspiration with a fat-percentage goal. However, most individuals are neither aware of their own fat level nor of the limitations of BMI as an index of health risk.

The exogeneity of differences in fat levels (total levels or percentages, at least) is also debatable. Differences between blacks and whites in body fat at a given BMI may reflect differences in the utility tradeoffs of individuals between overall size (BMI) and adiposity, and underlying utility tradeoffs between food consumption, exercise, and the risk of disease. Chosen differences in overall fat, controlling for BMI, may lead, wittingly or not, to differences in visceral fat. For example, some individuals aspire to look thin and have a low BMI, which may be easiest to achieve by reducing muscle mass disproportionately, given that lean tissue weighs more than fat, than by building up muscle mass. Conversely, some individuals place a priority on building muscle mass and fitness, which will tend to raise BMI unless a disproportionate amount of fat is lost as muscle is added. As noted above, the fact that the link between exercise and BMI is weaker for blacks suggests that their motivations to exercise may be different than those of whites.

In the following section, we discuss evidence of racial differences in aspirations towards overall 
BMI as well as gender differences in aspirations concerning the composition of BMI between fat and lean tissue.

\subsubsection{Evidence of differences in sociocultural ideals and related incentives}

A considerable volume of evidence suggests that physical health is not the only factor, and need not be the primary factor, that drives individuals' aspirations concerning their weight. Body size is a prominent aspect of appearance, and as such is subject to aesthetic judgments, which may differ from judgments based purely on health. Individuals judge their own size and the sizes of others, and in turn are judged by others on the basis of body size. (Of course, shape and other aspects of physique are also subject to aesthetic judgments, but we abstract from these dimensions for now.) Actions based on such judgments may hold significant consequences for an individual's economic, social, and mental well-being.

Social stigmatization of overweight and obese people is widely documented, whereby obese subjects are perceived as less attractive, less intelligent, less industrious, and less happy, among other qualities, than non-obese subjects. Obese people themselves report experiencing job discrimination, social exclusion, mistreatment by doctors, public ridicule, and numerous other insults. Weight discrimination may contribute to wage penalties, job-status penalties, and marriage-market penalties. Obesity among women has been linked to reduced self-esteem and elevated risk of depression. ${ }^{49}$ In addition, there is evidence - to which we will add - that norms related to body size, including conceptions of ideal weight and the pervasiveness of obesity stigma, vary across social groups and over time, rather than being universal or purely idiosyncratic. ${ }^{50}$ Thus, individuals have an incentive to conform to the aesthetic standards of others with whom they interact socially and with whom they identify culturally. People in different sociocultural environments may therefore face different incentives to achieve

\footnotetext{
${ }^{49}$ Studies of the stigmatization of obesity and its mental-health consequences include Rand and MacGregor (1990), Ross (1994), Hebl and Heatherton (1998), Myers and Rosen (1999), Puhl and Brownell (2001), Latner et al. (2005), and Graham and Felton (2005), among many others.

${ }^{50}$ See, for example, Stearns (1997), Voracek and Fisher (2002), Graham and Felton (2005), Garner et al. (1980). On the other side of the debate, sociobiologists such as Singh (1993) claim that standards of female beauty, such as the waist-to-hip ratio, are genetically hard-wired. Stunkard, LaFleur, and Wadden (1998) find that obesity was stigmatized in medieval times in both Japan and Europe. Park, Schaller, and Crandall (2007) suggest an evolutionary basis for stigmatization of obesity.
} 
a particular BMI and to avoid becoming overweight or obese.

In this section, we consider the hypothesis that gender-specific racial (black-white) differences in the social incentives pertaining to BMI contribute significantly to the observed patterns in mean BMI and obesity by race and sex. First, we present evidence of gender-specific racial differences in selfperception of weight status - and inferred values for ideal BMI — and in self-reported desired BMI values, using data from NHANES and BRFSS. This evidence supports the thesis-based on prior evidence - that blacks and whites, on average, refer to different cultural standards of ideal size and that the strength of incentives to avoid obesity may be weaker among blacks. We also find an interesting gender-specificity in these racial differences that is consistent with the observation that masculine body ideals tend to emphasize muscularity more so than feminine ideals. Furthermore, the observed body size standards do not line up consistently with health standards. We then consider whether weight standards exert a causal impact on individual outcomes. Finally, we discuss which incentives-health incentives or social incentives-can better support the stylized facts concerning labor and marriage penalties for overweight and obesity and their variation by race and sex.

To identify BMI standards or norms, we employ NHANES data on self-classification or selfperception of weight status. The NHANES III and NHANES 1999-2004 surveys contain a question that asks respondents whether they consider themselves (at their current weight) to be either "underweight," "about right," or "overweight." (Hereafter, we will refrain from using quotation marks around these responses.) The choice to self-classify as obese was not included. We use the responses to this question in three ways: first, to identify racial differences by gender in the respective tendencies to self-classify as underweight, about right, or overweight as a function of BMI; second, to infer a value for ideal weight within each race-sex group and test for differences among the inferred ideals; third, to assess the extent to which self-classifications of BMI agree with the official health-based classifications used by the CDC.

To achieve the first objective, we estimate a multinomial logit model in which the dependent variable is the response to the NHANES self-perception question and the independent variables are age, 
race/ethnicity, body mass index, educational attainment, household income, and marital status. An alternative specification adds percentage of body fat on the right-hand side in order to control for any influence of adiposity, independent of BMI, on weight perceptions. Results are shown in Tables 22 and 23. The model predicts the probability of each potential response to the self-perception question, where the baseline response is defined as about right and results are reported as coefficients of relative risk. Using the 1999-2004 data, the model estimates that black women's relative risk of self-classifying as underweight (relative to about right) is 3.22 times the equivalent relative risk for comparable white women, and black women's relative risk of self-classifying as overweight is 0.33 times that of comparable white women. Each of these relative risk estimates is significantly different from unity at the 1 percent significance level or better, and the relative risks are effectively unchanged in models that also control for percentage of body fat and waist circumference (results not shown). The comparison of relative risks between black women and white women yields similar qualitative results for the NHANES III data, as shown in Table 22.

For the 1999-2004 survey, we find that black men also have a lower relative risk than white men of perceiving themselves as overweight. The estimated effect of being a black male on this relative risk is roughly the same as that observed for women, at 0.35. However, black men do not exhibit a higher relative tendency than white men to self-classify as underweight. ${ }^{51}$ This gender-specificity reflects the fact that white women are significantly less likely than white men to classify themselves as underweight, even at BMI values considered underweight by CDC standards. Again, results are robust to inclusion of the percentage of body fat.

A few facts stand out. First, blacks are significantly less likely on average to classify themselves as overweight than whites with similar physical and socioeconomic characteristics. However, it should be noted that the predicted self-perception differences are greatest for BMI values between 20 and 30, and they vanish for BMI values above 38. Second, the racial differences in weight self-perception exhibit

\footnotetext{
${ }^{51}$ In a regression that pools the male and female samples, this gender difference in the effect of being black on selfclassification as underweight is found to be significant.
} 
gender-specificity. Third, within each race-sex group, classifications often depart from CDC standards.

To illustrate these facts, see Figure 2. Each panel shows the predicted probabilities of each selfperception response as a function of BMI, for each of two groups. The values of the other covariates are held at their respective (gender-specific) unconditional means over the regression sample. Panels 1 and 2 compare blacks and whites within each sex, and Panels 3 and 4 compare males and females within each racial group. ${ }^{52}$ The racial difference in the tendency to self-classify as overweight is readily apparent in Panels 1 and 2. The female-specific racial difference in the tendency to self-classify as underweight is also seen by comparing these panels. In Panels 3 and 4, observe that, within each racial group, men with normal BMI are less likely to self-classify as overweight than are women with normal BMI, while overweight men are more likely than overweight women to self-classify as about right. As examples of misclassification, note that the estimated risk is greater than 40 percent that a white woman with a BMI of 23 will consider herself overweight despite the fact that her objective status is normal. Conversely, a black woman with a BMI of 28 has a 30 percent chance of classifying herself as about right despite her objective status of being overweight.

Among women, the model does a very good job predicting overweight self-classifications, but does less well at predicting self-classifications as about right and underweight, erring on the side of predicting that women classify as overweight. Interestingly, however, this prediction bias becomes more severe, rather than less so, when percentage of body fat is included in the model. That is, one might have guessed that incorrect predictions of an overweight self-classification might obtain for women with high BMI values and a relatively low percentage of body fat. Rather, the additional bias toward overweight self-classification in the model that includes body fat indicates that the latter model overstates the salience of body fat for some individuals: for example, some women with normal BMI values but a relatively high percentage of body fat who are predicted — on the basis of their fat percentage- to

\footnotetext{
${ }^{52}$ The results are based on NHANES 1999-2004 data. The model used to generate these figures does not control for the percentage of body fat. Holding the percentage of body fat at its unconditional average while varying BMI distorts prediction levels relative to what is typical when body fat is allowed to covary with BMI, although it does not qualitatively affect the race and gender comparisons described here.
} 
classify as overweight, actually classify as about right. In both models (with and without percentage of body fat), black women are over-represented among those predicted to classify as overweight who actually classify as about right. This over-representation is more pronounced in the model that controls for percentage of body fat, indicating that body fat may be less salient for black women than for white women.

These findings are consistent with earlier evidence, from independent surveys, indicating that black women are more likely to be overweight or obese than women in other racial and ethnic groups but less likely than other women at the same BMI to perceive themselves as such (see Dawson 1988 and Molloy and Herzberger 1998). Previous studies have also found that black women identify a larger ideal body size than same-age white women do, based on selection of an ideal from an array of drawings of female figures of various sizes, where this ideal closely matches the same women's conception of the social norm for ideal size. ${ }^{53}$ Cusumano and Thompson's (1997) analysis of the body sizes of photographic images in women's magazines found that Essence, a magazine targeting black women, had the largest average image size ("body shape rating") among the magazines they studied, as shown in Table 11. Further, there is evidence that stigmatization of obesity—which may vary independently of weight ideals-is lowest among black women (see Latner, Stunkard, and Wilson 2005), compared with white women, white men, and black men.

Unfortunately, previous studies eliciting ideal weight conceptions have involved small, non-representative samples and have focused almost exclusively on women. The NHANES weight perception data enable us to identify putative size ideals from representative samples of both men and women. Using the results of the multinomial logit models described above, we define the ideal body size for each race-sex group as the BMI value at which the average individual is most likely to classify her weight as about right. By the average individual, we mean an individual with the gender-specific sample-mean values of all characteristics included in the regression other than race and BMI. Given the race-specific predic-

\footnotetext{
${ }^{53}$ See, for example, Anderson et al. (1992), Furnham and Alibhai (1983), Kemper et al. (1994), Flynn and Fitzgibbon (1998), and Lovejoy (2001).
} 
tions for self-classifying as about right, we can solve for the BMI argument of the maximum predicted probability. ${ }^{54}$

The blue curves in the Panels 1 and 2 of Figure 2 indicate the following: the ideals for white and black women, respectively, are 20.01 and 21.98-effectively, 20 and 22; the ideals for white and black men are 22.98 and 24.36. The white female ideal is close to, but somewhat higher than, the estimated mean value of BMI among Playboy centerfolds between 1978 and 1998, placed at 18.5 (standard error 0.8 units), based on the models' self-reported measurements (Katzmarzyk and Davis 2001, Sypeck et al. 2006). Higher male ideals are consistent with, but somewhat lower than, the estimated mean BMI values of male models in Playgirl magazine, which ranged from 24.8 to 27.7 (also based on self-reports) over the period 1986-1997 (Spitzer, Henderson, and Zivian 1999). Note that the racial gap is greater among females than among males; the gender gap is greater among whites than blacks; and the male ideal for either racial group is higher than the female ideal for the same racial group. The magnitude of the differences in estimated ideals does not change significantly when we add controls for percentage of body fat and/or waist circumference. The direction of the difference between black women and white women is consistent with the direction of the difference in their respective mean/median BMI values, and the gender difference in the racial differences is also consistent with the qualitative patterns in the data.

We have interpreted the data on weight self-classification as providing information on how individuals define underweight and overweight and, by implication, what constitutes an ideal weight. We have also argued that the observed standards are not reducible solely to health concerns, and that they reflect culturally transmitted differences in preferences that cut along lines of race and gender. As in the regression analysis, we can use additional information from the BRFSS to corroborate these assertions. The latter survey asks survey participants to report their desired weight, where the definition was taken to be self-evident. The BRFSS does not include values for desired height, but we construct values for desired BMI by combining the desired weight responses with the (bias-corrected) self-reports of actual

\footnotetext{
${ }^{54}$ This is done using a Mata command that uses a numerical solution method.
} 
height.

Considering first the raw data, we observe the following values for average desired BMI by race and sex: for white women and black women, respectively, 22.84 and 24.88; for white men and black men, 26.36 and 27.45. The within-sex racial differences of 2.04 and 1.09 line up closely with the differences in ideal BMI values inferred from the NHANES data, although in levels each value is roughly 3 units greater than the corresponding ideal. This difference indicates that self-reported desired weights may take into account to some extent the constraints individuals face in attaining a weight goal. In addition, desired weight may depend on realized weight, perhaps because individuals adjust desires ex post in order to reduce dissatisfaction with their actual weight. Therefore, we must also consider how BMI dissatisfaction—-defined as the difference between actual BMI and desired BMI—varies by race and sex, controlling for actual BMI and other covariates. To do this, we regress the difference between actual (bias-corrected) BMI and desired BMI against actual BMI, age, age-squared, race, education, marital status, and smoker status, using GLS. As shown in Table 21, we find a significant negative effect - that is, lower dissatisfaction — of 1.04 (standard error 0.026) BMI units for black women than for white women. We also observe significantly lower dissatisfaction among black men compared with white men, but the estimated difference is only about half the size of the difference found for women.

These measures—weight self-classification and desired weight—are, of course, imperfect indicators of individual preferences concerning body weight, and may not accurately reflect differences in sociocultural values and incentives. For example, the notion of desired weight may be interpreted differently by different people: some may express the weight they would choose in the absence of any constraints, while others may factor constraints into the calculation, and the degree of reverse causality from actual to desired BMI may vary across individuals. However, the fact that most individuals exhibit some degree of dissatisfaction with their weight suggests that they do not interpret desired weight as the solution to a constrained-optimization problem. Even if the patterns tell us only that black women make more realistic assessments of what BMI they can achieve, or that they have a stronger aversion to weight dissatisfaction, these are still surprising racial differences that demand explanation and that 
may have their roots in social incentives.

Sociological studies have argued that idealized body images exert a significant impact on the weight aspirations that individuals adopt and, therefore, on eating and exercise behavior and weight outcomes. Although wide variation in BMI values around purported ideals is observed within a given demographic group, differences in average group outcomes, such as between black and white women, have been attributed in part to differences in the cultural ideals that influence these two groups, and to greater social acceptance of overweight, among women in particular, in the black community than among whites. While our findings are consistent with the notion that culturally specific ideals and incentives may influence individual weight aspirations, it is difficult to identify rigorously a causal link from sociocultural standards to BMI outcomes. For such a link to exist, sociocultural standards must be to some extent exogenous at the individual level — that is, not freely selected on the basis of unobserved characteristics that also determine BMI. (However, group standards need not be exogenous to aggregate group outcomes, as long as the individual assumes that her impact on the group outcome is negligible.) In addition, sociocultural standards and corresponding incentives must have some salience in the individual's utility function.

Concerning the first requirement, we note that race and sex, dimensions along which we find significant variation in size standards, are arguably exogenous, or at least costly to alter. In addition, our inferred ideal BMI values are not perfectly correlated with either mean or median group BMI. This fact suggests that ideal points are not merely ex post functions of mean or median group outcomes. We noted above that studies of the stigmatization of obesity found variation in the strength of stigmatization by race and sex. However, controlling for these factors, a subject's own obesity status did not predict her tendency to stigmatize against obesity — that is, obese subjects were just as likely as others to attach unfavorable qualities to obese individuals. Still, group-level obesity rates may have a feedback effect into individual tendencies to stigmatize against obesity, such that people who identify with a group that has a higher rate of obesity may be less likely to stigmatize. However, in large groups, individual members take group outcomes as given, and the feedback component can be treated as exogenous to the 
individual. In addition, the tendency to stigmatize is likely to exhibit some inertia relative to short-term shifts in group outcomes.

Concerning salience, we noted above that numerous studies find that tangible, objective rewards and punishments - unrelated to physical health effects—accrue to people as a function of how their weight compares with the aesthetic preferences of others in society. Asserting that such external judgments vary exogenously across individuals on the basis of race, for example, is an oversimplification, to be sure, in that individuals may differ in the extent to which they choose to identify with, or interact socially with, others in the same racial group. However, people may nonetheless be judged based on their their skin color and on the expectations that others have of people with similar external characteristics.

In the case of black women, evidence of greater acceptance of overweight and reduced salience of weight concerns is long-standing (see, for example, Hebl and Heatherton 1998, Beauboeuf-LaFontant 2003, and Lynch et al. 2007). Social theorists tend to view this difference in weight salience as a reflection of the difference in cultural expectations pertaining to black women versus white women. Tamara Beauboeuf-LaFontant (2003, p. 111) explains as follows:

"While white women have fought against assumptions of their passivity and weakness, Black women have had to contend with the myth of the strong Black woman, a historically complex distillation of images derived from two sources: the rationalizations of a white slave-holding society and Black culture's attempt to define womanhood for itself."

The "mammy" image was the predominant stereotype of the black female slave. Physically, the mammy figure was "large, dark-skinned, and sexless" (Beauboeuf-LaFontant 2003, p. 112). In terms of temperament, the mammy is described as "a passive nurturer, a mother figure who gave all without expectation of return..." (hooks 1981, pp. 84-85), and as "a capable, domesticated woman and a dutiful, grateful slave" (Beauboeuf-LaFontant 2003, p. 112). According to Clinton (1982), BeauboeufLaFontant (2003), hooks (1981), and others, the mammy's psychological profile justified her enslavement and her physical deviance meant that her white master would not be tempted to sexually abuse her. 
While the mammy figure has been long since dismissed as a racist caricature, some black feminists see remnants of the stereotype in contemporary ideals of black womanhood, including ideals promoted from within the black community. Beauboeuf-LaFontant characterizes this ideal as "large and strong," where the strength inheres again in her caretaking abilities and in her selflessness. Townsend Gilkes (2001, p. 183) notes that “... African-American women know that the most respected physical image of black women, within and outside of the community, is that of the large woman." According to Beauboeuf-LaFontant, this seemingly affirming image nonetheless supports the racist notion that black women are physically deviant and, by extension, exempt from the health implications of obesity. Such a view is common, she claims, both within and outside of the black community, and has resulted in a lack of social support for overweight black women seeking to lose weight. Put differently, a black woman who wants to lose weight may be perceived as being selfish or as "acting white" (see, for example, Thompson 1994). At the same time, several authors have suggested that the expectation that black women be strong and stoic in the face of adversity may lead to their overeating, among other "self-medicating" actions, rather than seeking external help (see, for example, Mitchell and Herring 1998 and Thompson 1992).

Black men have also been stereotyped as physically deviant in the sense of being naturally stronger than white men, a stereotype that also appears to have been internalized to some extent in contemporary black male cultural ideals. According to Brown (1999) and hooks (1992), the idealized black male is hypermasculine, an image that is more an exaggeration of the white male ideal rather than a rejection of it. While this ideal is consistent with our observation that black men have a higher desired BMI than white men—since desire for greater muscle mass would imply higher desired BMI, ceteris paribusthis higher ideal does not translate into a large difference in the incidence of obesity between black men and white men. While images of black women and black men both use size to symbolize strength, the male ideal appears to emphasize physical strength and athleticism whereas the black female ideal emphasizes emotional strength. This emphasis on athleticism in the black male identity prescription may have a protective effect on black male obesity. For example, black men exhibit a greater propensity 
to engage in physical activity than black women and have lower body fat levels (as a percentage of total body weight) than white men. Furthermore, to the extent that the "mammy" stereotype and its modernday translation offer an implicit acceptance of overweight, such acceptance would apply specifically to black women.

\subsubsection{Explaining labor-market and marriage-market penalties for obesity: health incentives versus social incentives}

We can further evaluate our competing hypotheses on the basis of which framework better reconciles observed race and gender variation in penalties for obesity in labor and marriage markets. Negative health outcomes associated with obesity may affect labor-market outcomes for a number of reasons. For example, obese workers could have lower productivity than non-obese workers, with wage differences reflecting this fact. Reduced productivity among the obese could derive from lower physical fitness in general, and/or from a higher incidence of diseases such as diabetes and hypertension. Related to the health impacts of obesity, Bhattacharya and Bundorf (2005) argue that wage penalties for obesity compensate for obese workers' higher expected health expenditures when these are borne by employers who provide health insurance.

If the health impacts of obesity are the primary source of obesity-associated wage penalties, and if we assume that the health impacts of obesity (defined using BMI) are stronger among white women than among black women, we would expect obesity-associated wage penalties to be stronger for white women than for black women, assuming that employers recognize the demographic patterns in disease risk. Cawley (2004) and Averett and Korenman (1999) find that this predicted difference holds, and our NHANES analysis reveals a steeper (negative) income-obesity gradient among white women than among black women. However, wage penalties for obesity are found to be insignificant among men, regardless of race (Cawley 2004), and job status penalties for high BMI have also been observed to fall exclusively on women (Conley and Glauber 2005); yet we do not observe weaker relative health impacts of obesity among men than among women. In a non-rigorous way, this latter fact can be seen 
by comparing the male and female coefficients on BMI in the equations for risk of disease in Tables 19 and 20.

The gender-specificity of labor-market penalties for obesity points strongly toward the presence of appearance-based discrimination, based on race-by-gender weight standards. Baum and Ford (2004) argue similarly, based on the fact that within-occupation wage penalties for women do not vary much across occupational categories. (Racial differences were not tested for.) If this is the case, it suggests that such standards are widely internalized, and that the same employer may apply different weight criteria (consciously or not) to white women than to black women in hiring and wage-setting decisions. Thus, wage and job-status penalties can be viewed as one of the instruments that serve to enforce raceand gender-specific weight standards.

We have not yet touched on one important issue concerning enforcement of sociocultural weight standards, which is whether the race (and/or sex) of the person doing the judging, or the race (and/or sex) of the person being judged, determines which weight standard will be applied. In the case of wage penalties, unless we assume that labor markets are strongly segregated along lines of race and sex, it seems likely that managers of both sexes and both races apply different standards to men than to women, and to black women than to white women. This assertion is consistent with the fact that the obesity gap between black women and white women has not narrowed despite significant reductions in occupational segregation by race over the past 30 years (for example, Queneau 2005).

If the ideals we inferred from the NHANES data are good proxies for race-sex-specific standards applied to individuals by members of the opposite sex when making judgments of size attractiveness, we would expect marriage penalties for obesity to be strongest among white women, followed by black women, white men, and black men, in decreasing order of severity. ${ }^{55}$ Using longitudinal data, Mukhopadhyay (2008) finds significant negative effects of obesity on the probability of marriage for women only; among women, the point estimate of this effect is larger (in absolute terms) for white

\footnotetext{
${ }^{55}$ There is evidence that men identify higher values for ideal female BMI than women, and that black men identify a higher female ideal BMI than white men. Despite the fixed gender difference, the race differences are preserved, which is sufficient for our purposes.
} 
women than for black women, but the significance of the difference was not tested. Averett and Korenman $(1996,1999)$ find that the negative effect of obesity on women's probability of being married is significantly stronger for white women than for black women. In their earlier article they also examine the effect of obesity on the probability of marriage for men and reject a negative effect of overweight or obesity on the likelihood of marriage.

It is perhaps uncontroversial to assert that marriage-market penalties for obesity are grounded in appearance standards, and that appearance is more important in determining women's prospects for marriage than men's. Still, people may care also about a spouse's health and longevity, and obesity is an important predictor of such outcomes. If obesity exerts similar impacts on morbidity for men and women, then gender-specific marriage penalties based on health would imply that men care more than women about their potential spouse's future health. Against this hypothesis, Mukhopadhyay (2008) finds that marriage penalties for smoking and marijuana use are significant, and roughly equal, for both men and women. Alternatively, men's concern with a partner's obesity — and lack of reciprocal concern among women-may derive from the fact that obesity has been found to reduce female fertility but has not been proven to reduce male fertility. ${ }^{56}$ However, if fertility is the primary concern driving women's marriage-market penalties, we should not expect such penalties to be stronger among white women, since we find no evidence that the link between obesity and female infertility differs between blacks and whites. ${ }^{57}$ On balance, then, the evidence on marriage penalties also points more strongly toward the social-incentives hypothesis than toward the health-incentives hypothesis.

\footnotetext{
${ }^{56}$ Sallmen et al. (2006) find evidence supporting a link between male obesity and infertility, but the relationship has not been widely confirmed.

${ }^{57}$ For example, Gesink Law, Maclehose, and Longnecker (2007) find that race does not modify the negative association between obesity and fecundity.
} 


\section{Discussion and Conclusion}

This paper evaluates multiple explanations for the persistent and sizable gaps in mean BMI and obesity rates between black women and white women in the United States and the absence of such differences among American men. The hypotheses are based variously on economic forces, physiological forces, and sociocultural forces. Controlling for observable factors related to knowledge about health (represented by educational attainment) and economic constraints (represented by household income, occupation class, location, and marital status) reduces the gaps in the prevalence of elevated BMI and obesity between black women and white women by a small margin, but does not eliminate genderspecificity. Adding further controls for endogenous behavioral choices (exercise, smoking, and dietary composition) reduces the gaps between black and white women by similarly modest margins, and reduces the gender-specificity of the obesity gap in the NHANES III data, and of the BMI gap in the NHANES 1999-2004 data, but still leaves the puzzle largely unsolved. Allowing interactions between race and the controls, we identify subgroups of the population, such as blue-collar women, within which the obesity gap becomes insignificant, and other subgroups, such as non-smokers, within which gender-specificity disappears, as a gap in obesity emerges between black males and white males.

Despite gaining some traction on the puzzle with the available controls, the results of the multivariate analysis of BMI and obesity push the puzzle down to the level of behavioral choices and labor-market issues. For example, smoking accounts for a large portion of black men's lower risk of obesity, as smoking rates are high for this group, as is the (negative) effect of smoking on the risk of obesity. Furthermore, the fact that negative BMI gradients in income and occupation class are shallower for black women than for white women is not readily explained, although it squares with previous evidence of differences in the reverse-causal relationships from BMI to income or occupation.

We evaluate two competing explanations for the robust stylized facts: (1) that underlying variation in biological factors such as body composition yields exogenous variation in the marginal health effects of elevated BMI, so that black women (but not black men) have weaker health-related incentives than 
white women have to avoid obesity as defined using BMI; and (2) that differences by race and gender in sociocultural ideals of body size and in the social acceptance of overweight result in black women's facing weaker social and economic incentives to avoid obesity than white women face-incentives such as those enforced via labor-market and marriage-market penalties in addition to those enforced by internalized sociocultural norms.

Examining the NHANES data on health outcomes, we observe that black women face weaker marginal BMI effects than white women on the risks of hypertension and diabetes, two outcomes strongly associated with obesity. While this evidence may indeed imply that black women have a weaker incentive than white women to avoid excess BMI, the results of parallel tests for men reveal that black men share this incentive, although possibly to a lesser extent. Therefore, it remains to be explained why such a difference in health incentives would lead to black women's having significantly higher BMI than white women, and not lead to a similar effect on black men. The health-incentives story also requires that differences in marginal health risks be founded in exogenous factors and that subjects be aware of such risk differences. Concerning the first requirement, there is evidence that both the percentage of body fat and the percentage of visceral fat are lower among blacks than among whites at the same value of BMI, although an exogenous biological foundation for such differences has not been established. Concerning the second requirement, the facts that (1) official public health standards for obesity do not differ between blacks and whites, and (2) most individuals do not have the means to accurately gauge their overall percentage of body fat, let alone visceral fat, are likely to limit awareness of health-risk differences.

The NHANES and BRFSS data also provide measures of how individuals perceive the appropriateness of their weight and of the weight they would like to attain, respectively. Examining these data, we observe systematic differences in self-perception of weight and in desired BMI by race and sex. We show that black women are, other things being equal, relatively less likely to view themselves as overweight (as opposed to "about right"), and relatively more likely to classify themselves as underweight (as opposed to "about right"), than white women, where both differences are highly significant. In ad- 
dition, the ideal BMI value of black females inferred from the self-perceptions data is 2 units higher-a difference amounting to about 11.7 pounds for a woman of average height—-than the inferred ideal for white females. These differences in self-perception are robust to variation in percentage of body fat between black women and white women at the same value of BMI; in fact, the data indicate that the salience of body fat for weight perception is limited among women. The desired BMI data indicate that black women express significantly smaller gaps between their actual BMI and their desired BMI-indicating less dissatisfaction with their size than white women at the same value of BMI.

These findings confirm the results of numerous prior studies eliciting body ideals, weight aspirations, and weight satisfaction among black women and white women, and agree with the notion that, on average, black women and white women internalize different sociocultural norms of ideal and acceptable body sizes. For example, magazine images and messages to black women emphasize health and strength, not weight-loss and thinness, as they do more often in magazines targeting white women (Cusumano and Thompson 1997). The emergence of this racial difference has been interpreted both as a form of dis-identification with white culture and its unrealistic feminine weight standards, and as a remnant of racist caricatures of black female slaves as heavy, sexless, and deviant.

We also find differences in the self-perception of weight and in dissatisfaction with own weight between black men and white men, but the differences are not the same as those found for women. The key points of gender-specificity are that black men are no more likely than white men to selfclassify as underweight, and that there are smaller gaps than observed for women between black male and white male dissatisfaction with BMI and between the inferred BMI ideals for these two groups. While the difference between the inferred female ideals predicts differences in obesity not far from (but smaller than) those observed in the data, the difference between male ideals predicts a difference in obesity greater than what is actually observed, although smaller than that for women. The question then becomes: if black men aspire to a higher ideal than white men do, and have a looser definition of overweight, why are they not more likely to be obese than white men?

One explanation can be found in the cultural studies literature, which has found that both black 
men and black women view size as a symbol of strength and that both sexes are more accepting of overweight than whites are-both in terms of acceptance of self and others of the same sex and in terms of acceptance of the opposite sex. However, it has been theorized that identity prescriptions unique to black women, emphasizing service to others, make them less likely than black men to take care of themselves-both mentally and physically. Acceptance of overweight in the black community reinforces this tendency, creating an adverse feedback loop that does not arise for black men.

The results strongly suggest that physical ideals and the social incentives to achieve them vary with both race and sex, and that these differences contribute to the observed outcomes. However, there may be other factors that may have caused black women to be heavier than white women, resulting in an ideal physique that is larger than the ideals of white women (ideals follow realized values). Alternatively, the ideals may be the same for all women, but other factors may cause black women to be heavier than white women, and, as a result, their punishments for being overweight are weaker (punishments follow realized values). To counter these arguments, we note that obesity rates of white women and the dominant female ideal physique have moved in opposite directions during the second half of twentieth century (Spitzer, Henderson, and Zivian 1999), although this latter fact weakens the explanatory power of cultural ideals. Moreover, obesity patterns are similar between white women and white men despite the fact that white women's desired BMI is significantly lower than white men's desired BMI. Clearly, factors other than cultural ideals are also important, as evidenced by the rapid growth of obesity among white women during the past 20 years.

Regardless of what we conclude about the extent to which health incentives versus social incentives explain the stylized facts, the observed racial variation in percentage of body fat, controlling for BMI, has implications for the measurement of obesity and for setting appropriate obesity criteria. In particular, our results imply that the current, BMI-based obesity standard yields upward-biased estimates of the relative rates of "overfatness" of black women and black men, compared, respectively, with whites of the same sex. Our findings also suggest, consistent with the thesis of Carroll et al. (2008), that (undifferentiated) body fat itself may impose lower marginal risk of disease on blacks than on whites, 
because blacks' levels of visceral or inner belly fat — the riskiest kind — are lower than those of whites with similar levels of total abdominal fat and with similar waist circumference. In light of their findings, Carroll et al. (2008) call for race- and gender-specific BMI thresholds for overweight and obesity that adjust predicted risk levels for underlying differences in visceral fat. While they do not offer specific obesity thresholds, such adjustments would result in higher (that is, less restrictive) BMI thresholds for blacks compared with same-sex whites. Adjusting BMI thresholds to account for race and sex differences in visceral fat could prove problematic, however, if these differences are not stable over time, as may be the case if they are rooted in behaviors rather than genetics.

Cawley and Burkhauser (2006) argue that obesity should be defined on the basis of body-fat percentage directly, rather than on the basis of BMI. They adopt gender-specific obesity thresholds of 25 percent fat and 30 percent fat, respectively, for men and women. Using these thresholds, black women's average obesity rate still exceeds that of white women, but by a significantly smaller margin than it does using the BMI criterion, and black men's obesity rate becomes marginally lower than white men's. It should be noted that the obesity levels that obtain using the aforementioned fat-percentage thresholds are staggeringly high for both black women and white women-75 percent and 69 percent, respectively, as of NHANES III, for the 18-65 age group. Given these figures, Cawley and Burkhauser (2006) argue that official obesity statistics (based on BMI) overstate black women's relative risk of obesity and understate absolute obesity risk for women of all ethnic groups. However, the body-fat percentage thresholds that they adopt do not constitute consensus thresholds (Gallagher et al. 2000), nor do scientists agree that obesity should be defined on the basis of body fat percentage. A growing number of researchers are calling for the use of an anthropometric criterion that proxies for abdominal fat specifically, such as waist circumference, waist-to-hip ratio, or waist-to-height ratio, but different studies disagree as to which measure is best (see, for example, Lean, Han, and Morrison 1995, Yusuf et al. 2005, and Schneider et al. 2007). Given the sensitivity of measured obesity rates to the choice of the anthropometric criterion, more research and public debate concerning the choice of such a criterion seems warranted. 
As described above, we find that the marginal association between BMI and selected disease risks is weaker among blacks than among whites, while also finding that blacks (male and female) have significantly higher rates of hypertension and diabetes than whites at any given BMI value. In particular, the disparities in health risks (for hypertension and diabetes) between blacks and whites are greater among non-overweight individuals than among overweight people. Based on these findings, public health policy should focus on identifying the common factors among blacks that lead to their worse health outcomes regardless of their BMI, and on potential factors specific to normal-weight and underweight blacks that results in their particularly high relative risk levels.

Our findings highlight the importance of "culturally sensitive" public policy campaigns related to obesity, campaigns that nonetheless acknowledge objective health risks wherever they exist. On the one hand, the black community has been charged with failing to acknowledge the problem of obesity for fear of seeming to impose white cultural standards. On the other, policies that attempt to ramp up the stigmatization of obesity among blacks are likely to be ineffective at best and detrimental to mental health at worst. Rather, it could be argued that more realistic weight standards should be promoted among white women, especially in light of the fact that men—whites as well as blacks-express lessrestrictive weight standards and less body dissatisfaction than women and yet do not experience higher rates of obesity. Thinking more broadly, new policy initiatives should seek to sidestep racial tensions related to ideals of beauty and focus instead on health. To date, public policy on obesity has focused too narrowly on BMI and not on more fundamental risk factors such as abdominal fat, nutrition, and physical activity. Another implication is that further improving black women's status, and, in particular, generating greater equality in expectations of domestic responsibilities, may enable better self-care among black women. 


\section{References}

Anderson, J. L., Crawford, C. B., Nadeau, J., and T. Lindberg (1992), "Was the Duchess of Windsor Right? A Cross-Cultural Review of the Socioecology of Ideals of Female Body Shape," Ethology and Sociobiology, 13: 197-227.

Anderson, P., Butcher, K. and P. Levine (2003), "Maternal Employment and Overweight Children," Journal of Health Economics 22: 477-504.

Averett, S., and S. Korenman (1996), “The Economic Reality of the Beauty Myth,” Journal of Human Resources 31: 304-330.

Averett, S., and S. Korenman (1999), "Black-White Differences in Social and Economic Consequences of Obesity," International Journal of Obesity 223(2): 166-173.

Bacha, F., Saad, R., Gungor, N., Janosky, J. and S. A. Arslanian (2003), "Obesity, Regional Fat Distribution, and Syndrome X in Obese Black Versus White Adolescents: Race Differential in Diabetogenic and Atherogenic Risk Factors," The Journal of Clinical Endocrinology \& Metabolism 88(6): 2534-2540.

Baum, C. L. II, and W. F. Ford (2004), “The Wage Effects of Obesity: A Longitudinal Study,” Health Economics 13: 885-899.

Beauboeuf-LaFontant, T. (2003), "Strong and Large Black Women? Exploring Relationships between Deviant Womanhood and Weight," Gender and Society 17(1): 111-121.

Bhattacharya, J., and M. K. Bundorf (2005), "The Incidence of the Healthcare Costs of Obesity," NBER Working Paper No. 11303.

Bleich, S., Cutler, D., Murray, C., and A. Adams (2007), "Why is the Developed World So Obese?," NBER Working Paper No. 12954.

Brown, J. A. (1999), "Comic Book Masculinity and the New Black Superhero," African American Review 33: 25-42.

Burke, M. A., and F. Heiland (2006), "The Strength of Social Interactions and Obesity Among Women," in: F. Billari, T. Fent, A. Prskawetz, and J. Scheffran (eds.), Agent-Based Computational Modelling. Contributions in Economics Series. Heidelberg: Physica Verlag (Springer).

Burke, M. A., and F. Heiland (2007), “Social Dynamics of Obesity,” Economic Inquiry 45(3).

Carroll, J. F., Chiapa A. L., Rodriquez M., Phelps D. R., Cardarelli K. M., Vishwanatha J. K., Bae S., Cardarelli R. (2008), "Visceral Fat, Waist Circumference, and BMI: Impact of Race/Ethnicity," Obesity 16(3): 600-607.

Carpenter, W. H., Fonong, T., Toth, M. J., Ades, P. A., Calles-Escandon, J., Walston, J. D., and E. T. Poehlman (1998), "Total Daily Energy Expenditure in Free-Living Older African-Americans and Caucasians," American Journal of Physiology 274(37): E96-E101. 
Cawley, J. (2004), "The Impact of Obesity on Wages," Journal of Human Resources 39: 451-74.

Cawley, J., and R. V. Burkhauser (2006), "Beyond BMI: The Value of More Accurate Measures of Fatness and Obesity in Social Science Research," NBER Working Paper No. W12291.

Chou, S. Y., Grossman, M., and H. Saffer (2004), "An Economic Analysis of Adult Obesity: Results from the Behavioral Risk Factor Surveillance System," Journal of Health Economics 23: 565587.

Clinton, C. (1982), The Plantation Mistress: Woman's World in the Old South. New York: Pantheon Books.

Conley, D. and R. Glauber (2005), "Gender, Body Mass and Economic Status," NBER Working Paper No. 11343.

Costa-i-Font, J., and J. Gil (2005), "Obesity and the Incidence of Chronic Disease in Spain: A Seemingly Unrelated Probit Approach," Economics and Human Biology 3(2): 188-214.

Cutler, D. M., Glaeser, E. L., and J. M. Shapiro (2003), "Why Have Americans Become More Obese?," Journal of Economic Perspectives 17: 93-118. Also NBER Working Paper No. 9446.

Cusumano, D. L., and J. K. Thompson (1997), "Body Image and Body Shape Ideals in Magazines: Exposure, Awareness, and Internalization," Sex Roles 37(9/10): 701-721.

Dawson, D. E. (1988), "Ethnic Difference in Female Overweight: Data from the 1985 National Health Interview Survey," American Journal of Public Health 78: 1326-1329.

Durazo-Arvizu, R. A., McGee, D. L., Cooper, R. S., Liao, Y., and Luke, A. (1998), "Mortality and Optimal Body Mass Index in a Sample of the US Population," American Journal of Epidemiology 147(8): 739-749.

Fitzgibbon, M. L., Blackman, L. R., and M. E. Avellone (2000), "The Relationship Between Body Image Discrepancy and Body Mass Index Across Ethnic Groups," Obesity Research 8(9): 582589.

Flatt, J.-P. (2007), “Differences in Basal Energy Expenditure and Obesity," Obesity 15: 2546-2548.

Flegal, K. M., Carroll, M. D., Kuczmarski, R. J., and C. L. Johnson (1998), "Overweight and Obesity in the United States: Prevalence and Trends, 1960-1994," International Journal of Obesity 22: 39-47.

Flegal, K. M., B. I. Graubard, D. F. Williamson, and M. H. Gail (2005), "Excess Deaths Associated with Underweight, Overweight, and Obesity," Journal of the American Medical Association 293: 1861-1867.

Flynn, K. J., and M. Fitzgibbon (1998), "Body Images and Obesity Risk among Black Females: A Review of the Literature," Annals of Behavioral Medicine 20(1): 13-24. 
Foster, G. D., Wadden, T. A., and R. A. Vogt (1997), "Resting Energy Expenditure in Obese African American and Caucasian Women," Obesity Research 5: 1-8.

Furnham, A., and N. Alibhai (1983), "Cross-Cultural Differences in the Perception of Female Body Shapes," Psychological Medicine 13: 829-837.

Gallagher, D., Visser, M., Sepulveda, D., Pierson, R. N., Harris, T., and S. B. Heymsfield (1996), "How Useful is Body Mass Index for Comparison of Body Fatness Across Age, Sex, and Ethnic Groups?," American Journal of Epidemiology 143(3): 228-239.

Gallagher, D., Heymsfield, S. B., Heo, M., Jebb, S. A., Murgatroyd, P. R., and Y. Sakamoto (2000), "Healthy Percentage Body Fat Ranges: An Approach for Developing Guidelines Based on Body Mass Index," American Journal of Clinical Nutrition 72: 694-701.

Gannon, B., DiPietro, L., and E.T. Poehlman, (2000), “Do African Americans have Lower Energy Expenditure than Caucasians?" International Journal of Obesity 24: 4-13.

Garner, D. M., Garfinkel, P. E., Schwartz, D., and M. Thompson (1980), "Cultural Expectations of Thinness in Women," Psychological Reports 47: 483-491.

Gesink Law, D. C., Maclehose, R.F., and M. P. Longnecker (2007), "Obesity and Time to Pregnancy," Human Reproduction 22(2): 414-420.

Graham, C., and A. Felton (2005), "Variance in Obesity Across Cohorts and Countries: A NormsBased Explanation Using Happiness Surveys," Brookings Institution Center for Social and Economic Dynamics Working Paper No. 42.

Hill, J. O., Sidney, S., Lewis, C. E., Tolan, K. Scherzinger, A. L., and E.R. Stamm (1999), "Racial Differences in Amounts of Visceral Adipose Tissue in Young Adults : the CARDIA (Coronary Artery Risk Development in Young Adults) Study," American Journal of Clinical Nutrition 69(3): 381-387.

Grossman, M. (1972), “On the Concept of Health Capital and the Demand for Health," Journal of Political Economy 80(2): 223-55.

Hebl, M., and T. Heatherton (1998), "The Stigma of Obesity in Women: The Difference is Black and White," Personality and Social Psychology Bulletin 24: 417-26.

hooks, b. (1981), Ain't I a Woman: Black Women and Feminism. Boston: South End Press.

hooks, b. (1992), Black Looks: Race and Representation. Boston: South End Press.

Katzmarzyk, P. T. and C. Davis (2001), "Thinness and Body Shape of Playboy Centerfolds, 19781998," International Journal of Obesity 25(4): 590-592.

Kemper, K. A., Sargent, R. G., Drane, J. W., Valois, R. F., and J. R. Hussey (1994), "Black and White Females' Perceptions of Ideal Body Size and Social Norms," Obesity Research 1994(2): 117126. 
Kumanyika, S. (1987), “Obesity in Black Women,” Epidemiological Review 9: 31-50.

Kumanyika, S. K. (1994), "Obesity in Minority Populations: An Epidemiologic Assessment," Obesity Research 2: 166-182.

Kumanyika, S. K. (1999), "Understanding Ethnic Differences in Energy Balance: Can We Get There From Here?" American Journal of Clinical Nutrition 70: 1-2.

Kumanyika, S. K., Wilson, J. F., and M. Guilford-Davenport (1993), "Weight-Related Attitudes and Behaviors of Black Women," Journal of the American Dietary Association 93: 416-423.

Lakdawalla, D., and T. J. Philipson (2002), "The Growth of Obesity and Technological Change: A Theoretical and Empirical Examination,” NBER Working Paper No. 8946.

Latner, J., Stunkard, A. J., and G. T. Wilson (2005), "Stigmatized Students: Age, Sex, and Ethnicity Effects in the Stigmatization of Obesity," Obesity Research 13: 1226-1231.

Lean, M. E. J, Han, T. S., and C. E. Morrison (1995), "Waist Circumference as a Measure for Indicating Need for Weight Management," British Medical Journal” 311: 158-61.

Lovejoy, M. (2001), "Disturbances in the Social Body: Differences in Body Image and Eating Problems among African American and White Women," Gender and Society, 15(2): 239-261.

Luke, A., Rotimi, C. N., Adeyemo, A. A., Durazo-Arvizu, R. A., Prewitt, T. E., Maragne-Kayser, L., Harders, R., and R. S. Cooper (2000), "Comparability of Resting Energy Expenditure in Nigerians and U.S. Blacks," Obesity Research 8(5): 351-357.

Lynch, E., Liu, K., Spring, B., Hankinson, A., Wei, G., and P. Greenland (2007), “Association of Ethnicity and Socioeconomic Status with Judgments of Body Size: The Coronary Artery Risk Development in Young Adults (CARDIA) Study," American Journal of Epidemiology 165(9): $1055-1062$.

Martin, K., W. T. Garvey, P. F. Rust, and P. Wallace (2004), "Estimation of Resting Energy Expenditure Considering Effects of Race and Diabetes Status," Diabetes Care 27(6): 1405-1411.

Molloy, B. L., and S. D. Herzberger (1998), "Body Image and Self-Esteem: A Comparison of AfricanAmerican and Caucasian Women," Sex Roles 38(7-8): 631-643.

Mitchell, A., and K. Herring (1998), What the Blues is: Black Women Overcoming Stress and Depression. New York: Perigee.

Mukhopadhyay, S. (2008), "Do Women Value Marriage More? The Effect of Obesity on Cohabitation and Marriage in the USA," Review of Economics of the Household (online first, January 2008).

Myers, A., and J. C. Rosen (1999), "Obesity Stigmatization and Coping: Relation to Mental Health Symptoms, Body Image, and Self-Esteem," International Journal of Obesity and Related Metabolic Disorders 23(3): 221-230. 
National Center for Health Statistics Centers for Disease Control and Prevention, (1996), ANALYTIC AND REPORTING GUIDELINES: The Third National Health and Nutrition Examination Survey, NHANES III (1988-94). CDC, Hyattsville, Maryland (http://www.cdc.gov/nchs/data/ nhanes/nhanes3/nh3gui.pdf).

National Institute of Diabetes and Digestive and Kidney Diseases, National Institutes of Health (NIDDK) (2008), "Weight-Control Information Network," World wide web content. http://win.niddk.nih.gov/ publications/understanding.htm\#measured (accessed April 8, 2008).

Nicklas, B. A., Toth, J. J., Goldberg, A. P., and E. T. Poehlman, (1997) "Racial Differences in Plasma Leptin in Obese Postmenopausal Women," Journal of Clinical Endocrinology and Metabolism 82: $315-317$

Ogden, C. L., Carroll, M. D., Curtin, L. R., McDowell, M. A., Tabak, C. J., and K. M. Flegal (2006), "Prevalence of Overweight and Obesity in the United States, 1999-2004," Journal of the American Medical Association 295(13): 1549-1555.

Okosun, I. S., Tedders, S. H., S Choi, S., and G. E. A. Dever (2000), "Abdominal Adiposity Values Associated with Established Body Mass Indexes in White, Black and Hispanic Americans. A Study from the Third National Health and Nutrition Examination Survey," International Journal of Obesity 24(10): 1279-1285.

Olshansky, S. J., Passaro, D. J., Hershow, R. C., Layden, J., Carnes, B. A., Brody, J., Hayflick, L., Butler, R. N., Allison, D. B., and D. S. Ludwig (2005), "A Potential Decline in Life Expectancy in the United States in the 21st Century," New England Journal of Medicine 352(11): 1138-1145.

Park, J. H., Schaller, M., and C. S. Crandall (2007), "Pathogen-Avoidance Mechanisms and the Stigmatization of Obese People," Evolution and Human Behavior 28(6): 410-414.

Parker, S., Nichter, M., Nichter, M., Vuckovic, N., Sims, C., and C. Rilenbaugh (1995), "Body Image and Weight Concerns among African-American and White Adolescent Females: Differences that Make a Difference," Human Organization 54: 103-114.

Philipson, T. J., and R. A. Posner (1999), "The Long-Run Growth in Obesity as a Function of Technological Change,” NBER Working Paper No. 7423.

Powell, A. D., and A. S. Kahn (1995), "Racial Differences in Women's Desires To Be Thin," International Journal of Eating Disorders 17: 191-195.

Puhl, R. and K. D. Brownell (2001), "Bias, Discrimination, and Obesity," Obesity Research 9(12): 788-805.

Queneau, H. (2005), "Changes in Occupational Segregation by Race and Ethnicity in the United States," Applied Economics Letters 37: 781-784. 
Rand, C. S. W. and A. M. C. MacGregor (1990), "Morbidly Obese Patients' Perceptions of Social Discrimination Before and After Surgery for Obesity," Southern Medical Journal 83(12): 13901395.

Rashad, I. (2007), "Structural Estimation of Caloric Intake, Exercise, Smoking, and Obesity," NBER Working Paper No. 11957.

Ross, C. E. (1994), “Overweight and Depression,” Journal of Health and Social Behavior 35(1): 6379.

Rucker, C. E. and T. F. Cash (1992), "Body Images, Body-Size Perceptions, and Eating Behaviors among African-American and White College Women," International Journal of Eating Disorders 12: 291-299.

Sallmen, M., Sandler, D. P., Hoppin, J. A., Blair, A., and D. D. Baird (2006), "Reduced Fertility Among Overweight and Obese Men,” Epidemiology 17(5): 520-523.

Schneider, H. J., Glaesmer, H., Klotsche, J., Bhler, S., Lehnert, H., Zeiher, A. M., Mrz, W., Pittrow, D., Stalla, G. K., Wittchen, H.U.: DETECT Study Group (2007), "Accuracy of Anthropometric Indicators of Obesity to Predict Cardiovascular Risk," Journal of Clinical Endocrinology and Metabolism 92: 589-594.

Sharp, T. A., Bell, M. L., Grunwald, G. K., Schmitz, K. H., Sidney, S., Lewis, C. E., Tolan, K., and J. O. Hill (2002), "Differences in Resting Metabolic Rate Between White and African-American Young Adults," Obesity Research 10(8): 726-732.

Singh, D. (1993), "Adaptive Significance of Female Physical Attractiveness: Role of Waist-To-Hip Ratio," Journal of Personality and Social Psychology 65(2): 293-307.

Spitzer, B. L., Henderson, K. A., and M. T. Zivian (1999). "Gender Differences in Population Versus Media Body Sizes: A Comparison over Four Decades,” Sex Roles 40(7-8): 545-565.

Stearns, P. N. (1997), Fat History: Bodies and Beauty in the Modern West, New York: New York University Press.

Stevens, J., Kumanyika, S. K., and J. E. Keil (1994), "Attitudes Toward Body Size and Dieting: Differences Between Elderly Black and White Women," American Journal of Public Health 84: $1322-1325$.

Stunkard, A. J., LaFleur, W. R., and T. A. Wadden (1998), "Stigmatization of Obesity in Medieval Times: Asia and Europe," International Journal of Obesity 22(12): 1141-1144.

Sun, S. S., Chumlea, W. C., Heymsfield, S. B., Lukaski, H. C., Schoeller, D., Friedl, K., Kuczmarski, R. J., Flegal, K. M., Johnson, C. L., and V. S. Hubbard (2003), "Development of Bioelectrical Impedance Analysis Prediction Equations for Body Composition With the Use of a Multicomponent Model for Use in Epidemiologic Surveys," American Journal of Clinical Nutrition 77: $331-40$. 
Sypeck, M. F., Gray, J. J., Etu, S. F., Ahrens, J. E., Mossimann, J. E., and C. V. Wiseman (2006), “Cultural Representations of Thinness in Women, Redux: Playboy Magazine's Depiction of Beauty from 1979 to 1999," Body Image 3(3): 229-235.

Thompson, B. W. (1992), “'A Way Outa No Way': Eating Problems among African-American, Latina, and White Women," Gender and Society 6(4): 546-561.

Thompson, B. W. (1994), A Hunger So Wide and So Deep: American Women Speak Out on Eating Problems, Minneapolis: University of Minnesota Press.

Thompson, S. H., Sargent, R. G., and K. A. Kemper, (1996) "Black and White Adolescent Males' Perceptions of Ideal Body Size," Sex Roles 34(5/6): 391-406.

Townsend Gilkes, C. (2001), If it Wasn't for the Women.. .: Black Women's Experience and Womanist Culture in Church and Community. Maryknoll, NY: Orbis.

Troiano, R. P., Frongillo, E. A. Jr, Sobal, J., and D. A. Levitsky (1996), "The Relationship Between Body Weight and Mortality: A Quantitative Analysis of Combined Information from Existing Studies," International Journal of Obesity and Related Metabolic Disorders 20(1): 63-75.

Villanueva, E. V. (2001), "The Validity of Self-Reported Weight in U.S. Adults: A Population Based Cross-Sectional Study," BMC Public Health, 1-11 (http://www.biomedcentral.com/1471-2458/1/11).

Voracek, M., and M. L. Fisher (2002), "Shapely Centrefolds? Temporal Change in Body Measures: Trend Analysis," British Medical Journal 325: 1447-1448.

Weyer, C., Sniker, S., Bogardus, C., and E. Ravussin (1999), "Energy Metabolism in African Americans: Potential Risk Factors for Obesity," American Journal of Clinical Nutrition 70: 13-20.

Yanovski, S. Z., Reynolds, J. C., Boyle, A. J., and J. A. Yanovski (1997), "Resting Metabolic Rate in African-American and Caucasian Girls," Obesity Research 5(4): 321-325.

Yusuf, S., Hawken, S., Ounpuu, S., Bautista, L., Franzosi, M. G., Commerford, P., Lang, C. C., Rumboldt, Z., Onen, C. L., Lisheng, L., Tanomsup, S., Wangai, P. Jr, Razak, F., Sharma, A. M., Anand, S. S.: INTERHEART Study Investigators (2005), "Obesity and the Risk of Myocardial Infarction in 27,000 Participants from 52 countries: a Case-Control Study," Lancet 366: 1640-49. 


\section{Appendix}

\section{Variables from NHANES}

\section{Body Mass Index (BMI)}

We restrict our analysis to individuals whose height and weight were measured by NHANES examiners. We use the height and weight values taken in the NHANES examinations to construct the BMI value for each individual. BMI is computed as weight (measured in kilograms), divided by the square of height (measured in meters).

\section{Race}

NHANES III uses four racial categories: non-Hispanic white, non-Hispanic black, Mexican-American, and "other." In NHANES 1999-2004, an additional category, "other Hispanic," was added, to capture non-Mexican Hispanics. In the regression analysis, we include dummy variables for each racial category available in the given survey, letting whites be the omitted category, so our reported contrasts pertain explicitly to blacks versus whites. Because our analysis focuses on comparisons between whites and blacks, changes in the number of remaining categories should not affect comparisons of results between NHANES III and NHANES 1999-2004.

Age

Age is self-reported and measured in years.

\section{Education}

Educational attainment is measured through self-reports of years of education, top-coded at 17+ years in the first three waves of NHANES, where 16 years is an imperfect threshold indicating college completion. The 1999-2004 data are top-coded at 13, so that individuals with just some college cannot be distinguished from those with a college degree or more. In order to compare education effects across NHANES III and NHANES 1999-2004, we create consistent education categories, defined as 0-11 years or "less than high school," 12 years exactly or "high school," and 13 or more years or "some college (or above)." In a separate, unreported regression using the NHANES III data, we find that including a fourth education category for those with 16 or more years of schooling does not substantively affect the results.

\section{Income}

NHANES collects self-reported data on household income, rather than individual income, as a categorical variable. NHANES also includes a related variable based on household income, the "poverty income ratio," which is recommended for comparing income effects across different surveys. The poverty income ratio is roughly standardized for inflation and takes into account household size, whereas the raw income categories are not easy to align in real terms across surveys. As recommended in the NHANES analytical guidelines, we collapse the poverty-income ratio into three categories, "low," "middle," and "high," representing, respectively, individuals with household income up to 1.3 times the poverty threshold, between 1.3 and 3.5 times the threshold, and more than 3.5 times the threshold. Individuals with incomes up to 1.3 times the poverty line are eligible for food assistance programs, and thus we might expect categorical differences in outcomes across this divide. 


\section{Marital Status}

NHANES provides self-reported information pertaining to interviewees' marital status and living situation. In addition to the standard legal categories, the data indicate whether individuals are cohabiting with a partner and whether individuals are separated. Using this information, we create three categories, "married," which includes legally married people living with a spouse as well as unmarried individuals cohabiting with a partner, "formerly married," which includes divorced individuals as well as separated (or married but estranged) individuals no longer living with a spouse, and "never married," which includes non-cohabiting individuals who have never been married.

\section{Foreign-born status}

The NHANES data indicate whether each participant was born in the United States or not. We use this information to define the dummy variable "foreign-born."

\section{Geographic Location}

NHANES reports limited geographic information that is released with a lag. In NHANES III, we observe an indicator of the census region, among Northeast, South, Midwest, and West; we also observe a binary indicator of whether the individual lives in a metropolitan area with a population of one million or greater. Geographic variables have not yet been released for the 1999-2004 data, however, so these indicators are included only in the regressions involving NHANES III data.

\section{Occupation}

NHANES reports individual occupations. From a longer list of occupations, we create a variable involving four occupation categories: "skilled white collar," "unskilled white collar," "blue collar," and "unemployed or left blank." The latter category includes individuals who are unemployed in the economic sense as well as those outside the labor force and those individuals who did not select an occupation category.

\section{Exercise}

In NHANES III, respondents were asked about the frequency of leisure-time physical activity as well as the intensity. The NHANES 1999-2004 survey measures the intensity of exercise activities but not also their frequency. Rather than lose the richer information available in NHANES III, we employ a different exercise variable for each survey. For NHANES III, we create an exercise index that represents the sum, across the list of physical activities provided in the questionnaire, of the product of the reported monthly frequency of the activity and the physical intensity or "MET" score for the activity. The MET is a widely-used, standardized measure of the relative intensity of physical work, computed as the ratio of the work metabolic rate to the resting metabolic rate. For the 1999-2004 data, we construct a discrete variable with three categories of leisure-time physical activity, including "sedentary," "moderate activity," and "vigorous activity," based on responses to "yes" or "no" questions concerning whether the individual participated in a given type of activity for at least 10 minutes during the previous month. Individuals who indicate participation in both moderate and vigorous activities are placed in the vigorous category, as were individuals who indicate participation only in vigorous activities. 


\section{Smoking}

The NHANES surveys contain self-reported information on both past and present smoking activity. Based on this information, we construct a smoking variable with three categories: "never smoked," for those who report having smoked fewer than 100 cigarettes in their lifetime; "former smoker," for those who have smoked at least 100 cigarettes in their lifetime but who were not smokers as of the time of the interview; and "current smoker," for those who have smoked at least 100 cigarettes in their lifetime and who were smokers as of the time of the interview.

\section{Dietary Intake and Composition}

In both NHANES III and 1999-2004, survey participants reported extensive information on food consumption, using the " 24 hour recall" method, in which individuals are asked to write down every food item, and its quantity, that they consumed in the previous 24-hour period. Using the reports of food items consumed, such as "cheeseburger with bun," the survey uses standardized nutrition information to compute an estimate of total daily caloric intake and estimates of dietary composition. Concerning the latter, we include the estimated percentages of total calories derived, respectively, from fat, carbohydrates, protein, and alcohol.

\section{Body Fat Percentage}

NHANES III provides readings from bioelectrical impedance analysis (BIA) performed in health examinations; these readings can be converted into values of total fat-free body mass, according to equations in Chumlea et al. (2002) and Sun et al. (2003). Percentage of body fat can then be calculated as the ratio of total fat mass to body weight - where fat mass is calculated as the difference between total weight and total fat-free mass. See Cawley and Burkhauser (2006) for a detailed description of the conversion process involving the results of these two papers. As explained by Cawley and Burkhauser (2006), the equations can be reliably used to generate fat mass values only for non-Hispanic blacks and non-Hispanic whites.

BIA readings are available for the 1999-2004 data, but scientists do not agree on what equations should be used to convert these readings into measures of total fat-free mass. Cawley and Burkhauser (2006) estimate equations that predict fat-free mass (and, indirectly, fat percentage) on the basis of self-reported weight and self-reported height, using the NHANES III observations for which measured fat percentages, and self-reports of weight and height, are available. The prediction equations are raceand gender-specific. For the more recent survey, then, we generate values of body fat percentage based on the prediction equations of Cawley and Burkhauser (2006).

\section{Health Outcomes}

NHANES III and NHANES 1999-2004 ask individuals whether they have (or ever have had) various health conditions, including hypertension, diabetes, heart failure, and heart attack. We use this self-reported information to construct dummy variables for each of these conditions.

\section{Self-Perception of Weight}

The NHANES III and NHANES 1999-2004 surveys ask individuals how they would characterize their current weight. The possible responses are "underweight," "about right," and "overweight." Based 
on the responses, we define a weight self-perception variable that can take on any one of these three values.

\section{Variables from BRFSS}

The BRFSS is a separate CDC survey that contains self-reports of height and weight, desired weight, numerous health-related behaviors, and demographic information, based on telephone interviews of very large random samples (repeated cross-sections) of the non-pregnant resident population 18 years and older in participating states of the United States. To match the age range used in the NHANES analysis, we select only individuals 25 and older. In order to match food CPI data to the BRFSS data, we restrict the analysis to those individuals residing within one of the 27 MSAs for which the Bureau of Labor Statistics provides MSA-level price indexes. The latter sample restriction does not substantively affect the results concerning racial differences in BMI and obesity.

Because height and weight in the BRFSS are self-reported, we must correct for self-reporting bias. To do this we exploit the fact that, for many NHANES subjects, we observe both self-reported weight and examined weight as well as self-reported height and examined height. The correction equations constitute gender-and-race-specific regressions of examined weight (or examined height) against selfreported weight (or height). We use NHANES 1999-2004 data to generate the correction equations that are applied to the BRFSS data from 1998-2002. Because the BRFSS self-reports are based on telephone interviews rather than in-person interviews (as in NHANES), self-reporting bias may be more severe in the BRFSS than that in the NHANES (Villanueva 2001). If this is true, our corrected BMI values for the BRFSS are likely to understate true BMI on average.

Although it is possible to determine whether individuals completed college in the BRFSS, for consistency we group educational attainment into the same three categories as in the NHANES analysis: "less than high school," "high school diploma," and "some college (or above)."

Income is self-reported and divided into eight nominal categories. For the data years we use, the cutoff values are constant and therefore not adjusted for inflation. The quantiles implied by the nominal cutoffs do not vary widely across the years 1998 through 2002. They correspond roughly to octiles of the income distribution.

Labor-force status can take one of three values: "employed," "unemployed," and "homemaker, student, retiree, or disabled." The employed group is the omitted category.

Based on more detailed information, we construct a binary indicator of participation in physical activities, which takes the value "exercise" if the person engaged in any physical activities or exercise during the previous month, and "no exercise" if the person reported engaging in no leisure-time physical activity during the previous month.

The "smoker" variable is based on whether the person has smoked at least 100 cigarettes over his or her lifetime.

Based on the geographic information observed in the BRFSS, we form 27 regions that roughly match the 27 MSAs for which food CPI data are available from the Bureau of Labor Statistics (BLS). Individuals living in non-MSA areas are omitted from the sample in the analysis of BMI and obesity. 
Figure 1: Predicted Body Fat Percentage in NHANES III and 1999-2004
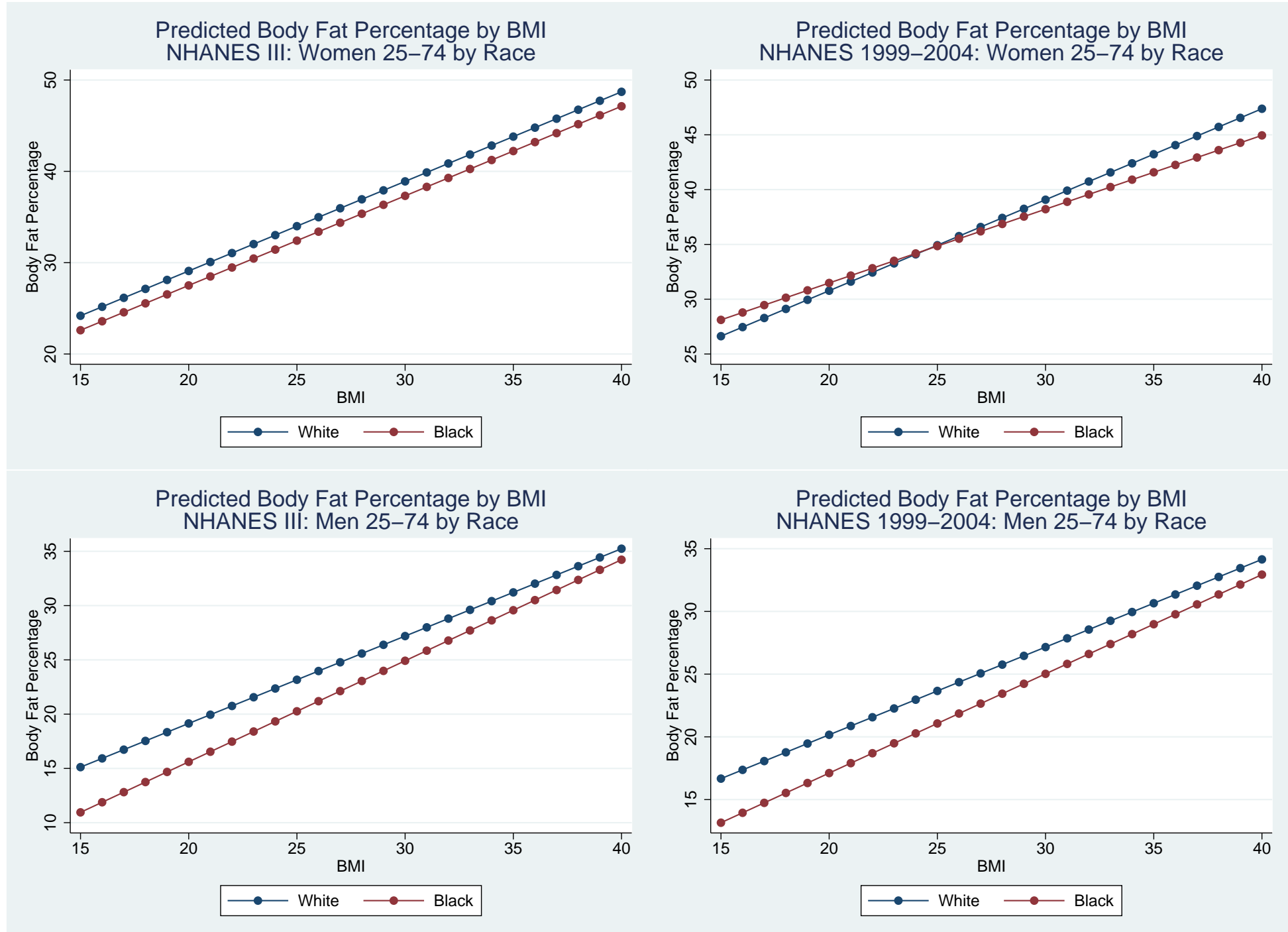
Figure 2: Predicted Weight Perceptions in NHANES 1999-2004

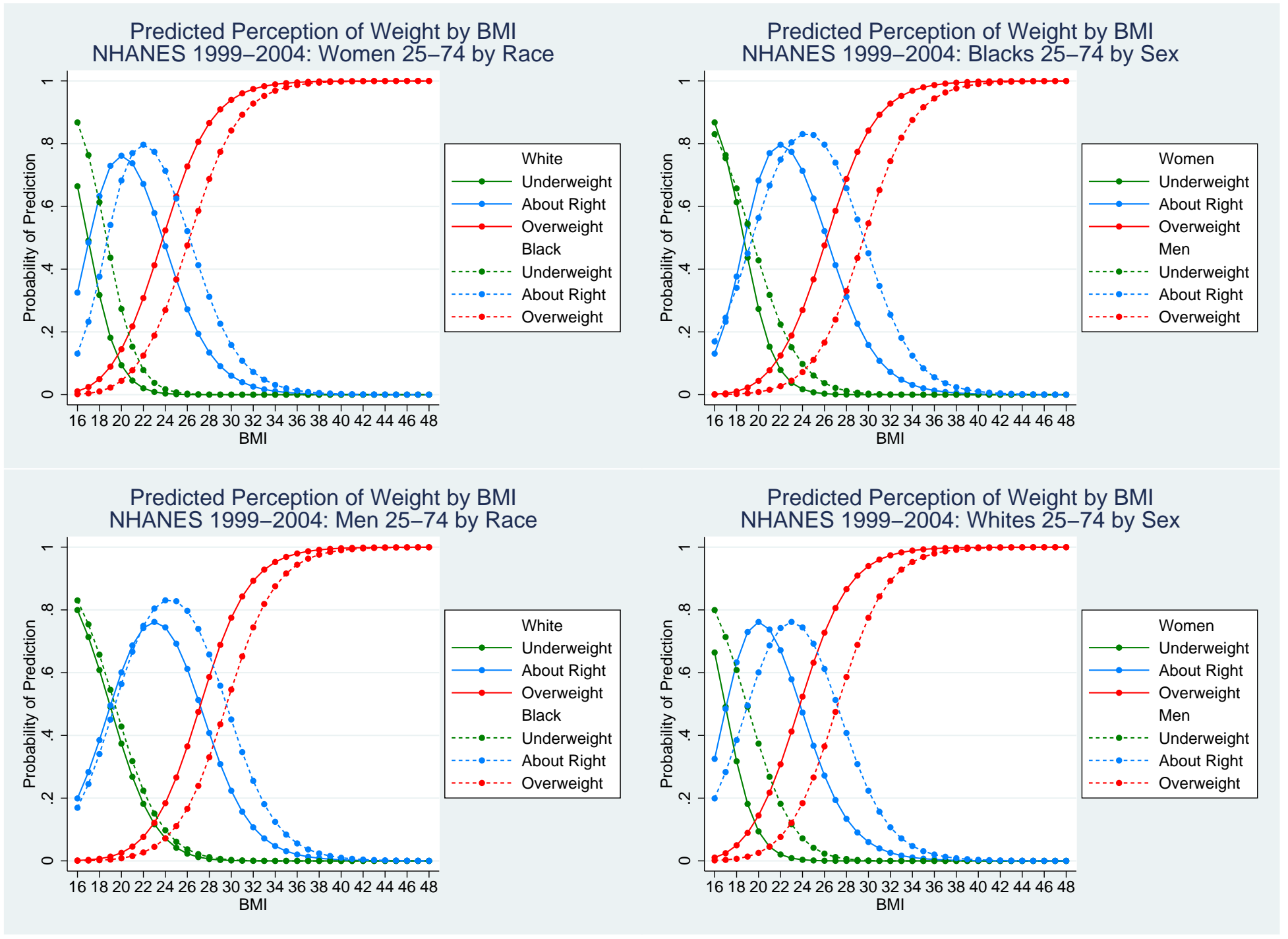


Table 1: Percent of Population Age 20-74 Obese by Gender, Race, and Poverty Status ${ }^{1}$

$1960-62 \quad 1971-74 \quad 1976-80 \quad 1988-94 \quad 1999-02 \quad 2001-04$

Total population:

Both sexes

13.3

14.6

20-74 Years, Age adjusted ${ }^{3}$

Male

10.7

12.2

15.1

23.3

31.1

32.1

Female

15.7

16.8

12.8

20.6

28.1

30.2

17.1

26.0

34.0

34.0

Not Hispanic or Latino:

White, male

- $\quad$ -

White, female

- $\quad-\quad-\quad 15.4$

20.7

28.7

31.0

Black/African American, male

- $\quad-$

16.5

23.3

31.3

31.5

Black/African American, female

一 $\quad$ - $\quad 31.0$

21.3

27.9

31.2

39.1

49.6

51.6

Percent of poverty level: ${ }^{2}$

Below 100\%

$100 \%$-less than $200 \%$

$200 \%$ or more

$\begin{array}{llllll}- & 20.7 & 21.9 & 29.2 & 36.0 & 34.9 \\ - & 18.4 & 18.7 & 26.6 & 35.4 & 34.6 \\ - & 12.4 & 12.9 & 21.4 & 29.2 & 30.6\end{array}$

Total population:

Both sexes

Male

Female

$-\quad-\quad-$

$-\quad-$

$-$

-

-

$\begin{array}{lll}- & - & - \\ - & - & - \\ - & - & -\end{array}$

- $\quad-$

- -
$-$
$-$

28.1

34.7

33.7

100\%-less than $200 \%$

26.1

34.1

33.6

21.1
31.4

29.5

33.2

$33.2 \quad 33.2$

$28.0 \quad 30.2$

$30.7 \quad 30.7$

$27.8 \quad 30.8$

$48.8 \quad 51.1$

Notes: —Data not available. ${ }^{1}$ Based on CDC Trend tables and Chartbook Tables in Excel format, 2006 Edition, Table 73 (http://www.cdc.gov/nchs/hus.htm). ${ }^{2}$ Poverty level is based on family income and family size. Persons with unknown poverty level are excluded. ${ }^{3}$ Age adjusted to the 2000 standard population using five age groups: 20-34 years, 35-44 years, 45-54 years, 55-64 years, and 65 years and over (65-74 years for estimates for 20-74 years). 
Table 2: Percent Obese, Individuals Age 25-74 in NHANES 1999-2004

\begin{tabular}{|c|c|c|c|c|}
\hline & \multicolumn{2}{|c|}{ Women } & \multicolumn{2}{|c|}{ Men } \\
\hline & Whites & Blacks & Whites & Blacks \\
\hline \multicolumn{5}{|l|}{ Age } \\
\hline $25-39$ & 26.7 & 51.3 & 24.4 & 28.1 \\
\hline $40-59$ & 35.5 & 53.0 & 32.6 & 32.0 \\
\hline $60-74$ & 36.9 & 55.0 & 35.9 & 31.9 \\
\hline \multicolumn{5}{|l|}{ Education } \\
\hline HS Dropout & 41.9 & 52.5 & 31.0 & 27.8 \\
\hline High School & 35.4 & 53.9 & 33.2 & 30.0 \\
\hline Some College & 30.0 & 52.2 & 29.2 & 32.9 \\
\hline \multicolumn{5}{|l|}{ Income Group } \\
\hline Low & 41.0 & 54.8 & 30.8 & 25.0 \\
\hline Middle & 35.8 & 56.3 & 34.0 & 34.1 \\
\hline High & 27.8 & 46.9 & 29.1 & 33.8 \\
\hline \multicolumn{5}{|l|}{ Marital Status } \\
\hline Never Married & 38.2 & 54.9 & 26.0 & 29.3 \\
\hline Currently Married & 32.1 & 45.7 & 32.7 & 31.8 \\
\hline Formerly Married & 34.9 & 57.7 & 26.0 & 26.5 \\
\hline \multicolumn{5}{|l|}{ Occupation } \\
\hline Skilled Whitecollar & 29.1 & 51.5 & 28.8 & 29.8 \\
\hline Unskilled Whitecollar & 32.3 & 55.1 & 33.1 & 43.4 \\
\hline Bluecollar & 39.2 & 48.2 & 28.8 & 29.9 \\
\hline Blank/NA & 34.5 & 54.5 & 35.1 & 28.3 \\
\hline \multicolumn{5}{|l|}{ Exercise } \\
\hline Low/None & 40.6 & 53.1 & 34.6 & 27.6 \\
\hline Moderate & 33.1 & 55.0 & 34.5 & 34.3 \\
\hline Vigorous & 22.9 & 47.8 & 24.1 & 30.7 \\
\hline \multicolumn{5}{|l|}{ Smoking } \\
\hline$\overline{\text { Never Smoked }}$ & 34.8 & 53.7 & 31.6 & 32.9 \\
\hline Former Smoker & 33.6 & 58.4 & 35.6 & 43.6 \\
\hline Current Smoker & 28.3 & 46.3 & 22.8 & 20.1 \\
\hline
\end{tabular}

Notes: Authors' calculations. 
Table 3: Means, Individuals Age 25-74 in NHANES 1999-2004

\begin{tabular}{|c|c|c|c|c|}
\hline & \multicolumn{2}{|c|}{ Women } & \multicolumn{2}{|c|}{ Men } \\
\hline & Whites & Blacks & Whites & Blacks \\
\hline \multicolumn{5}{|l|}{ Age } \\
\hline $25-39$ & 0.35 & 0.45 & 0.34 & 0.42 \\
\hline $40-59$ & 0.45 & 0.42 & 0.46 & 0.46 \\
\hline $60-74$ & 0.20 & 0.13 & 0.19 & 0.13 \\
\hline \multicolumn{5}{|l|}{ Education } \\
\hline HS Dropout & 0.11 & 0.30 & 0.12 & 0.30 \\
\hline High School & 0.25 & 0.23 & 0.27 & 0.25 \\
\hline Some College & 0.64 & 0.47 & 0.61 & 0.45 \\
\hline \multicolumn{5}{|l|}{ Income Group } \\
\hline Low & 0.22 & 0.48 & 0.18 & 0.37 \\
\hline Middle & 0.27 & 0.27 & 0.25 & 0.27 \\
\hline High & 0.51 & 0.25 & 0.57 & 0.36 \\
\hline \multicolumn{5}{|l|}{ Foreign-Born } \\
\hline Not born in the US & 0.04 & 0.08 & 0.04 & 0.11 \\
\hline \multicolumn{5}{|l|}{ Marital Status } \\
\hline Never Married & 0.08 & 0.27 & 0.13 & 0.26 \\
\hline Currently Married & 0.73 & 0.40 & 0.76 & 0.58 \\
\hline Formerly Married & 0.20 & 0.33 & 0.12 & 0.16 \\
\hline \multicolumn{5}{|l|}{ Occupation } \\
\hline Skilled Whitecollar & 0.33 & 0.28 & 0.37 & 0.19 \\
\hline Unskilled Whitecollar & 0.20 & 0.15 & 0.06 & 0.07 \\
\hline Bluecollar & 0.12 & 0.20 & 0.34 & 0.42 \\
\hline Blank/NA & 0.36 & 0.37 & 0.23 & 0.31 \\
\hline \multicolumn{5}{|l|}{ Exercise } \\
\hline$\overline{\text { Low/None }}$ & 0.31 & 0.53 & 0.28 & 0.41 \\
\hline Moderate & 0.37 & 0.25 & 0.31 & 0.21 \\
\hline Vigorous & 0.32 & 0.23 & 0.41 & 0.38 \\
\hline \multicolumn{5}{|l|}{ Smoking } \\
\hline$\overline{\text { Never Smoked }}$ & 0.53 & 0.62 & 0.42 & 0.49 \\
\hline Former Smoker & 0.25 & 0.15 & 0.32 & 0.18 \\
\hline Current Smoker & 0.22 & 0.23 & 0.26 & 0.34 \\
\hline \multicolumn{5}{|l|}{$\underline{\text { Diet }}$} \\
\hline Percent Fat & 33.76 & 33.47 & 33.84 & 32.20 \\
\hline Percent Alcohol & 2.12 & 1.65 & 3.99 & 4.03 \\
\hline Percent Protein & 14.93 & 14.93 & 15.31 & 15.49 \\
\hline Total Daily Calories & 1868.8 & 1864.9 & 2656.8 & 2462.7 \\
\hline \multicolumn{5}{|l|}{ Body Composition } \\
\hline Body Fat Percentage & 37.26 & 39.18 & 25.93 & 23.65 \\
\hline
\end{tabular}


Table 4: Structural BMI/Obesity Regressions, NHANES 1999-2004, Age 25-74

\begin{tabular}{|c|c|c|c|c|c|c|c|c|c|c|c|c|c|c|c|c|}
\hline & \multicolumn{8}{|c|}{ BMI (Regression) } & \multicolumn{8}{|c|}{ Obese (Linear Probability Model) } \\
\hline & (1) & (2) ${ }^{W}$ & en (3) & (4) & (1) & (2) ${ }^{\mathrm{N}}$ & $\begin{array}{ll}\mathrm{n}^{\mathrm{n}} & \\
& (3)\end{array}$ & (4) & (1) & (2) ${ }^{\mathrm{W}}$ & en (3) & (4) & (1) & (2) & Ien (3) & (4) \\
\hline Black & & & $\begin{array}{c}3.64^{* * *} \\
(0.34)\end{array}$ & $\begin{array}{c}10.20 * * * \\
(2.21)\end{array}$ & & & $\begin{array}{l}0.74^{*} \\
(0.28)\end{array}$ & $\begin{array}{c}2.01 \\
(1.36)\end{array}$ & & & $\begin{array}{c}0.20^{* * *} \\
(0.02)\end{array}$ & $\begin{array}{c}0.59^{* * *} \\
(0.13)\end{array}$ & & & $\begin{array}{l}0.04^{*} \\
(0.02)\end{array}$ & $\begin{array}{c}0.08 \\
(0.12)\end{array}$ \\
\hline Moderate Exercise & $\begin{array}{c}-1.26^{* * *} \\
(0.32)\end{array}$ & $\begin{array}{c}-1.22^{* * *} \\
(0.32)\end{array}$ & $\begin{array}{l}-0.85^{*} \\
(0.32)\end{array}$ & $\begin{array}{c}-1.18^{* *} \\
(0.39)\end{array}$ & $\begin{array}{c}0.46 \\
(0.27)\end{array}$ & $\begin{array}{c}0.44 \\
(0.26)\end{array}$ & $\begin{array}{r}0.49 \\
(0.26)\end{array}$ & $\begin{array}{r}0.29 \\
(0.32)\end{array}$ & $\begin{array}{c}-0.07^{* *} \\
(0.02)\end{array}$ & $\begin{array}{l}-0.07^{* *} \\
(0.02)\end{array}$ & $\begin{array}{l}-0.04^{*} \\
-0.02)\end{array}$ & $-0.07^{*}$ & 0.03 & 0.03 & 0.03 & 0.01 \\
\hline Vigorous Exercise & $\begin{array}{c}-2.97^{* * *} \\
(0.32)\end{array}$ & $\begin{array}{l}-2.93^{* * *} \\
(0.35)\end{array}$ & $\begin{array}{l}-2.53^{* * *} \\
(0.34)\end{array}$ & $\begin{array}{c}-3.12^{* * *} \\
(0.38)\end{array}$ & $\begin{array}{l}-0.98^{* *} \\
(0.28)\end{array}$ & $\begin{array}{l}-0.95^{* *} \\
(0.28)\end{array}$ & $\begin{array}{c}-0.90^{* *} \\
(0.28)\end{array}$ & $\begin{array}{l}-1.24^{* * *} \\
(0.33)\end{array}$ & $\begin{array}{l}-0.18^{* * *} \\
(0.02)\end{array}$ & $\begin{array}{c}-0.18^{* * *} \\
(0.02)\end{array}$ & $\begin{array}{c}-0.16^{* * * *} \\
(0.02)\end{array}$ & $\begin{array}{c}-0.19^{* * *} \\
(0.03)\end{array}$ & $\begin{array}{c}-0.05)^{* *} \\
(0.02)\end{array}$ & $\begin{array}{l}(0.0)^{* *} \\
(0.02)\end{array}$ & $\begin{array}{l}-0.07^{*} \\
(0.02)\end{array}$ & $\begin{array}{r}\left.-0.10^{* * *}\right) \\
(0.03)\end{array}$ \\
\hline Current Smoker & $\begin{array}{c}-1.63^{* * *} \\
(0.38)\end{array}$ & $\begin{array}{c}-1.55^{* * *} \\
(0.40)\end{array}$ & $\begin{array}{c}-1.66^{* * *} \\
(0.39)\end{array}$ & $\begin{array}{c}-1.70^{* * *} \\
(0.45)\end{array}$ & $\begin{array}{l}-2.00^{* * *} \\
(0.26)\end{array}$ & $\begin{array}{c}-1.97^{* * *} \\
(0.26)\end{array}$ & $\begin{array}{l}-2.01^{* * *} \\
(0.26)\end{array}$ & $\begin{array}{c}-2.06 * * * \\
(0.32)\end{array}$ & $\begin{array}{l}-0.07^{*} \\
(0.03)\end{array}$ & $\begin{array}{l}-0.07^{*} \\
(0.03)\end{array}$ & $\begin{array}{l}-0.07^{*} \\
(0.03)\end{array}$ & $\begin{array}{l}-0.06 \\
(0.03)\end{array}$ & $\begin{array}{l}-0.11^{* * *} \\
(0.02)\end{array}$ & $\begin{array}{c}-0.10^{* * *} \\
(0.02)\end{array}$ & $\begin{array}{l}-0.10^{* * *} \\
(0.02)\end{array}$ & $\begin{array}{c}\left.-0.11^{* * *}\right) \\
(0.03)\end{array}$ \\
\hline Former Smoker & $\begin{array}{l}0.69^{*} \\
(0.33)\end{array}$ & $\begin{array}{l}0.61 \\
(0.33)\end{array}$ & $\begin{array}{l}0.79^{*} \\
(0.32)\end{array}$ & $\begin{array}{l}0.58 \\
(0.37)\end{array}$ & $\begin{array}{l}0.48 \\
(0.25)\end{array}$ & $\begin{array}{c}0.41 \\
(0.27)\end{array}$ & $\begin{array}{l}0.44 \\
(0.26)\end{array}$ & $\begin{array}{l}0.58 \\
(0.31)\end{array}$ & $\begin{array}{r}0.02 \\
(0.02)\end{array}$ & $\begin{array}{c}0.02 \\
(0.02)\end{array}$ & $\begin{array}{l}0.03 \\
(0.02)\end{array}$ & $\begin{array}{l}0.00 \\
(0.02)\end{array}$ & $\begin{array}{l}0.03 \\
(0.02)\end{array}$ & $\begin{array}{c}0.02 \\
(0.02)\end{array}$ & $\begin{array}{l}0.03 \\
(0.02)\end{array}$ & $\begin{array}{c}0.04 \\
(0.03)\end{array}$ \\
\hline Percent Fat & $\begin{array}{l}0.05^{* *} \\
(0.02)\end{array}$ & $\begin{array}{l}0.05^{* *} \\
(0.02)\end{array}$ & $\begin{array}{l}0.05^{* *} \\
(0.02)\end{array}$ & $\begin{array}{l}0.07^{* *} \\
0.02\end{array}$ & $\begin{array}{c}0.08^{* * *} \\
(0.02)\end{array}$ & $\begin{array}{c}0.08^{* * *} \\
(0.02)\end{array}$ & $\begin{array}{c}0.08^{* * *} \\
(0.02)\end{array}$ & $\begin{array}{c}0.08^{* * *} \\
(0.02)\end{array}$ & $\begin{array}{l}0.00^{* *} \\
(0.00)\end{array}$ & $\begin{array}{l}0.00^{* *} \\
(000)\end{array}$ & $\begin{array}{l}0.00^{* *} \\
0.00)\end{array}$ & $\begin{array}{l}0.01^{* * *} \\
(0.00)\end{array}$ & $0.01^{* * *}$ & $0.00^{* * *}$ & $0.01^{* * * *}$ & $0.01^{* * *}$ \\
\hline Percent Alcohol & $-0.09^{* * *}$ & $-0.09^{* * *}$ & $-0.09^{* * *}$ & $-0.07^{*}$ & -0.00 & $\begin{array}{l}-0.01 \\
-0.01\end{array}$ & $\begin{array}{l}(0.02) \\
-0.01\end{array}$ & $\begin{array}{l}(0.02) \\
-0.00\end{array}$ & $-0.01^{* *}$ & $-0.01^{* * *}$ & $-0.00^{* * *}$ & $\begin{array}{l}(0.00) \\
-0.01^{* *}\end{array}$ & $\begin{array}{c}(0.00) \\
0.00 \\
0.00\end{array}$ & $\begin{array}{l}(0.00) \\
-0.00 \\
-0.009\end{array}$ & $\begin{array}{l}(0.00) \\
-0.00 \\
-0.00\end{array}$ & $\begin{array}{l}(0.00) \\
-0.00 \\
-0.00)\end{array}$ \\
\hline Percent Protein & $\begin{array}{l}(0.02) \\
0.08^{* *}\end{array}$ & $\begin{array}{l}(0.02) \\
0.08^{* *}\end{array}$ & $\begin{array}{l}(0.02) \\
0.07^{* *}\end{array}$ & $\begin{array}{l}(0.03) \\
0.13^{* * *}\end{array}$ & $\begin{array}{l}(0.01) \\
0.07 * * \\
(0.02)\end{array}$ & $\begin{array}{l}(0.01) \\
0.07^{* *} \\
(0.02)\end{array}$ & $\begin{array}{l}(0.01) \\
0.07 * * \\
0.03\end{array}$ & $\begin{array}{l}(0.02) \\
0.12^{* * *}\end{array}$ & $\begin{array}{c}(0.00) \\
0.00 \\
(0.00)\end{array}$ & $\begin{array}{c}(0.00) \\
0.00\end{array}$ & $\begin{array}{c}(0.00) \\
0.00 \\
0.009\end{array}$ & $\begin{array}{l}(0.00) \\
0.01^{*}\end{array}$ & $\begin{array}{c}(0.00) \\
0.00\end{array}$ & $\begin{array}{c}(0.00) \\
0.00 \\
0.009\end{array}$ & $\begin{array}{c}(0.00) \\
0.00 \\
(0.00)\end{array}$ & $\begin{array}{l}(0.00) \\
0.01^{*}\end{array}$ \\
\hline Total Kcal (in 1000s) & $\begin{array}{c}(0.02) \\
0.34 \\
(0.22)\end{array}$ & $\begin{array}{c}(0.02) \\
0.39 \\
(0.23)\end{array}$ & $\begin{array}{c}(0.02) \\
0.39 \\
(0.23)\end{array}$ & $\begin{array}{l}(0.03) \\
0.61^{*} \\
(0.30)\end{array}$ & $\begin{array}{c}(0.02) \\
0.06 \\
(0.13)\end{array}$ & $\begin{array}{c}(0.02) \\
0.08 \\
(0.13)\end{array}$ & $\begin{array}{c}(0.03) \\
0.09 \\
(0.12)\end{array}$ & $\begin{array}{c}(0.03) \\
0.12 \\
(0.15)\end{array}$ & $\begin{array}{c}(0.00) \\
0.03 \\
(0.01)\end{array}$ & $\begin{array}{l}(0.00) \\
0.03^{*} \\
(0.01)\end{array}$ & $\begin{array}{l}(0.00) \\
0.03^{*} \\
(0.01)\end{array}$ & $\begin{array}{l}(0.00) \\
0.04^{*} \\
(0.02)\end{array}$ & $\begin{array}{l}(0.00) \\
-0.00 \\
(0.01)\end{array}$ & $\begin{array}{c}(0.00) \\
0.00 \\
(0.01)\end{array}$ & $\begin{array}{c}(0.00) \\
0.00 \\
(0.01)\end{array}$ & $\begin{array}{c}(0.00) \\
0.00 \\
(0.01)\end{array}$ \\
\hline Black x Moderate Exercise & & & & $\begin{array}{c}0.60 \\
(0.73)\end{array}$ & & & & $\begin{array}{l}1.07 \\
(0.67)\end{array}$ & & & & $\begin{array}{c}0.11 \\
(0.05)\end{array}$ & & & & $\begin{array}{l}0.08 \\
(0.06)\end{array}$ \\
\hline Black x Vigorous Exercise & & & & $\begin{array}{l}1.37 \\
(0.83)\end{array}$ & & & & $\begin{array}{l}1.40^{*} \\
(0.58)\end{array}$ & & & & $\begin{array}{l}0.07 \\
(0.05)\end{array}$ & & & & $\begin{array}{l}0.12^{* *} \\
(0.04)\end{array}$ \\
\hline Black x Current Smoker & & & & $\begin{array}{l}0.28 \\
(1.11)\end{array}$ & & & & $\begin{array}{l}-1.94 \\
(1.02)\end{array}$ & & & & $\begin{array}{l}-0.03 \\
0.07)\end{array}$ & & & & $\begin{array}{l}-0.13^{*} \\
(0.05)\end{array}$ \\
\hline Black x Former Smoker & & & & -0.33 & & & & 0.07 & & & & 0.03 & & & & $\begin{array}{l}(0.05) \\
-0.01\end{array}$ \\
\hline & & & & $(0.84)$ & & & & $(0.86)$ & & & & $(0.06)$ & & & & $(0.06)$ \\
\hline Black $x$ Percent Fat & & & & -0.06 & & & & 0.02 & & & & $-0.01^{*}$ & & & & 0.00 \\
\hline & & & & $(0.05)$ & & & & $(0.04)$ & & & & $(0.00)$ & & & & $(0.00)$ \\
\hline Black x Percent Alcohol & & & & -0.04 & & & & 0.02 & & & & 0.00 & & & & 0.00 \\
\hline & & & & $(0.05)$ & & & & $(0.03)$ & & & & $(0.00)$ & & & & $(0.00)$ \\
\hline Black $x$ Percent Protein & & & & $-0.22^{* * *}$ & & & & -0.11 & & & & $-0.01^{*}$ & & & & -0.01 \\
\hline Black x Total Kcal (in 1000s) & & & & $\begin{array}{l}(0.06) \\
-0.88^{*} \\
(0.40)\end{array}$ & & & & $\begin{array}{l}(0.07) \\
-0.22 \\
(0.31)\end{array}$ & & & & $\begin{array}{l}(0.00) \\
-0.05 \\
(0.03)\end{array}$ & & & & $\begin{array}{l}(0.01) \\
-0.022 \\
(0.02)\end{array}$ \\
\hline Constant & $26.48^{* * *}$ & $20.36^{* * *}$ & $19.25^{* * *}$ & $17.48^{* * *}$ & $24.67^{* * *}$ & $19.69^{* * *}$ & $19.50^{* * *}$ & $18.33^{* * *}$ & $0.22^{* * *}$ & -0.01 & -0.06 & -0.17 & 0.08 & $-0.27^{*}$ & $-0.27^{*}$ & $-0.35^{*}$ \\
\hline & $(0.85)$ & $(2.01)$ & $(2.03)$ & $(2.15)$ & $(0.75)$ & $(1.32)$ & $(1.38)$ & $(1.52)$ & $(0.06)$ & $(0.13)$ & $(0.13)$ & $(0.14)$ & $(0.06)$ & $(0.12)$ & $(0.13)$ & $(0.14)$ \\
\hline$N$ & 5011 & 5011 & 5011 & 5011 & 4617 & 4617 & 4617 & 4617 & 5011 & 5011 & 5011 & 5011 & 4617 & 4617 & 4617 & 4617 \\
\hline$R^{2}$ & 0.051 & 0.056 & 0.086 & 0.100 & 0.060 & 0.065 & 0.069 & 0.089 & 0.041 & 0.042 & 0.065 & 0.079 & 0.034 & 0.038 & 0.041 & 0.058 \\
\hline
\end{tabular}

.01 level. 
Table 5: BMI Predicted from Structural Regressions

\begin{tabular}{|c|c|c|c|}
\hline & White & Black & Black w/ White Behavior \\
\hline & & & \\
\hline \multicolumn{4}{|l|}{ Mean Age (45.75) } \\
\hline NHANES 1999-2004 & 27.805 & 31.698 & 31.449 \\
\hline NHANES III & 26.318 & 29.379 & 29.218 \\
\hline \multicolumn{4}{|l|}{ Age 25} \\
\hline NHANES 1999-2004 & 26.443 & 30.336 & 30.087 \\
\hline NHANES III & 24.107 & 27.168 & 27.007 \\
\hline \multicolumn{4}{|l|}{ Age 55} \\
\hline NHANES 1999-2004 & 28.338 & 32.232 & 31.982 \\
\hline \multirow[t]{2}{*}{ NHANES III } & 27.359 & 30.420 & 30.259 \\
\hline & \multicolumn{3}{|c|}{ Men } \\
\hline \multicolumn{4}{|l|}{ Mean Age (45.75) } \\
\hline NHANES 1999-2004 & 28.165 & 28.538 & 28.908 \\
\hline NHANES III & 27.055 & 26.708 & 26.939 \\
\hline \multicolumn{4}{|l|}{ Age 25} \\
\hline NHANES 1999-2004 & 27.191 & 27.564 & 27.933 \\
\hline NHANES III & 26.029 & 25.683 & 25.914 \\
\hline \multicolumn{4}{|l|}{ Age 55} \\
\hline NHANES 1999-2004 & 28.543 & 28.916 & 29.285 \\
\hline NHANES III & 27.552 & 27.206 & 27.437 \\
\hline
\end{tabular}



(1)
(2)
(3)
(4)
(5)
(6)
(7)

\begin{tabular}{|c|c|c|c|c|c|c|c|}
\hline Black & $\begin{array}{c}\mathbf{3 . 1 5}^{* * *} \\
(0.32)\end{array}$ & $\begin{array}{c}\mathbf{2 . 9 2}^{* * *} \\
(0.30)\end{array}$ & $\begin{array}{c}\mathbf{2 . 5 4}^{* * *} \\
(0.35)\end{array}$ & $\begin{array}{c}\mathbf{2 . 5 7}^{* * *} \\
(0.36)\end{array}$ & $\begin{array}{c}\mathbf{2 . 4 7}^{* * *} \\
(0.36)\end{array}$ & $\begin{array}{c}\mathbf{2 . 4 8}^{* * *} \\
(0.35)\end{array}$ & $\begin{array}{c}\mathbf{2 . 4 1}^{* * *} \\
(0.35)\end{array}$ \\
\hline High School & & $\begin{array}{l}-0.13 \\
(0.33)\end{array}$ & $\begin{array}{c}0.19 \\
(0.32)\end{array}$ & $\begin{array}{c}0.20 \\
(0.32)\end{array}$ & $\begin{array}{c}0.30 \\
(0.33)\end{array}$ & $\begin{array}{c}0.16 \\
(0.31)\end{array}$ & $\begin{array}{c}0.20 \\
(0.31)\end{array}$ \\
\hline Some College & & $\begin{array}{c}-1.77^{* * *} \\
(0.33)\end{array}$ & $\begin{array}{c}-1.11^{* * *} \\
(0.31)\end{array}$ & $\begin{array}{c}-1.05^{\text {*** }} \\
(0.31)\end{array}$ & $\begin{array}{c}-0.76^{* *} \\
(0.32)\end{array}$ & $\begin{array}{c}-1.04^{* * *} \\
(0.30)\end{array}$ & $\begin{array}{c}-1.03^{* * *} \\
(0.29)\end{array}$ \\
\hline Middle Income & & & $\begin{array}{l}-0.58^{*} \\
(0.33)\end{array}$ & $\begin{array}{l}-0.48 \\
(0.33)\end{array}$ & $\begin{array}{l}-0.47 \\
(0.33)\end{array}$ & $\begin{array}{l}-0.59^{*} \\
(0.33)\end{array}$ & $\begin{array}{l}-0.63^{*} \\
(0.32)\end{array}$ \\
\hline High Income & & & $\begin{array}{c}-1.58^{* * *} \\
(0.32)\end{array}$ & $\begin{array}{c}-1.43^{* * *} \\
(0.35)\end{array}$ & $\begin{array}{c}-1.33^{* * *} \\
(0.34)\end{array}$ & $\begin{array}{c}-1.51^{* * *} \\
(0.35)\end{array}$ & $\begin{array}{c}-1.55^{* * *} \\
(0.34)\end{array}$ \\
\hline Foreign-Born & & & & $\begin{array}{l}-0.46 \\
(0.45)\end{array}$ & $\begin{array}{l}-0.58 \\
(0.45)\end{array}$ & $\begin{array}{l}-0.82^{*} \\
(0.44)\end{array}$ & $\begin{array}{l}-0.84^{*} \\
(0.43)\end{array}$ \\
\hline Midwest & & & & $\begin{array}{c}0.15 \\
(0.68)\end{array}$ & $\begin{array}{c}0.19 \\
(0.65)\end{array}$ & $\begin{array}{c}0.20 \\
(0.64)\end{array}$ & $\begin{array}{c}0.18 \\
(0.65)\end{array}$ \\
\hline South & & & & $\begin{array}{c}0.15 \\
(0.65)\end{array}$ & $\begin{array}{l}-0.02 \\
(0.65)\end{array}$ & $\begin{array}{l}-0.11 \\
(0.64)\end{array}$ & $\begin{array}{l}-0.11 \\
(0.65)\end{array}$ \\
\hline West & & & & $\begin{array}{c}0.15 \\
(0.59)\end{array}$ & $\begin{array}{c}0.15 \\
(0.58)\end{array}$ & $\begin{array}{c}0.11 \\
(0.58)\end{array}$ & $\begin{array}{c}0.11 \\
(0.58)\end{array}$ \\
\hline Not Metro & & & & $\begin{array}{c}0.17 \\
(0.37)\end{array}$ & $\begin{array}{c}0.20 \\
(0.36)\end{array}$ & $\begin{array}{c}0.25 \\
(0.36)\end{array}$ & $\begin{array}{c}0.23 \\
(0.36)\end{array}$ \\
\hline Skilled Whitecollar & & & & $\begin{array}{l}-0.11 \\
(0.34)\end{array}$ & $\begin{array}{l}-0.17 \\
(0.34)\end{array}$ & $\begin{array}{l}-0.21 \\
(0.34)\end{array}$ & $\begin{array}{l}-0.22 \\
(0.33)\end{array}$ \\
\hline Unskilled Whitecollar & & & & $\begin{array}{l}-0.02 \\
(0.48)\end{array}$ & $\begin{array}{l}-0.14 \\
(0.48)\end{array}$ & $\begin{array}{l}-0.16 \\
(0.47)\end{array}$ & $\begin{array}{l}-0.21 \\
(0.46)\end{array}$ \\
\hline Blank & & & & $\begin{array}{c}0.53 \\
(0.35)\end{array}$ & $\begin{array}{c}0.53 \\
(0.35)\end{array}$ & $\begin{array}{c}0.52 \\
(0.34)\end{array}$ & $\begin{array}{c}0.51 \\
(0.34)\end{array}$ \\
\hline Married or Cohabiting & & & & $\begin{array}{l}-0.25 \\
(0.53)\end{array}$ & $\begin{array}{l}-0.33 \\
(0.51)\end{array}$ & $\begin{array}{l}-0.31 \\
(0.52)\end{array}$ & $\begin{array}{l}-0.33 \\
(0.51)\end{array}$ \\
\hline Formerly Married & & & & $\begin{array}{l}-0.37 \\
(0.56)\end{array}$ & $\begin{array}{l}-0.39 \\
(0.56)\end{array}$ & $\begin{array}{l}-0.31 \\
(0.55)\end{array}$ & $\begin{array}{l}-0.31 \\
(0.55)\end{array}$ \\
\hline Exercise Level & & & & & $\begin{array}{c}-0.01^{* * *} \\
(0.00)\end{array}$ & $\begin{array}{c}-0.01^{* * *} \\
(0.00)\end{array}$ & $\begin{array}{c}-0.01^{* * *} \\
(0.00)\end{array}$ \\
\hline Current Smoker & & & & & & $\begin{array}{c}-1.95^{* * *} \\
(0.36)\end{array}$ & $\begin{array}{c}-1.89^{* * *} \\
(0.37)\end{array}$ \\
\hline Former Smoker & & & & & & $\begin{array}{c}0.47 \\
(0.34)\end{array}$ & $\begin{array}{c}0.41 \\
(0.34)\end{array}$ \\
\hline Percent Fat & & & & & & & $\begin{array}{c}0.02^{* * *} \\
(0.01)\end{array}$ \\
\hline Percent Alcohol & & & & & & & $\begin{array}{l}-0.02 \\
(0.01)\end{array}$ \\
\hline Percent Protein & & & & & & & $\begin{array}{c}0.08^{* * *} \\
(0.02)\end{array}$ \\
\hline$R^{2}$ & 0.0527 & 0.0682 & 0.076 & 0.0782 & 0.0905 & 0.1022 & 0.1082 \\
\hline
\end{tabular}

Notes: Standard errors are reported in parentheses. All regressions also control for Hispanic, other Race/Ethnicity, age, and age squared. ${ }^{*}$ Statistically significant at the $.10 \mathrm{level;}{ }^{* *}$ at the $.05 \mathrm{level} ;{ }^{* * *}$ at the .01 level. 
Table 7: Determinants of Obesity, Poisson Regressions, NHANESIII, Women age 25-74, N=5950
(1)
(2)
(3)
(4)
(5)
(6)
(7)

\begin{tabular}{|c|c|c|c|c|c|c|c|}
\hline Black & $\begin{array}{c}\mathbf{1 . 7 0}^{* * * *} \\
(0.13)\end{array}$ & $\begin{array}{c}\mathbf{1 . 6 0}^{* * *} \\
(0.11)\end{array}$ & $\begin{array}{c}\mathbf{1 . 4 8}^{\text {**** }} \\
(0.11)\end{array}$ & $\begin{array}{c}\mathbf{1 . 4 7}^{* * *} \\
(0.12)\end{array}$ & $\begin{array}{c}\mathbf{1 . 4 4}^{* * * *} \\
(0.12)\end{array}$ & $\begin{array}{c}\mathbf{1 . 4 4}^{* * *} \\
(0.12)\end{array}$ & $\begin{array}{c}\mathbf{1 . 4 1}^{* * *} \\
(0.11)\end{array}$ \\
\hline High School & & $\begin{array}{c}0.94 \\
(0.06)\end{array}$ & $\begin{array}{c}1.00 \\
(0.07)\end{array}$ & $\begin{array}{c}1.01 \\
(0.07)\end{array}$ & $\begin{array}{c}1.03 \\
(0.07)\end{array}$ & $\begin{array}{c}1.01 \\
(0.07)\end{array}$ & $\begin{array}{c}1.02 \\
(0.07)\end{array}$ \\
\hline Some College & & $\begin{array}{c}0.64^{* * *} \\
(0.05)\end{array}$ & $\begin{array}{c}0.74^{* * *} \\
(0.06)\end{array}$ & $\begin{array}{c}0.77^{* * *} \\
(0.06)\end{array}$ & $\begin{array}{l}0.82^{\text {** }} \\
(0.07)\end{array}$ & $\begin{array}{c}0.79^{* * *} \\
(0.06)\end{array}$ & $\begin{array}{c}0.79^{* * *} \\
(0.06)\end{array}$ \\
\hline Middle Income & & & $\begin{array}{c}0.91 \\
(0.07)\end{array}$ & $\begin{array}{c}0.96 \\
(0.08)\end{array}$ & $\begin{array}{c}0.96 \\
(0.08)\end{array}$ & $\begin{array}{c}0.95 \\
(0.08)\end{array}$ & $\begin{array}{c}0.94 \\
(0.07)\end{array}$ \\
\hline High Income & & & $\begin{array}{c}0.70^{* * *} \\
(0.06)\end{array}$ & $\begin{array}{c}0.76^{* * *} \\
(0.06)\end{array}$ & $\begin{array}{c}0.78^{* * *} \\
(0.07)\end{array}$ & $\begin{array}{c}0.76^{* * *} \\
(0.07)\end{array}$ & $\begin{array}{c}0.75^{* * *} \\
(0.06)\end{array}$ \\
\hline Foreign-Born & & & & $\begin{array}{c}0.82 \\
(0.10)\end{array}$ & $\begin{array}{l}0.80^{*} \\
(0.10)\end{array}$ & $\begin{array}{l}0.76^{* *} \\
(0.10)\end{array}$ & $\begin{array}{l}0.77^{* *} \\
(0.09)\end{array}$ \\
\hline Midwest & & & & $\begin{array}{c}1.06 \\
(0.18)\end{array}$ & $\begin{array}{c}1.06 \\
(0.18)\end{array}$ & $\begin{array}{c}1.06 \\
(0.18)\end{array}$ & $\begin{array}{c}1.04 \\
(0.17)\end{array}$ \\
\hline South & & & & $\begin{array}{c}1.03 \\
(0.18)\end{array}$ & $\begin{array}{c}1.00 \\
(0.17)\end{array}$ & $\begin{array}{c}0.98 \\
(0.17)\end{array}$ & $\begin{array}{c}0.97 \\
(0.16)\end{array}$ \\
\hline West & & & & $\begin{array}{c}1.04 \\
(0.16)\end{array}$ & $\begin{array}{c}1.04 \\
(0.16)\end{array}$ & $\begin{array}{c}1.04 \\
(0.16)\end{array}$ & $\begin{array}{c}1.03 \\
(0.16)\end{array}$ \\
\hline Not Metro & & & & $\begin{array}{c}1.00 \\
(0.10)\end{array}$ & $\begin{array}{c}1.00 \\
(0.10)\end{array}$ & $\begin{array}{c}1.01 \\
(0.10)\end{array}$ & $\begin{array}{c}1.00 \\
(0.10)\end{array}$ \\
\hline Skilled Whitecollar & & & & $\begin{array}{l}0.82^{*} \\
(0.09)\end{array}$ & $\begin{array}{l}0.82^{*} \\
(0.09)\end{array}$ & $\begin{array}{l}0.81^{*} \\
(0.09)\end{array}$ & $\begin{array}{l}0.81^{*} \\
(0.09)\end{array}$ \\
\hline Unskilled Whitecollar & & & & $\begin{array}{c}0.91 \\
(0.10)\end{array}$ & $\begin{array}{c}0.90 \\
(0.10)\end{array}$ & $\begin{array}{c}0.90 \\
(0.10)\end{array}$ & $\begin{array}{c}0.89 \\
(0.10)\end{array}$ \\
\hline Blank & & & & $\begin{array}{c}1.08 \\
(0.08)\end{array}$ & $\begin{array}{c}1.08 \\
(0.08)\end{array}$ & $\begin{array}{c}1.08 \\
(0.08)\end{array}$ & $\begin{array}{c}1.08 \\
(0.08)\end{array}$ \\
\hline Married or Cohabiting & & & & $\begin{array}{c}0.95 \\
(0.12)\end{array}$ & $\begin{array}{c}0.94 \\
(0.12)\end{array}$ & $\begin{array}{c}0.94 \\
(0.12)\end{array}$ & $\begin{array}{c}0.94 \\
(0.12)\end{array}$ \\
\hline Formerly Married & & & & $\begin{array}{c}1.03 \\
(0.14)\end{array}$ & $\begin{array}{c}1.02 \\
(0.14)\end{array}$ & $\begin{array}{c}1.04 \\
(0.14)\end{array}$ & $\begin{array}{c}1.04 \\
(0.14)\end{array}$ \\
\hline Exercise Level & & & & & $\begin{array}{c}1.00^{* * *} \\
(0.00)\end{array}$ & $\begin{array}{c}1.00^{* * *} \\
(0.00)\end{array}$ & $\begin{array}{c}1.00^{* * *} \\
(0.00)\end{array}$ \\
\hline Current Smoker & & & & & & $\begin{array}{c}0.77^{* * *} \\
(0.07)\end{array}$ & $\begin{array}{l}0.78^{* *} \\
(0.08)\end{array}$ \\
\hline Former Smoker & & & & & & $\begin{array}{c}1.01 \\
(0.08)\end{array}$ & $\begin{array}{c}1.00 \\
(0.08)\end{array}$ \\
\hline Percent Fat & & & & & & & $\begin{array}{c}1.01^{* * *} \\
(0.00)\end{array}$ \\
\hline Percent Alcohol & & & & & & & $\begin{array}{c}0.99 \\
(0.01)\end{array}$ \\
\hline Percent Protein & & & & & & & $\begin{array}{c}1.02^{* * *} \\
(0.01)\end{array}$ \\
\hline
\end{tabular}

Notes: Standard errors are reported in parentheses. Estimates represent relative risks. All regressions also control for Hispanic, other Race/Ethnicity, age, and age squared. ${ }^{*}$ Statistically significant at the .10 level; ** at the .05 level; ${ }^{* * *}$ at the .01 level. 
Table 8: Determinants of BMI, Linear Regressions, NHANES1999-2004, Women age 25-74, N=4430

(1)

Middle Income

High Income

Foreign-Born

Skilled Whitecollar

Unskilled Whitecollar

Blank

Married or Cohabiting

Formerly Married

Moderate Activity

Vigorous Activity

Current Smoker

Former Smoker

Percent Fat

Percent Alcohol

Percent Protein

$R^{2}$

0.0484

0.0537
(4)

(5)

(6)

(7)

$\mathbf{4 . 0 4}^{* * *}$

3.79 $^{* * *}$

(0.32)

$-0.30$

(0.38)

$-1.23^{* * *}$

(0.36)

\section{(0.34)}

$3^{4.46}{ }^{* * *}$

(0.35)

3.33 $^{\text {*** }}$

(0.38)

0.07

(0.40)

$-0.48$

(0.39)

$-0.85^{* *}$

(0.39)

$-1.87^{* * *}$

(0.36)

$-0.11$

(0.41)

$-0.50$

$(0.42)$

$-0.94^{* *}$

(0.40)

$-1.86^{* * *}$

(0.41)

$-2.17^{* * *}$

(0.50)

$-0.85^{*}$

(0.45)

$-0.27$

(0.50)

$-0.45$

(0.45)

$-1.24^{* *}$

(0.59)

$-1.58^{* *}$

(0.72)

(1)

$\mathbf{3 . 1 9}^{* * *}$
$(0.38)$

$\mathbf{3 . 0 4}^{* * *}$

(0.39)

0.02

(0.40)

$-0.22$

(0.42)

$-0.77^{*}$

(0.41)

$-1.50^{* * *}$

(0.42)

$-2.33^{* * *}$

(0.49)

$-0.64$

(0.47)

$-0.18$

(0.50)

$-0.35$

(0.44)

$-1.25^{* *}$

(0.59)

$-1.57^{* *}$

(0.72)

$-0.59$

(0.38)

$-2.14^{* * *}$

(0.37)

$-0.04$

(0.40)

$-0.41$

(0.41)

$-0.93^{* *}$

(0.41)

$-1.79^{* * *}$

(0.42)

$-2.47^{* * *}$

(0.49)

$-0.66$

(0.45)

$-0.15$

(0.50)

$-0.37$

(0.42)

$-1.46^{* *}$

(0.59)

$-1.62^{* *}$

(0.71)

$-0.68^{*}$

(0.37)

$-2.33^{* * *}$

(0.38)

$-2.18^{* * *}$

(0.43)

$0.53^{*}$

(0.30)
3.02 $^{* * *}$

(0.40)

$-0.07$

(0.40)

$-0.44$

(0.40)

$-0.94^{* *}$

(0.41)

$-1.75^{* * *}$

(0.42)

$-2.32^{* * *}$

(0.48)

$-0.71$

(0.45)

$-0.19$

(0.50)

$-0.38$

(0.41)

$-1.41^{* *}$

(0.59)

$-1.53^{* *}$

(0.69)

$-0.65^{*}$

(0.37)

$-2.21^{* * *}$

(0.38)

$-2.05^{* * *}$

(0.43)

$0.57^{*}$

(0.29)

$0.05^{* * *}$

(0.02)

$-0.09^{* * *}$

(0.02)

$0.05^{\text {** }}$

0.1146

Notes: Standard errors are reported in parentheses. All regressions also control for Hispanic, other Race/Ethnicity, age, and age squared. ${ }^{*}$ Statistically significant at the $.10 \mathrm{level} ;{ }^{* *}$ at the $.05 \mathrm{level} ;{ }^{* * *}$ at the .01 level. 
Table 9: Determinants of Obesity, Poisson Regressions, NHANES1999-2004, Women age 25-74, $\underline{N}=4430$

(1)

$(2)$

(3)

(4)

(5)

(6)

(7)

\begin{tabular}{|c|c|c|c|c|c|c|c|}
\hline Black & $\begin{array}{c}\mathbf{1 . 7 2}^{* * *} \\
(0.09)\end{array}$ & $\begin{array}{c}\mathbf{1 . 6 4}^{* * *} \\
(0.08)\end{array}$ & $\begin{array}{c}\mathbf{1 . 5 4}^{* * *} \\
(0.08)\end{array}$ & $\begin{array}{c}\mathbf{1 . 5 0}^{* * * *} \\
(0.08)\end{array}$ & $\begin{array}{c}\mathbf{1 . 4 7}^{* * *} \\
(0.08)\end{array}$ & $\begin{array}{c}\mathbf{1 . 4 3}^{* * *} \\
(0.09)\end{array}$ & $\begin{array}{c}\mathbf{1 . 4 3}^{* * *} \\
(0.09)\end{array}$ \\
\hline High School & & $\begin{array}{c}0.97 \\
(0.07)\end{array}$ & $\begin{array}{c}1.03 \\
(0.07)\end{array}$ & $\begin{array}{c}1.01 \\
(0.07)\end{array}$ & $\begin{array}{c}1.04 \\
(0.07)\end{array}$ & $\begin{array}{c}1.02 \\
(0.07)\end{array}$ & $\begin{array}{c}1.01 \\
(0.07)\end{array}$ \\
\hline Some College & & $\begin{array}{c}0.80^{* * *} \\
(0.06)\end{array}$ & $\begin{array}{c}0.93 \\
(0.07)\end{array}$ & $\begin{array}{c}0.94 \\
(0.08)\end{array}$ & $\begin{array}{c}0.98 \\
(0.08)\end{array}$ & $\begin{array}{c}0.96 \\
(0.08)\end{array}$ & $\begin{array}{c}0.95 \\
(0.07)\end{array}$ \\
\hline Middle Income & & & $\begin{array}{c}0.88^{*} \\
(0.06)\end{array}$ & $\begin{array}{l}0.88^{* *} \\
(0.06)\end{array}$ & $\begin{array}{c}0.90 \\
(0.06)\end{array}$ & $\begin{array}{c}0.88^{*} \\
(0.06)\end{array}$ & $\begin{array}{l}0.89^{*} \\
(0.06)\end{array}$ \\
\hline High Income & & & $\begin{array}{c}0.69^{* * *} \\
(0.04)\end{array}$ & $\begin{array}{c}0.70^{* * *} \\
(0.05)\end{array}$ & $\begin{array}{c}0.75^{* * *} \\
(0.05)\end{array}$ & $\begin{array}{c}0.72^{* * *} \\
(0.05)\end{array}$ & $\begin{array}{c}0.73^{* * *} \\
(0.05)\end{array}$ \\
\hline Foreign-Born & & & & $\begin{array}{c}0.65^{* * *} \\
(0.08)\end{array}$ & $\begin{array}{c}0.62^{* * *} \\
(0.07)\end{array}$ & $\begin{array}{c}0.60^{* * * *} \\
(0.07)\end{array}$ & $\begin{array}{c}0.63^{* * *} \\
(0.07)\end{array}$ \\
\hline Skilled Whitecollar & & & & $\begin{array}{c}0.80^{* *} \\
(0.08)\end{array}$ & $\begin{array}{c}0.83^{*} \\
(0.08)\end{array}$ & $\begin{array}{l}0.83^{*} \\
(0.08)\end{array}$ & $\begin{array}{l}0.82^{* *} \\
(0.08)\end{array}$ \\
\hline Unskilled Whitecollar & & & & $\begin{array}{l}0.84^{*} \\
(0.09)\end{array}$ & $\begin{array}{c}0.85 \\
(0.09)\end{array}$ & $\begin{array}{c}0.85 \\
(0.09)\end{array}$ & $\begin{array}{c}0.84 \\
(0.09)\end{array}$ \\
\hline Blank & & & & $\begin{array}{l}0.86^{*} \\
(0.07)\end{array}$ & $\begin{array}{c}0.87^{*} \\
(0.07)\end{array}$ & $\begin{array}{l}0.87^{*} \\
(0.07)\end{array}$ & $\begin{array}{l}0.87^{*} \\
(0.07)\end{array}$ \\
\hline Married or Cohabiting & & & & $\begin{array}{l}0.84^{*} \\
(0.09)\end{array}$ & $\begin{array}{c}0.84 \\
(0.09)\end{array}$ & $\begin{array}{l}0.82^{*} \\
(0.08)\end{array}$ & $\begin{array}{l}0.82^{* *} \\
(0.08)\end{array}$ \\
\hline Formerly Married & & & & $\begin{array}{l}0.81^{*} \\
(0.10)\end{array}$ & $\begin{array}{l}0.82^{*} \\
(0.10)\end{array}$ & $\begin{array}{l}0.81^{*} \\
(0.09)\end{array}$ & $\begin{array}{l}0.82^{*} \\
(0.09)\end{array}$ \\
\hline Moderate Activity & & & & & $\begin{array}{c}0.92 \\
(0.06)\end{array}$ & $\begin{array}{c}0.91 \\
(0.06)\end{array}$ & $\begin{array}{c}0.92 \\
(0.06)\end{array}$ \\
\hline Vigourous Activity & & & & & $\begin{array}{c}0.64^{* * *} \\
(0.05)\end{array}$ & $\begin{array}{c}0.62^{* * *} \\
(0.05)\end{array}$ & $\begin{array}{c}0.64^{* * *} \\
(0.05)\end{array}$ \\
\hline Current Smoker & & & & & & $\begin{array}{c}0.76^{* * * *} \\
(0.06)\end{array}$ & $\begin{array}{c}0.78^{* * *} \\
(0.06)\end{array}$ \\
\hline Former Smoker & & & & & & $\begin{array}{c}1.02 \\
(0.06)\end{array}$ & $\begin{array}{c}1.03 \\
(0.06)\end{array}$ \\
\hline Percent Fat & & & & & & & $\begin{array}{c}1.01^{* * *} \\
(0.00)\end{array}$ \\
\hline Percent Alcohol & & & & & & & $\begin{array}{c}0.97^{* * *} \\
(0.01)\end{array}$ \\
\hline Percent Protein & & & & & & & $\begin{array}{c}1.00 \\
(0.01)\end{array}$ \\
\hline
\end{tabular}

Notes: Standard errors are reported in parentheses. Estimates represent relative risks. All regressions also control for Hispanic, other Race/Ethnicity, age, and age squared. ${ }^{*}$ Statistically significant at the .10 level; ${ }^{* *}$ at the .05 level; ${ }^{* * *}$ at the .01 level. 
$\begin{array}{llllll}(1) & (2) & (3) & \text { (4) } & \text { (5) }\end{array}$

\begin{tabular}{|c|c|c|c|c|c|c|c|}
\hline Black & $\begin{array}{c}\mathbf{- 0 . 2 8} \\
(0.22)\end{array}$ & $\begin{array}{l}\mathbf{- 0 . 4 3} \\
(0.23)\end{array}$ & $\begin{array}{c}\mathbf{- 0 . 3 6} \\
(0.22)\end{array}$ & $\begin{array}{l}\mathbf{- 0 . 0 4} \\
(0.26)\end{array}$ & $\begin{array}{c}\mathbf{0 . 0 1} \\
(0.26)\end{array}$ & $\begin{array}{c}\mathbf{0 . 0 6} \\
(0.25)\end{array}$ & $\begin{array}{c}\mathbf{0 . 0 5} \\
(0.25)\end{array}$ \\
\hline High School & & $\begin{array}{c}0.00 \\
(0.26)\end{array}$ & $\begin{array}{l}-0.05 \\
(0.26)\end{array}$ & $\begin{array}{l}-0.14 \\
(0.26)\end{array}$ & $\begin{array}{l}-0.13 \\
(0.26)\end{array}$ & $\begin{array}{l}-0.19 \\
(0.25)\end{array}$ & $\begin{array}{l}-0.10 \\
(0.25)\end{array}$ \\
\hline Some College & & $\begin{array}{c}-0.79^{* * *} \\
(0.20)\end{array}$ & $\begin{array}{c}-0.78^{* * *} \\
(0.22)\end{array}$ & $\begin{array}{c}-0.63^{* * *} \\
(0.22)\end{array}$ & $\begin{array}{c}-0.53^{* *} \\
(0.22)\end{array}$ & $\begin{array}{c}-0.93^{* * *} \\
(0.24)\end{array}$ & $\begin{array}{c}-0.86^{* * *} \\
(0.23)\end{array}$ \\
\hline Middle Income & & & $\begin{array}{l}0.74^{* *} \\
(0.29)\end{array}$ & $\begin{array}{l}0.66^{* *} \\
(0.28)\end{array}$ & $\begin{array}{l}0.66^{* *} \\
(0.28)\end{array}$ & $\begin{array}{l}0.56^{* *} \\
(0.26)\end{array}$ & $\begin{array}{l}0.54^{* *} \\
(0.25)\end{array}$ \\
\hline High Income & & & $\begin{array}{c}0.11 \\
(0.27)\end{array}$ & $\begin{array}{c}0.18 \\
(0.29)\end{array}$ & $\begin{array}{c}0.24 \\
(0.29)\end{array}$ & $\begin{array}{c}0.11 \\
(0.28)\end{array}$ & $\begin{array}{c}0.09 \\
(0.28)\end{array}$ \\
\hline Foreign-Born & & & & $\begin{array}{c}-1.00^{* * *} \\
(0.33)\end{array}$ & $\begin{array}{c}-1.04^{* * *} \\
(0.32)\end{array}$ & $\begin{array}{c}-1.18^{* * *} \\
(0.30)\end{array}$ & $\begin{array}{c}-1.08^{* * *} \\
(0.30)\end{array}$ \\
\hline Midwest & & & & $\begin{array}{l}-0.10 \\
(0.37)\end{array}$ & $\begin{array}{l}-0.14 \\
(0.36)\end{array}$ & $\begin{array}{l}-0.06 \\
(0.35)\end{array}$ & $\begin{array}{l}-0.05 \\
(0.36)\end{array}$ \\
\hline South & & & & $\begin{array}{c}-0.57^{* *} \\
(0.28)\end{array}$ & $\begin{array}{c}-0.66^{* *} \\
(0.28)\end{array}$ & $\begin{array}{c}-0.54^{* *} \\
(0.26)\end{array}$ & $\begin{array}{c}-0.58^{* *} \\
(0.23)\end{array}$ \\
\hline West & & & & $\begin{array}{l}-0.29 \\
(0.28)\end{array}$ & $\begin{array}{l}-0.30 \\
(0.29)\end{array}$ & $\begin{array}{l}-0.22 \\
(0.27)\end{array}$ & $\begin{array}{l}-0.21 \\
(0.26)\end{array}$ \\
\hline Not Metro & & & & $\begin{array}{c}0.65^{* * *} \\
(0.25)\end{array}$ & $\begin{array}{c}0.66^{* * *} \\
(0.25)\end{array}$ & $\begin{array}{c}0.66^{* * *} \\
(0.24)\end{array}$ & $\begin{array}{c}0.71^{* * *} \\
(0.23)\end{array}$ \\
\hline Skilled Whitecollar & & & & $\begin{array}{l}-0.26 \\
(0.21)\end{array}$ & $\begin{array}{l}-0.25 \\
(0.21)\end{array}$ & $\begin{array}{l}-0.33 \\
(0.22)\end{array}$ & $\begin{array}{l}-0.31 \\
(0.23)\end{array}$ \\
\hline Unskilled Whitecollar & & & & $\begin{array}{c}0.40 \\
(0.46)\end{array}$ & $\begin{array}{c}0.37 \\
(0.47)\end{array}$ & $\begin{array}{c}0.36 \\
(0.46)\end{array}$ & $\begin{array}{c}0.36 \\
(0.47)\end{array}$ \\
\hline Blank & & & & $\begin{array}{c}0.01 \\
(0.35)\end{array}$ & $\begin{array}{c}0.02 \\
(0.35)\end{array}$ & $\begin{array}{c}0.02 \\
(0.34)\end{array}$ & $\begin{array}{l}-0.04 \\
(0.34)\end{array}$ \\
\hline Married or Cohabiting & & & & $\begin{array}{c}0.42 \\
(0.34)\end{array}$ & $\begin{array}{c}0.37 \\
(0.34)\end{array}$ & $\begin{array}{c}0.37 \\
(0.34)\end{array}$ & $\begin{array}{c}0.34 \\
(0.34)\end{array}$ \\
\hline Formerly Married & & & & $\begin{array}{l}-0.37 \\
(0.46)\end{array}$ & $\begin{array}{l}-0.34 \\
(0.46)\end{array}$ & $\begin{array}{l}-0.08 \\
(0.46)\end{array}$ & $\begin{array}{l}-0.10 \\
(0.47)\end{array}$ \\
\hline Exercise Level & & & & & $\begin{array}{c}0.00^{* * *} \\
(0.00)\end{array}$ & $\begin{array}{c}0.00^{* * *} \\
(0.00)\end{array}$ & $\begin{array}{c}0.00^{* * *} \\
(0.00)\end{array}$ \\
\hline Current Smoker & & & & & & $\begin{array}{c}-2.02^{* * *} \\
(0.28)\end{array}$ & $\begin{array}{c}-1.94^{* * *} \\
(0.28)\end{array}$ \\
\hline Former Smoker & & & & & & $\begin{array}{c}0.10 \\
(0.24)\end{array}$ & $\begin{array}{c}0.10 \\
(0.23)\end{array}$ \\
\hline Percent Fat & & & & & & & $\begin{array}{c}0.04^{* * *} \\
(0.01)\end{array}$ \\
\hline Percent Alcohol & & & & & & & $\begin{array}{l}-0.01 \\
(0.01)\end{array}$ \\
\hline Percent Protein & & & & & & & $\begin{array}{c}0.09^{* * *} \\
(0.03)\end{array}$ \\
\hline$R^{2}$ & 0.018 & 0.0243 & 0.0286 & 0.0413 & 0.0454 & 0.0772 & 0.0913 \\
\hline
\end{tabular}

Notes: Standard errors are reported in parentheses. All regressions also control for Hispanic, other Race/Ethnicity, age, and age squared. * Statistically significant at the $.10 \mathrm{level;}{ }^{* *}$ at the .05 level; ${ }^{* * *}$ at the .01 level. 

(1)
(2)
(3)
(4)
(5)
(6)
(7)

\begin{tabular}{|c|c|c|c|c|c|c|c|}
\hline Black & $\begin{array}{c}\mathbf{1 . 0 7} \\
(0.07)\end{array}$ & $\begin{array}{c}\mathbf{1 . 0 2} \\
(0.07)\end{array}$ & $\begin{array}{c}\mathbf{1 . 0 1} \\
(0.07)\end{array}$ & $\begin{array}{c}\mathbf{1 . 1 2} \\
(0.09)\end{array}$ & $\begin{array}{l}\mathbf{1 . 1 4}^{*} \\
(0.09)\end{array}$ & $\begin{array}{l}\mathbf{1 . 1 8}^{* *} \\
(0.09)\end{array}$ & $\begin{array}{l}\mathbf{1 . 1 8}^{* *} \\
(0.09)\end{array}$ \\
\hline High School & & $\begin{array}{c}0.94 \\
(0.09)\end{array}$ & $\begin{array}{c}0.95 \\
(0.09)\end{array}$ & $\begin{array}{c}0.93 \\
(0.08)\end{array}$ & $\begin{array}{c}0.94 \\
(0.08)\end{array}$ & $\begin{array}{c}0.92 \\
(0.08)\end{array}$ & $\begin{array}{c}0.95 \\
(0.08)\end{array}$ \\
\hline Some College & & $\begin{array}{c}0.77^{* * *} \\
(0.07)\end{array}$ & $\begin{array}{c}0.81^{\text {** }} \\
(0.08)\end{array}$ & $\begin{array}{c}0.85 \\
(0.08)\end{array}$ & $\begin{array}{c}0.90 \\
(0.09)\end{array}$ & $\begin{array}{l}0.82^{* *} \\
(0.08)\end{array}$ & $\begin{array}{l}0.84^{*} \\
(0.08)\end{array}$ \\
\hline Middle Income & & & $\begin{array}{c}1.17 \\
(0.11)\end{array}$ & $\begin{array}{c}1.14 \\
(0.11)\end{array}$ & $\begin{array}{c}1.15 \\
(0.11)\end{array}$ & $\begin{array}{c}1.11 \\
(0.10)\end{array}$ & $\begin{array}{c}1.12 \\
(0.10)\end{array}$ \\
\hline High Income & & & $\begin{array}{c}0.91 \\
(0.10)\end{array}$ & $\begin{array}{c}0.93 \\
(0.11)\end{array}$ & $\begin{array}{c}0.97 \\
(0.11)\end{array}$ & $\begin{array}{c}0.93 \\
(0.10)\end{array}$ & $\begin{array}{c}0.92 \\
(0.10)\end{array}$ \\
\hline Foreign-Born & & & & $\begin{array}{c}0.69^{*} \\
(0.14)\end{array}$ & $\begin{array}{c}0.68^{*} \\
(0.14)\end{array}$ & $\begin{array}{c}0.65^{* *} \\
(0.13)\end{array}$ & $\begin{array}{c}0.69^{*} \\
(0.13)\end{array}$ \\
\hline Midwest & & & & $\begin{array}{c}0.96 \\
(0.09)\end{array}$ & $\begin{array}{c}0.95 \\
(0.10)\end{array}$ & $\begin{array}{c}0.97 \\
(0.10)\end{array}$ & $\begin{array}{c}0.97 \\
(0.11)\end{array}$ \\
\hline South & & & & $\begin{array}{c}0.87 \\
(0.08)\end{array}$ & $\begin{array}{c}0.84^{*} \\
(0.08)\end{array}$ & $\begin{array}{c}0.86 \\
(0.08)\end{array}$ & $\begin{array}{c}0.85^{*} \\
(0.08)\end{array}$ \\
\hline West & & & & $\begin{array}{c}0.96 \\
(0.12)\end{array}$ & $\begin{array}{c}0.96 \\
(0.12)\end{array}$ & $\begin{array}{c}0.99 \\
(0.12)\end{array}$ & $\begin{array}{c}0.99 \\
(0.13)\end{array}$ \\
\hline Not Metro & & & & $\begin{array}{c}1.24^{* * *} \\
(0.10)\end{array}$ & $\begin{array}{c}1.25^{\text {*** }} \\
(0.10)\end{array}$ & $\begin{array}{c}1.24^{* * *} \\
(0.10)\end{array}$ & $\begin{array}{c}1.26^{* * *} \\
(0.10)\end{array}$ \\
\hline Skilled Whitecollar & & & & $\begin{array}{c}0.95 \\
(0.09)\end{array}$ & $\begin{array}{c}0.96 \\
(0.10)\end{array}$ & $\begin{array}{c}0.94 \\
(0.10)\end{array}$ & $\begin{array}{c}0.95 \\
(0.10)\end{array}$ \\
\hline Unskilled Whitecollar & & & & $\begin{array}{c}1.04 \\
(0.20)\end{array}$ & $\begin{array}{c}1.02 \\
(0.20)\end{array}$ & $\begin{array}{c}1.02 \\
(0.20)\end{array}$ & $\begin{array}{c}1.03 \\
(0.20)\end{array}$ \\
\hline Blank & & & & $\begin{array}{c}1.08 \\
(0.14)\end{array}$ & $\begin{array}{c}1.10 \\
(0.14)\end{array}$ & $\begin{array}{c}1.10 \\
(0.14)\end{array}$ & $\begin{array}{c}1.07 \\
(0.14)\end{array}$ \\
\hline Married or Cohabiting & & & & $\begin{array}{c}1.18 \\
(0.17)\end{array}$ & $\begin{array}{c}1.17 \\
(0.17)\end{array}$ & $\begin{array}{c}1.16 \\
(0.17)\end{array}$ & $\begin{array}{c}1.15 \\
(0.17)\end{array}$ \\
\hline Formerly Married & & & & $\begin{array}{c}0.87 \\
(0.17)\end{array}$ & $\begin{array}{c}0.90 \\
(0.18)\end{array}$ & $\begin{array}{c}0.97 \\
(0.19)\end{array}$ & $\begin{array}{c}0.94 \\
(0.18)\end{array}$ \\
\hline Exercise Level & & & & & $\begin{array}{c}1.00^{* * *} \\
(0.00)\end{array}$ & $\begin{array}{c}1.00^{* * *} \\
(0.00)\end{array}$ & $\begin{array}{c}1.00^{* * *} \\
(0.00)\end{array}$ \\
\hline Current Smoker & & & & & & $\begin{array}{c}0.51^{* * *} \\
(0.06)\end{array}$ & $\begin{array}{c}0.52^{* * *} \\
(0.06)\end{array}$ \\
\hline Former Smoker & & & & & & $\begin{array}{c}1.17 \\
(0.12)\end{array}$ & $\begin{array}{c}1.17 \\
(0.12)\end{array}$ \\
\hline Percent Fat & & & & & & & $\begin{array}{c}1.01^{* * *} \\
(0.00)\end{array}$ \\
\hline Percent Alcohol & & & & & & & $\begin{array}{c}1.00 \\
(0.01)\end{array}$ \\
\hline Percent Protein & & & & & & & $\begin{array}{c}1.03^{* * *} \\
(0.01)\end{array}$ \\
\hline
\end{tabular}

Notes: Standard errors are reported in parentheses. Estimates represent relative risks. All regressions also control for Hispanic, other Race/Ethnicity, age, and age squared. ${ }^{*}$ Statistically significant at the .10 level; ** at the .05 level; ${ }^{* * *}$ at the .01 level. 
Table 12: Determinants of BMI, Linear Regressions, NHANES1999-2004, Men age 25-74, N=4087
(1)
(2)
(3)
(4)
(5)
(6)
(7)

\begin{tabular}{|c|c|c|c|c|c|c|c|}
\hline Black & $\begin{array}{l}\mathbf{0 . 5 2}^{*} \\
(0.30)\end{array}$ & $\begin{array}{c}\mathbf{0 . 4 9} \\
(0.31)\end{array}$ & $\begin{array}{c}\mathbf{0 . 5 4}{ }^{*} \\
(0.32)\end{array}$ & $\begin{array}{l}\mathbf{0 . 7 5}^{* *} \\
(0.34)\end{array}$ & $\begin{array}{l}\mathbf{0 . 8 2}^{* *} \\
(0.34)\end{array}$ & $\begin{array}{l}\mathbf{0 . 8 3}^{* *} \\
(0.34)\end{array}$ & $\begin{array}{c}\mathbf{0 . 8 7}^{* * *} \\
(0.33)\end{array}$ \\
\hline High School & & $\begin{array}{c}0.28 \\
(0.42)\end{array}$ & $\begin{array}{c}0.15 \\
(0.44)\end{array}$ & $\begin{array}{l}-0.06 \\
(0.46)\end{array}$ & $\begin{array}{l}-0.02 \\
(0.45)\end{array}$ & $\begin{array}{l}-0.10 \\
(0.42)\end{array}$ & $\begin{array}{l}-0.16 \\
(0.41)\end{array}$ \\
\hline Some College & & $\begin{array}{l}-0.23 \\
(0.34)\end{array}$ & $\begin{array}{l}-0.39 \\
(0.39)\end{array}$ & $\begin{array}{l}-0.58 \\
(0.41)\end{array}$ & $\begin{array}{l}-0.48 \\
(0.41)\end{array}$ & $\begin{array}{l}-0.69^{*} \\
(0.37)\end{array}$ & $\begin{array}{c}-0.72^{* *} \\
(0.36)\end{array}$ \\
\hline Middle Income & & & $\begin{array}{c}0.75^{* * *} \\
(0.29)\end{array}$ & $\begin{array}{l}0.57^{*} \\
(0.31)\end{array}$ & $\begin{array}{l}0.59^{*} \\
(0.30)\end{array}$ & $\begin{array}{l}0.51^{*} \\
(0.29)\end{array}$ & $\begin{array}{c}0.46 \\
(0.30)\end{array}$ \\
\hline High Income & & & $\begin{array}{c}0.47 \\
(0.34)\end{array}$ & $\begin{array}{c}0.19 \\
(0.35)\end{array}$ & $\begin{array}{c}0.27 \\
(0.35)\end{array}$ & $\begin{array}{c}0.16 \\
(0.35)\end{array}$ & $\begin{array}{c}0.10 \\
(0.35)\end{array}$ \\
\hline Foreign-Born & & & & $\begin{array}{c}-1.94^{* * *} \\
(0.39)\end{array}$ & $\begin{array}{c}-1.89^{* * *} \\
(0.38)\end{array}$ & $\begin{array}{c}-2.03^{* * *} \\
(0.37)\end{array}$ & $\begin{array}{c}-1.85^{* * *} \\
(0.37)\end{array}$ \\
\hline Skilled Whitecollar & & & & $\begin{array}{c}0.25 \\
(0.37)\end{array}$ & $\begin{array}{c}0.33 \\
(0.37)\end{array}$ & $\begin{array}{c}0.17 \\
(0.37)\end{array}$ & $\begin{array}{c}0.15 \\
(0.36)\end{array}$ \\
\hline Unskilled Whitecollar & & & & $\begin{array}{c}0.64 \\
(0.63)\end{array}$ & $\begin{array}{c}0.63 \\
(0.63)\end{array}$ & $\begin{array}{c}0.58 \\
(0.65)\end{array}$ & $\begin{array}{c}0.67 \\
(0.65)\end{array}$ \\
\hline Blank & & & & $\begin{array}{c}0.17 \\
(0.36)\end{array}$ & $\begin{array}{c}0.16 \\
(0.36)\end{array}$ & $\begin{array}{c}0.25 \\
(0.35)\end{array}$ & $\begin{array}{c}0.22 \\
(0.34)\end{array}$ \\
\hline Married or Cohabiting & & & & $\begin{array}{l}0.89^{* *} \\
(0.45)\end{array}$ & $\begin{array}{l}0.94^{* *} \\
(0.44)\end{array}$ & $\begin{array}{c}0.75^{*} \\
(0.43)\end{array}$ & $\begin{array}{c}0.57 \\
(0.42)\end{array}$ \\
\hline Formerly Married & & & & $\begin{array}{l}-0.17 \\
(0.56)\end{array}$ & $\begin{array}{l}-0.10 \\
(0.53)\end{array}$ & $\begin{array}{l}-0.10 \\
(0.53)\end{array}$ & $\begin{array}{l}-0.18 \\
(0.50)\end{array}$ \\
\hline Moderate Activity & & & & & $\begin{array}{l}0.55^{*} \\
(0.31)\end{array}$ & $\begin{array}{c}0.43 \\
(0.31)\end{array}$ & $\begin{array}{c}0.44 \\
(0.31)\end{array}$ \\
\hline Vigorous Activity & & & & & $\begin{array}{c}-0.70^{* *} \\
(0.33)\end{array}$ & $\begin{array}{c}-0.93^{* * *} \\
(0.32)\end{array}$ & $\begin{array}{c}-0.90^{* * *} \\
(0.32)\end{array}$ \\
\hline Current Smoker & & & & & & $\begin{array}{c}-1.96^{* * *} \\
(0.28)\end{array}$ & $\begin{array}{c}-1.88^{* * *} \\
(0.27)\end{array}$ \\
\hline Former Smoker & & & & & & $\begin{array}{c}0.34 \\
(0.23)\end{array}$ & $\begin{array}{c}0.30 \\
(0.21)\end{array}$ \\
\hline Percent Fat & & & & & & & $\begin{array}{c}0.08^{* * *} \\
(0.02)\end{array}$ \\
\hline Percent Alcohol & & & & & & & $\begin{array}{c}0.00 \\
(0.02)\end{array}$ \\
\hline Percent Protein & & & & & & & $\begin{array}{c}0.08^{* * *} \\
(0.03)\end{array}$ \\
\hline$R^{2}$ & 0.0125 & 0.0104 & 0.0163 & 0.0321 & 0.0405 & 0.0591 & 0.0814 \\
\hline
\end{tabular}


Table 13: Determinants of Obesity, Poisson Regressions, NHANES1999-2004, Men age 25-74, $\underline{\mathrm{N}=4087}$

(1)

(2)

(3)

(4)

(5)

(6)

(7)

\begin{tabular}{|c|c|c|c|c|c|c|c|}
\hline Black & $\begin{array}{c}\mathbf{1 . 0 8} \\
(0.08)\end{array}$ & $\begin{array}{c}\mathbf{1 . 0 7} \\
(0.08)\end{array}$ & $\begin{array}{c}\mathbf{1 . 0 7} \\
(0.08)\end{array}$ & $\begin{array}{c}\mathbf{1 . 1 1} \\
(0.09)\end{array}$ & $\begin{array}{c}\mathbf{1 . 1 3} \\
(0.09)\end{array}$ & $\begin{array}{l}\mathbf{1 . 1 4}^{*} \\
(0.09)\end{array}$ & $\begin{array}{c}\mathbf{1 . 1 4}^{*} \\
(0.09)\end{array}$ \\
\hline High School & & $\begin{array}{c}1.04 \\
(0.11)\end{array}$ & $\begin{array}{c}1.02 \\
(0.11)\end{array}$ & $\begin{array}{c}0.97 \\
(0.11)\end{array}$ & $\begin{array}{c}0.98 \\
(0.10)\end{array}$ & $\begin{array}{c}0.97 \\
(0.10)\end{array}$ & $\begin{array}{c}0.96 \\
(0.10)\end{array}$ \\
\hline Some College & & $\begin{array}{c}0.95 \\
(0.08)\end{array}$ & $\begin{array}{c}0.95 \\
(0.09)\end{array}$ & $\begin{array}{c}0.93 \\
(0.09)\end{array}$ & $\begin{array}{c}0.95 \\
(0.09)\end{array}$ & $\begin{array}{c}0.92 \\
(0.08)\end{array}$ & $\begin{array}{c}0.92 \\
(0.08)\end{array}$ \\
\hline Middle Income & & & $\begin{array}{c}1.21^{* * *} \\
(0.09)\end{array}$ & $\begin{array}{l}1.17^{* *} \\
(0.09)\end{array}$ & $\begin{array}{l}1.17^{\text {** }} \\
(0.09)\end{array}$ & $\begin{array}{l}1.15^{*} \\
(0.08)\end{array}$ & $\begin{array}{c}1.13 \\
(0.08)\end{array}$ \\
\hline High Income & & & $\begin{array}{c}1.02 \\
(0.08)\end{array}$ & $\begin{array}{c}0.98 \\
(0.09)\end{array}$ & $\begin{array}{c}0.99 \\
(0.09)\end{array}$ & $\begin{array}{c}0.97 \\
(0.09)\end{array}$ & $\begin{array}{c}0.95 \\
(0.09)\end{array}$ \\
\hline Foreign-Born & & & & $\begin{array}{c}0.53^{* * * *} \\
(0.08)\end{array}$ & $\begin{array}{c}0.54^{* * *} \\
(0.08)\end{array}$ & $\begin{array}{c}0.52^{* * *} \\
(0.08)\end{array}$ & $\begin{array}{c}0.55^{* * *} \\
(0.09)\end{array}$ \\
\hline Skilled Whitecollar & & & & $\begin{array}{c}0.96 \\
(0.08)\end{array}$ & $\begin{array}{c}0.98 \\
(0.09)\end{array}$ & $\begin{array}{c}0.95 \\
(0.08)\end{array}$ & $\begin{array}{c}0.95 \\
(0.08)\end{array}$ \\
\hline Unskilled Whitecollar & & & & $\begin{array}{c}1.04 \\
(0.18)\end{array}$ & $\begin{array}{c}1.04 \\
(0.18)\end{array}$ & $\begin{array}{l}1.03 \\
(0.18)\end{array}$ & $\begin{array}{c}1.04 \\
(0.18)\end{array}$ \\
\hline Blank & & & & $\begin{array}{c}1.06 \\
(0.10)\end{array}$ & $\begin{array}{c}1.06 \\
(0.10)\end{array}$ & $\begin{array}{c}1.07 \\
(0.10)\end{array}$ & $\begin{array}{c}1.06 \\
(0.09)\end{array}$ \\
\hline Married or Cohabiting & & & & $\begin{array}{c}1.15 \\
(0.13)\end{array}$ & $\begin{array}{c}1.17 \\
(0.13)\end{array}$ & $\begin{array}{c}1.13 \\
(0.13)\end{array}$ & $\begin{array}{c}1.09 \\
(0.12)\end{array}$ \\
\hline Formerly Married & & & & $\begin{array}{c}0.85 \\
(0.12)\end{array}$ & $\begin{array}{c}0.86 \\
(0.12)\end{array}$ & $\begin{array}{c}0.86 \\
(0.12)\end{array}$ & $\begin{array}{c}0.85 \\
(0.12)\end{array}$ \\
\hline Moderate Activity & & & & & $\begin{array}{c}1.13 \\
(0.10)\end{array}$ & $\begin{array}{c}1.10 \\
(0.10)\end{array}$ & $\begin{array}{c}1.11 \\
(0.10)\end{array}$ \\
\hline Vigorous Activity & & & & & $\begin{array}{l}0.84^{*} \\
(0.08)\end{array}$ & $\begin{array}{l}0.81^{* *} \\
(0.08)\end{array}$ & $\begin{array}{l}0.81^{\text {** }} \\
(0.08)\end{array}$ \\
\hline Current Smoker & & & & & & $\begin{array}{c}0.71^{* * *} \\
(0.06)\end{array}$ & $\begin{array}{c}0.72^{* * *} \\
(0.06)\end{array}$ \\
\hline Former Smoker & & & & & & $\begin{array}{c}1.04 \\
(0.06)\end{array}$ & $\begin{array}{c}1.03 \\
(0.06)\end{array}$ \\
\hline Percent Fat & & & & & & & $\begin{array}{c}1.02^{* * *} \\
(0.00)\end{array}$ \\
\hline Percent Alcohol & & & & & & & $\begin{array}{c}1.00 \\
(0.01)\end{array}$ \\
\hline Percent Protein & & & & & & & $\begin{array}{l}1.01^{* *} \\
(0.01)\end{array}$ \\
\hline
\end{tabular}

Notes: Standard errors are reported in parentheses. Estimates represent relative risks. All regressions also control for Hispanic, other Race/Ethnicity, age, and age squared. ${ }^{*}$ Statistically significant at the .10 level; ${ }^{* *}$ at the .05 level; ${ }^{* * *}$ at the .01 level. 


\begin{tabular}{|c|c|c|c|c|c|c|c|c|c|c|}
\hline & (1) & (2) & $\begin{array}{l}\text { Women } \\
\text { (3) }\end{array}$ & (4) & (5) & (1) & (2) & $\begin{array}{l}\text { Men } \\
(3)\end{array}$ & (4) & (5) \\
\hline Black & $\begin{array}{l}1.23^{* *} \\
(0.11)\end{array}$ & $\begin{array}{c}1.18 \\
(0.14)\end{array}$ & $\begin{array}{l}1.22^{* * *} \\
(0.09)\end{array}$ & $\begin{array}{c}1.39^{* * *} \\
(0.13)\end{array}$ & $\begin{array}{c}4.35^{* * *} \\
(1.25)\end{array}$ & $\begin{array}{c}1.08 \\
(0.15)\end{array}$ & $\begin{array}{c}1.17 \\
(0.12)\end{array}$ & $\begin{array}{c}0.92 \\
(0.10)\end{array}$ & $\begin{array}{l}1.37^{* * *} \\
(0.14)\end{array}$ & $\begin{array}{c}1.43 \\
(0.54)\end{array}$ \\
\hline Middle Income x Black & $\begin{array}{l}1.35^{* *} \\
(0.18)\end{array}$ & & & & & $\begin{array}{c}0.97 \\
(0.20)\end{array}$ & & & & \\
\hline High Income x Black & $\begin{array}{l}1.25^{*} \\
(0.14)\end{array}$ & & & & & $\begin{array}{c}1.18 \\
(0.20)\end{array}$ & & & & \\
\hline Skilled Whitecollar x Black & & $\begin{array}{l}1.33^{*} \\
(0.20)\end{array}$ & & & & & $\begin{array}{c}0.92 \\
(0.19)\end{array}$ & & & \\
\hline Unskilled Whitecollar x Black & & $\begin{array}{l}1.44^{* *} \\
(0.24)\end{array}$ & & & & & $\begin{array}{c}1.26 \\
(0.37)\end{array}$ & & & \\
\hline Less Active x Black & & & $\begin{array}{c}1.34^{* * *} \\
(0.14)\end{array}$ & & & & & $\begin{array}{c}1.27 \\
(0.22)\end{array}$ & & \\
\hline More Active x Black & & & $\begin{array}{l}1.41^{* *} \\
(0.21)\end{array}$ & & & & & $\begin{array}{c}1.55^{* * *} \\
(0.24)\end{array}$ & & \\
\hline Current Smoker x Black & & & & $\begin{array}{c}1.04 \\
(0.16)\end{array}$ & & & & & $\begin{array}{l}0.65^{* *} \\
(0.14)\end{array}$ & \\
\hline Former Smoker x Black & & & & $\begin{array}{c}1.03 \\
(0.14)\end{array}$ & & & & & $\begin{array}{c}0.87 \\
(0.14)\end{array}$ & \\
\hline Percent Fat x Black & & & & & $\begin{array}{c}0.97^{* * *} \\
(0.01)\end{array}$ & & & & & $\begin{array}{c}1.00 \\
(0.01)\end{array}$ \\
\hline Percent Alcohol x Black & & & & & $\begin{array}{c}1.02 \\
(0.02)\end{array}$ & & & & & $\begin{array}{c}1.01 \\
(0.01)\end{array}$ \\
\hline Percent Protein x Black & & & & & $\begin{array}{c}0.99 \\
(0.01)\end{array}$ & & & & & $\begin{array}{c}0.99 \\
(0.02)\end{array}$ \\
\hline$N$ & & & 4430 & & & & & 4087 & & \\
\hline
\end{tabular}


Table 15: BMI, Linear Regressions, Women age 25+, BRFSS 1998-2002 $(N=420,290)$

(1)

(2)

(3)

(4)

(5)

(6)

\begin{tabular}{|c|c|c|c|c|c|c|}
\hline Black & $\begin{array}{c}\mathbf{3 . 0 7}^{* * *} \\
(0.05)\end{array}$ & $\begin{array}{c}\mathbf{2 . 8 7 ^ { * * * }} \\
(0.05)\end{array}$ & $\begin{array}{l}\mathbf{2 . 5 7 ^ { * * * }} \\
(0.05)\end{array}$ & $\begin{array}{c}\mathbf{2 . 5 6}^{* * *} \\
(0.06)\end{array}$ & $\begin{array}{c}\mathbf{2 . 3 7}^{* * *} \\
(0.05)\end{array}$ & $\begin{array}{c}\mathbf{2 . 3 8}^{* * *} \\
(0.06)\end{array}$ \\
\hline High School & & $\begin{array}{c}-0.56^{* * *} \\
(0.04)\end{array}$ & $\begin{array}{c}-0.28^{* * *} \\
(0.04)\end{array}$ & $\begin{array}{c}-0.28^{* * *} \\
(0.04)\end{array}$ & $\begin{array}{c}-0.24^{* * *} \\
(0.04)\end{array}$ & $\begin{array}{c}-0.24^{* * *} \\
(0.04)\end{array}$ \\
\hline Some College (or above) & & $\begin{array}{c}-1.76^{* * *} \\
(0.04)\end{array}$ & $\begin{array}{c}-1.11^{* * *} \\
(0.04)\end{array}$ & $\begin{array}{c}-1.11^{* * *} \\
(0.04)\end{array}$ & $\begin{array}{c}-1.14^{* * *} \\
(0.04)\end{array}$ & $\begin{array}{c}-1.14^{* * *} \\
(0.04)\end{array}$ \\
\hline Income Category 2 & & & $\begin{array}{c}0.50^{* * *} \\
(0.09)\end{array}$ & $\begin{array}{c}0.50^{* * *} \\
(0.09)\end{array}$ & $\begin{array}{c}0.56^{* * *} \\
(0.09)\end{array}$ & $\begin{array}{c}0.55^{* * *} \\
(0.09)\end{array}$ \\
\hline Income Category 3 & & & $\begin{array}{c}0.23^{* * *} \\
(0.07)\end{array}$ & $\begin{array}{c}0.23^{* * *} \\
(0.07)\end{array}$ & $\begin{array}{c}0.32^{* * *} \\
(0.07)\end{array}$ & $\begin{array}{l}0.31^{* * *} \\
(0.07)\end{array}$ \\
\hline Income Category 4 & & & $\begin{array}{l}-0.15^{* *} \\
(0.07)\end{array}$ & $\begin{array}{l}-0.15^{* *} \\
(0.07)\end{array}$ & $\begin{array}{l}-0.03 \\
(0.07)\end{array}$ & $\begin{array}{l}-0.03 \\
(0.07)\end{array}$ \\
\hline Income Category 5 & & & $\begin{array}{c}-0.38^{* * *} \\
(0.06)\end{array}$ & $\begin{array}{c}-0.38^{* * *} \\
(0.06)\end{array}$ & $\begin{array}{c}-0.27^{* * *} \\
(0.06)\end{array}$ & $\begin{array}{c}-0.26^{* * *} \\
(0.06)\end{array}$ \\
\hline Income Category 6 & & & $\begin{array}{c}-0.61^{* * *} \\
(0.06)\end{array}$ & $\begin{array}{c}-0.62^{* * *} \\
(0.06)\end{array}$ & $\begin{array}{c}-0.50^{* * *} \\
(0.06)\end{array}$ & $\begin{array}{c}-0.50^{* * *} \\
(0.06)\end{array}$ \\
\hline Income Category 7 & & & $\begin{array}{c}-1.02^{* * *} \\
(0.06)\end{array}$ & $\begin{array}{c}-1.05^{* * *} \\
(0.06)\end{array}$ & $\begin{array}{c}-0.94^{* * *} \\
(0.06)\end{array}$ & $\begin{array}{c}-0.94^{* * *} \\
(0.06)\end{array}$ \\
\hline Income Category 8 & & & $\begin{array}{c}-1.90^{* * *} \\
(0.06)\end{array}$ & $\begin{array}{c}-1.95^{* * *} \\
(0.07)\end{array}$ & $\begin{array}{c}-1.86^{* * *} \\
(0.07)\end{array}$ & $\begin{array}{c}-1.86^{* * *} \\
(0.07)\end{array}$ \\
\hline Year 1999 & & & & $\begin{array}{c}0.18^{* * *} \\
(0.05)\end{array}$ & $\begin{array}{l}0.34^{* * *} \\
(0.08)\end{array}$ & $\begin{array}{l}0.33^{* * *} \\
(0.08)\end{array}$ \\
\hline Year 2000 & & & & $\begin{array}{c}0.43^{* * *} \\
(0.05)\end{array}$ & $\begin{array}{l}0.44^{* * *} \\
(0.05)\end{array}$ & $\begin{array}{l}0.45^{* * *} \\
(0.05)\end{array}$ \\
\hline Year 2001 & & & & $\begin{array}{c}0.68^{* * *} \\
(0.05)\end{array}$ & $\begin{array}{c}0.72^{* * *} \\
(0.05)\end{array}$ & $\begin{array}{l}0.72^{* * *} \\
(0.05)\end{array}$ \\
\hline Year 2002 & & & & $\begin{array}{c}0.76^{* * *} \\
(0.05)\end{array}$ & $\begin{array}{c}0.79^{* * *} \\
(0.05)\end{array}$ & $\begin{array}{l}0.80^{* * *} \\
(0.05)\end{array}$ \\
\hline Food CPI (by MSA-year) & & & & $\begin{array}{c}0.00^{* * *} \\
(0.00)\end{array}$ & $\begin{array}{l}0.00^{* * *} \\
(0.00)\end{array}$ & $\begin{array}{l}0.00^{*} \\
(0.00)\end{array}$ \\
\hline Unemployed & & & & & $\begin{array}{c}0.34^{* * *} \\
(0.09)\end{array}$ & $\begin{array}{l}0.34^{* * *} \\
(0.09)\end{array}$ \\
\hline $\begin{array}{l}\text { Homemaker, student, } \\
\text { retiree, or disabled }\end{array}$ & & & & & $\begin{array}{c}0.21^{* * *} \\
(0.04)\end{array}$ & $\begin{array}{l}0.21^{* * *} \\
(0.04)\end{array}$ \\
\hline Smoker & & & & & $\begin{array}{c}-1.54^{* * *} \\
(0.04)\end{array}$ & $\begin{array}{c}-1.54^{* * *} \\
(0.04)\end{array}$ \\
\hline Exercise & & & & & $\begin{array}{c}-1.36^{* * *} \\
(0.04)\end{array}$ & $\begin{array}{c}-1.36^{* * *} \\
(0.04)\end{array}$ \\
\hline $\begin{array}{l}\text { MSA Fixed Effects } \\
R^{2}\end{array}$ & 0.040 & 0.055 & 0.065 & 0.068 & 0.086 & $\begin{array}{c}\text { Included } \\
0.087\end{array}$ \\
\hline
\end{tabular}


$\begin{array}{lllll}(1) & (2) & \text { (3) } & \text { (4) }\end{array}$

\begin{tabular}{|c|c|c|c|c|c|c|}
\hline Black & $\begin{array}{c}\mathbf{1 . 8 6}^{* * *} \\
(0.02)\end{array}$ & $\begin{array}{c}\mathbf{1 . 7 7}^{* * *} \\
(0.02)\end{array}$ & $\begin{array}{c}\mathbf{1 . 6 3}^{* * *} \\
(0.02)\end{array}$ & $\begin{array}{c}\mathbf{1 . 6 2}^{* * *} \\
(0.02)\end{array}$ & $\begin{array}{c}\mathbf{1 . 5 5}^{* * *} \\
(0.02)\end{array}$ & $\begin{array}{c}\mathbf{1 . 5 5}^{\text {*** }} \\
(0.02)\end{array}$ \\
\hline High School & & $\begin{array}{c}0.87^{* * *} \\
(0.01)\end{array}$ & $\begin{array}{c}0.94^{* * *} \\
(0.01)\end{array}$ & $\begin{array}{c}0.94^{* * *} \\
(0.01)\end{array}$ & $\begin{array}{c}0.96^{* * *} \\
(0.01)\end{array}$ & $\begin{array}{c}0.96^{* * *} \\
(0.01)\end{array}$ \\
\hline Some College (or above) & & $\begin{array}{c}0.62^{* * *} \\
(0.01)\end{array}$ & $\begin{array}{l}0.75^{* * *} \\
(0.01)\end{array}$ & $\begin{array}{c}0.74^{* * *} \\
(0.01)\end{array}$ & $\begin{array}{l}0.75^{* * *} \\
(0.01)\end{array}$ & $\begin{array}{c}0.75^{* * *} \\
(0.01)\end{array}$ \\
\hline Income Category 2 & & & $\begin{array}{l}1.09^{* * *} \\
(0.02)\end{array}$ & $\begin{array}{l}1.09^{* * *} \\
(0.02)\end{array}$ & $\begin{array}{l}1.11^{* * *} \\
(0.02)\end{array}$ & $\begin{array}{l}1.10^{* * *} \\
(0.02)\end{array}$ \\
\hline Income Category 3 & & & $\begin{array}{l}1.04^{* *} \\
(0.02)\end{array}$ & $\begin{array}{l}1.04^{* *} \\
(0.02)\end{array}$ & $\begin{array}{l}1.06^{* * *} \\
(0.02)\end{array}$ & $\begin{array}{l}1.06^{* * *} \\
(0.02)\end{array}$ \\
\hline Income Category 4 & & & $\begin{array}{l}0.96^{* *} \\
(0.02)\end{array}$ & $\begin{array}{l}0.95^{* *} \\
(0.02)\end{array}$ & $\begin{array}{c}0.98 \\
(0.02)\end{array}$ & $\begin{array}{c}0.99 \\
(0.02)\end{array}$ \\
\hline Income Category 5 & & & $\begin{array}{l}0.90^{* * *} \\
(0.02)\end{array}$ & $\begin{array}{c}0.90^{* * *} \\
(0.02)\end{array}$ & $\begin{array}{l}0.93^{* * *} \\
(0.02)\end{array}$ & $\begin{array}{c}0.93^{* * *} \\
(0.02)\end{array}$ \\
\hline Income Category 6 & & & $\begin{array}{l}0.85^{* * *} \\
(0.01)\end{array}$ & $\begin{array}{c}0.85^{* * *} \\
(0.01)\end{array}$ & $\begin{array}{l}0.88^{* * *} \\
(0.02)\end{array}$ & $\begin{array}{c}0.88^{* * *} \\
(0.02)\end{array}$ \\
\hline Income Category 7 & & & $\begin{array}{c}0.74^{* * *} \\
(0.01)\end{array}$ & $\begin{array}{c}0.74^{* * *} \\
(0.01)\end{array}$ & $\begin{array}{c}0.76^{* * *} \\
(0.01)\end{array}$ & $\begin{array}{c}0.76^{* * *} \\
(0.01)\end{array}$ \\
\hline Income Category 8 & & & $\begin{array}{c}0.54^{* * *} \\
(0.01)\end{array}$ & $\begin{array}{c}0.54^{* * *} \\
(0.01)\end{array}$ & $\begin{array}{c}0.56^{* * * *} \\
(0.01)\end{array}$ & $\begin{array}{c}0.55^{\text {*** }} \\
(0.01)\end{array}$ \\
\hline Year 1999 & & & & $\begin{array}{c}1.06^{* * *} \\
(0.02)\end{array}$ & $\begin{array}{l}1.10^{* * *} \\
(0.03)\end{array}$ & $\begin{array}{l}1.09^{* * *} \\
(0.03)\end{array}$ \\
\hline Year 2000 & & & & $\begin{array}{c}1.12^{* * *} \\
(0.02)\end{array}$ & $\begin{array}{c}1.12^{* * *} \\
(0.02)\end{array}$ & $\begin{array}{c}1.12^{\text {*** }} \\
(0.02)\end{array}$ \\
\hline Year 2001 & & & & $\begin{array}{l}1.20^{* * *} \\
(0.02)\end{array}$ & $\begin{array}{l}1.21^{* * *} \\
(0.02)\end{array}$ & $\begin{array}{l}1.21^{* * *} \\
(0.02)\end{array}$ \\
\hline Year 2002 & & & & $\begin{array}{l}1.21^{* * *} \\
(0.02)\end{array}$ & $\begin{array}{l}1.22^{* * *} \\
(0.02)\end{array}$ & $\begin{array}{l}1.22^{* * *} \\
(0.02)\end{array}$ \\
\hline Food CPI (by MSA-year) & & & & $\begin{array}{l}1.00^{* *} \\
(0.00)\end{array}$ & $\begin{array}{l}1.00^{* *} \\
(0.00)\end{array}$ & $\begin{array}{l}1.00^{*} \\
(0.00)\end{array}$ \\
\hline Unemployed & & & & & $\begin{array}{l}1.09^{* * *} \\
(0.02)\end{array}$ & $\begin{array}{l}1.09^{* * *} \\
(0.02)\end{array}$ \\
\hline $\begin{array}{l}\text { Homemaker, student, } \\
\text { retiree, or disabled }\end{array}$ & & & & & $\begin{array}{l}1.06^{* * *} \\
(0.01)\end{array}$ & $\begin{array}{l}1.06^{* * *} \\
(0.01)\end{array}$ \\
\hline Smoker & & & & & $\begin{array}{r}0.70^{* * *} \\
(0.01)\end{array}$ & $\begin{array}{c}0.70^{* * *} \\
(0.01)\end{array}$ \\
\hline Exercise & & & & & $\begin{array}{l}0.70^{* * *} \\
(0.01)\end{array}$ & $\begin{array}{c}0.70^{* * *} \\
(0.01)\end{array}$ \\
\hline MSA Fixed Effects & & & & & & Included \\
\hline
\end{tabular}

Notes: Estimated effects are reported as relative risks. All regressions also control for Hispanic, age and age squared. ${ }^{*}$ Statistically significant at the .10 level; ${ }^{* *}$ at the .05 level; ${ }^{* * *}$ at the .01 level. 
(1)

(2)

(3)

(4)

(5)

(6)

\begin{tabular}{|c|c|c|c|c|c|c|}
\hline Black & $\begin{array}{c}\mathbf{0 . 6 9}^{* * *} \\
(0.06)\end{array}$ & $\begin{array}{c}\mathbf{0 . 5 8}^{* * *} \\
(0.06)\end{array}$ & $\begin{array}{c}\mathbf{0 . 6 3}^{* * *} \\
(0.06)\end{array}$ & $\begin{array}{c}\mathbf{0 . 6 4}^{* * *} \\
(0.06)\end{array}$ & $\begin{array}{c}\mathbf{0 . 5 9}^{* * *} \\
(0.06)\end{array}$ & $\begin{array}{l}\mathbf{0 . 6 1}^{* * *} \\
(0.06)\end{array}$ \\
\hline High School & & $\begin{array}{c}-0.08^{* *} \\
(0.04)\end{array}$ & $\begin{array}{c}-0.14^{* * *} \\
(0.04)\end{array}$ & $\begin{array}{c}-0.13^{* * *} \\
(0.04)\end{array}$ & $\begin{array}{c}-0.17^{* * *} \\
(0.04)\end{array}$ & $\begin{array}{c}-0.16^{* * *} \\
(0.04)\end{array}$ \\
\hline Some College (or above) & & $\begin{array}{c}-0.71^{* * *} \\
(0.03)\end{array}$ & $\begin{array}{c}-0.79^{* * *} \\
(0.04)\end{array}$ & $\begin{array}{c}-0.78^{* * *} \\
(0.04)\end{array}$ & $\begin{array}{c}-0.92^{* * *} \\
(0.04)\end{array}$ & $\begin{array}{c}-0.91^{* * *} \\
(0.04)\end{array}$ \\
\hline Income Category 2 & & & $\begin{array}{l}0.22^{*} \\
(0.12)\end{array}$ & $\begin{array}{l}0.23^{*} \\
(0.12)\end{array}$ & $\begin{array}{l}0.24^{* *} \\
(0.12)\end{array}$ & $\begin{array}{l}0.24^{* *} \\
(0.12)\end{array}$ \\
\hline Income Category 3 & & & $\begin{array}{l}0.18^{*} \\
(0.10)\end{array}$ & $\begin{array}{l}0.18^{*} \\
(0.10)\end{array}$ & $\begin{array}{l}0.24^{* *} \\
(0.10)\end{array}$ & $\begin{array}{l}0.24^{* *} \\
(0.10)\end{array}$ \\
\hline Income Category 4 & & & $\begin{array}{l}0.20^{* *} \\
(0.09)\end{array}$ & $\begin{array}{l}0.21^{* *} \\
(0.09)\end{array}$ & $\begin{array}{l}0.29^{* * *} \\
(0.09)\end{array}$ & $\begin{array}{l}0.28^{* * *} \\
(0.09)\end{array}$ \\
\hline Income Category 5 & & & $\begin{array}{c}0.36^{* * *} \\
(0.09)\end{array}$ & $\begin{array}{c}0.36^{* * *} \\
(0.09)\end{array}$ & $\begin{array}{l}0.45^{* * *} \\
(0.08)\end{array}$ & $\begin{array}{l}0.45^{* * *} \\
(0.08)\end{array}$ \\
\hline Income Category 6 & & & $\begin{array}{l}0.38^{* * *} \\
(0.08)\end{array}$ & $\begin{array}{c}0.38^{* * *} \\
(0.08)\end{array}$ & $\begin{array}{l}0.48^{* * *} \\
(0.08)\end{array}$ & $\begin{array}{l}0.48^{* * *} \\
(0.08)\end{array}$ \\
\hline Income Category 7 & & & $\begin{array}{c}0.53^{* * *} \\
(0.09)\end{array}$ & $\begin{array}{c}0.52^{* * *} \\
(0.09)\end{array}$ & $\begin{array}{l}0.61^{* * *} \\
(0.08)\end{array}$ & $\begin{array}{l}0.61^{* * *} \\
(0.08)\end{array}$ \\
\hline Income Category 8 & & & $\begin{array}{c}0.39^{* * *} \\
(0.09)\end{array}$ & $\begin{array}{c}0.37^{* * *} \\
(0.09)\end{array}$ & $\begin{array}{c}0.46^{* * *} \\
(0.09)\end{array}$ & $\begin{array}{c}0.47^{* * *} \\
(0.09)\end{array}$ \\
\hline Year 1999 & & & & $\begin{array}{l}0.21^{* * *} \\
(0.05)\end{array}$ & $\begin{array}{l}0.20^{* * *} \\
(0.08)\end{array}$ & $\begin{array}{l}0.17^{* *} \\
(0.08)\end{array}$ \\
\hline Year 2000 & & & & $\begin{array}{c}0.38^{* * *} \\
(0.05)\end{array}$ & $\begin{array}{l}0.38^{* * *} \\
(0.05)\end{array}$ & $\begin{array}{l}0.38^{* * *} \\
(0.05)\end{array}$ \\
\hline Year 2001 & & & & $\begin{array}{c}0.54^{* * *} \\
(0.04)\end{array}$ & $\begin{array}{l}0.55^{* * *} \\
(0.04)\end{array}$ & $\begin{array}{l}0.55^{* * *} \\
(0.04)\end{array}$ \\
\hline Year 2002 & & & & $\begin{array}{c}0.64^{* * *} \\
(0.05)\end{array}$ & $\begin{array}{c}0.66^{* * *} \\
(0.05)\end{array}$ & $\begin{array}{l}0.67^{* * *} \\
(0.05)\end{array}$ \\
\hline Food CPI (by MSA-year) & & & & $\begin{array}{c}0.00^{* * *} \\
(0.00)\end{array}$ & $\begin{array}{l}0.00^{* * *} \\
(0.00)\end{array}$ & $\begin{array}{c}0.00 \\
(0.00)\end{array}$ \\
\hline Unemployed & & & & & $\begin{array}{l}0.24^{* *} \\
(0.10)\end{array}$ & $\begin{array}{l}0.25^{* *} \\
(0.10)\end{array}$ \\
\hline $\begin{array}{l}\text { Homemaker, student, } \\
\text { retiree, or disabled }\end{array}$ & & & & & $\begin{array}{c}0.56^{* * *} \\
(0.06)\end{array}$ & $\begin{array}{l}0.56^{* * *} \\
(0.06)\end{array}$ \\
\hline Smoker & & & & & $\begin{array}{c}-1.31^{* * *} \\
(0.04)\end{array}$ & $\begin{array}{c}-1.32^{* * *} \\
(0.04)\end{array}$ \\
\hline Exercise & & & & & $\begin{array}{c}-0.57^{* * *} \\
(0.04)\end{array}$ & $\begin{array}{c}-0.56^{* * *} \\
(0.04)\end{array}$ \\
\hline $\begin{array}{l}\text { MSA Fixed Effects } \\
R^{2}\end{array}$ & 0.014 & 0.018 & 0.019 & 0.022 & 0.038 & $\begin{array}{c}\text { Included } \\
0.039\end{array}$ \\
\hline
\end{tabular}


Table 18: Obesity, Poisson Regressions, Men age 25+, BRFSS 1998-2002 (N=298,494)
(1)
(2)
(3)
(4)
(5)
(6)

\begin{tabular}{|c|c|c|c|c|c|c|}
\hline Black & $\begin{array}{c}\mathbf{1 . 2 4}^{* * *} \\
(0.02)\end{array}$ & $\begin{array}{c}\mathbf{1 . 2 0}^{* * *} \\
(0.02)\end{array}$ & $\begin{array}{l}\mathbf{1 . 2 0}^{* * *} \\
(0.02)\end{array}$ & $\begin{array}{c}\mathbf{1 . 2 0}^{* * *} \\
(0.02)\end{array}$ & $\begin{array}{l}\mathbf{1 . 1 8}^{* * *} \\
(0.02)\end{array}$ & $\begin{array}{l}\mathbf{1 . 1 9}^{* * *} \\
(0.02)\end{array}$ \\
\hline High School & & $\begin{array}{c}0.96^{* * *} \\
(0.01)\end{array}$ & $\begin{array}{c}0.96^{* * *} \\
(0.01)\end{array}$ & $\begin{array}{c}0.96^{* * *} \\
(0.01)\end{array}$ & $\begin{array}{c}0.96^{* * *} \\
(0.01)\end{array}$ & $\begin{array}{c}0.96^{* * *} \\
(0.01)\end{array}$ \\
\hline Some College (or above) & & $\begin{array}{c}0.79^{* * *} \\
(0.01)\end{array}$ & $\begin{array}{l}0.79^{* * *} \\
(0.01)\end{array}$ & $\begin{array}{c}0.79^{* * *} \\
(0.01)\end{array}$ & $\begin{array}{l}0.78^{* * *} \\
(0.01)\end{array}$ & $\begin{array}{c}0.78^{* * *} \\
(0.01)\end{array}$ \\
\hline Income Category 2 & & & $\begin{array}{c}1.04 \\
(0.03)\end{array}$ & $\begin{array}{c}1.04 \\
(0.03)\end{array}$ & $\begin{array}{c}1.05 \\
(0.03)\end{array}$ & $\begin{array}{l}1.05 \\
(0.03)\end{array}$ \\
\hline Income Category 3 & & & $\begin{array}{l}1.03 \\
(0.03)\end{array}$ & $\begin{array}{l}1.03 \\
(0.03)\end{array}$ & $\begin{array}{l}1.05^{*} \\
(0.03)\end{array}$ & $\begin{array}{l}1.05^{*} \\
(0.03)\end{array}$ \\
\hline Income Category 4 & & & $\begin{array}{l}1.03 \\
(0.03)\end{array}$ & $\begin{array}{l}1.03 \\
(0.03)\end{array}$ & $\begin{array}{l}1.06^{* *} \\
(0.03)\end{array}$ & $\begin{array}{l}1.06^{* *} \\
(0.03)\end{array}$ \\
\hline Income Category 5 & & & $\begin{array}{l}1.04^{*} \\
(0.02)\end{array}$ & $\begin{array}{l}1.04^{*} \\
(0.02)\end{array}$ & $\begin{array}{l}1.08^{* * *} \\
(0.03)\end{array}$ & $\begin{array}{l}1.08^{* * *} \\
(0.03)\end{array}$ \\
\hline Income Category 6 & & & $\begin{array}{c}1.04 \\
(0.02)\end{array}$ & $\begin{array}{c}1.04 \\
(0.02)\end{array}$ & $\begin{array}{l}1.08^{* * *} \\
(0.02)\end{array}$ & $\begin{array}{l}1.08^{* * *} \\
(0.02)\end{array}$ \\
\hline Income Category 7 & & & $\begin{array}{l}1.06^{* * *} \\
(0.02)\end{array}$ & $\begin{array}{l}1.06^{* * *} \\
(0.02)\end{array}$ & $\begin{array}{l}1.10^{* * *} \\
(0.03)\end{array}$ & $\begin{array}{l}1.10^{* * *} \\
(0.03)\end{array}$ \\
\hline Income Category 8 & & & $\begin{array}{l}1.00 \\
(0.02)\end{array}$ & $\begin{array}{c}0.99 \\
(0.02)\end{array}$ & $\begin{array}{c}1.03 \\
(0.03)\end{array}$ & $\begin{array}{l}1.04 \\
(0.03)\end{array}$ \\
\hline Year 1999 & & & & $\begin{array}{l}1.07^{* * *} \\
(0.02)\end{array}$ & $\begin{array}{l}1.07^{* *} \\
(0.03)\end{array}$ & $\begin{array}{l}1.06^{* *} \\
(0.03)\end{array}$ \\
\hline Year 2000 & & & & $\begin{array}{l}1.13^{* * *} \\
(0.02)\end{array}$ & $\begin{array}{l}1.13^{* * *} \\
(0.02)\end{array}$ & $\begin{array}{l}1.13^{* * *} \\
(0.02)\end{array}$ \\
\hline Year 2001 & & & & $\begin{array}{c}1.18^{* * *} \\
(0.02)\end{array}$ & $\begin{array}{l}1.18^{* * *} \\
(0.02)\end{array}$ & $\begin{array}{l}1.18^{* * *} \\
(0.02)\end{array}$ \\
\hline Year 2002 & & & & $\begin{array}{c}1.20^{* * *} \\
(0.02)\end{array}$ & $\begin{array}{l}1.21^{* * *} \\
(0.02)\end{array}$ & $\begin{array}{l}1.21^{* * *} \\
(0.02)\end{array}$ \\
\hline Food CPI (by MSA-year) & & & & $\begin{array}{c}1.00^{* * *} \\
(0.00)\end{array}$ & $\begin{array}{l}1.00^{* * *} \\
(0.00)\end{array}$ & $\begin{array}{c}1.00 \\
(0.00)\end{array}$ \\
\hline Unemployed & & & & & $\begin{array}{l}1.09^{* * *} \\
(0.03)\end{array}$ & $\begin{array}{l}1.09^{* * *} \\
(0.03)\end{array}$ \\
\hline $\begin{array}{l}\text { Homemaker, student, } \\
\text { retiree, or disabled }\end{array}$ & & & & & $\begin{array}{l}1.15^{* * *} \\
(0.02)\end{array}$ & $\begin{array}{l}1.15^{* * *} \\
(0.02)\end{array}$ \\
\hline Smoker & & & & & $\begin{array}{c}0.72^{* * *} \\
(0.01)\end{array}$ & $\begin{array}{c}0.72^{* * *} \\
(0.01)\end{array}$ \\
\hline Exercise & & & & & $\begin{array}{c}0.82^{* * *} \\
(0.01)\end{array}$ & $\begin{array}{c}0.82^{* * *} \\
(0.01)\end{array}$ \\
\hline MSA Fixed Effects & & & & & & Included \\
\hline
\end{tabular}

Notes: Estimated effects are reported as relative risks. All regressions also control for Hispanic, age and age squared. ${ }^{*}$ Statistically significant at the .10 level; ${ }^{* *}$ at the .05 level; ${ }^{* * *}$ at the .01 level. 
Table 19: Diabetes, Poisson Regressions, NHANES III and 1999-2004, Age 25-74

\begin{tabular}{|c|c|c|c|c|c|c|c|c|}
\hline & \multicolumn{4}{|c|}{ Women } & \multicolumn{4}{|c|}{ Men } \\
\hline & (1) & (2) & (3) & (4) & (1) & (2) & (3) & (4) \\
\hline & \multicolumn{8}{|c|}{ NHANES III } \\
\hline Black & $\begin{array}{c}5.94^{* * *} \\
(2.46)\end{array}$ & $\begin{array}{c}3.92^{* * *} \\
(1.68)\end{array}$ & $\begin{array}{c}5.87^{* * *} \\
(2.34)\end{array}$ & $\begin{array}{c}3.76^{* * *} \\
(1.61)\end{array}$ & $\begin{array}{l}3.28^{*} \\
(1.99)\end{array}$ & $\begin{array}{l}3.88^{* *} \\
(2.46)\end{array}$ & $\begin{array}{l}4.85^{* *} \\
(3.10)\end{array}$ & $\begin{array}{l}4.80^{* *} \\
(3.28)\end{array}$ \\
\hline BMI & $\begin{array}{l}1.09^{* * *} \\
(0.01)\end{array}$ & $\begin{array}{c}1.07^{* * *} \\
(0.01)\end{array}$ & $\begin{array}{c}1.10^{* * *} \\
(0.01)\end{array}$ & $\begin{array}{c}1.09^{* * *} \\
(0.01)\end{array}$ & $\begin{array}{l}1.09^{* * *} \\
(0.01)\end{array}$ & $\begin{array}{c}1.07^{* * *} \\
(0.01)\end{array}$ & $\begin{array}{l}1.08^{* * *} \\
(0.02)\end{array}$ & $\begin{array}{c}1.07^{* * *} \\
(0.02)\end{array}$ \\
\hline BMI * Black & $\begin{array}{c}0.96^{* * *} \\
(0.01)\end{array}$ & $\begin{array}{c}0.97^{* * *} \\
(0.01)\end{array}$ & $\begin{array}{c}0.96^{* * *} \\
(0.01)\end{array}$ & $\begin{array}{c}0.97^{* * *} \\
(0.01)\end{array}$ & $\begin{array}{c}0.97 \\
(0.02)\end{array}$ & $\begin{array}{c}0.97 \\
(0.02)\end{array}$ & $\begin{array}{l}0.96^{*} \\
(0.02)\end{array}$ & $\begin{array}{c}0.96^{*} \\
(0.02)\end{array}$ \\
\hline Body Fat Percentage & & & $\begin{array}{l}0.98^{*} \\
(0.01)\end{array}$ & $\begin{array}{l}0.97^{* *} \\
(0.01)\end{array}$ & & & $\begin{array}{c}1.03 \\
(0.02)\end{array}$ & $\begin{array}{c}1.01 \\
(0.02)\end{array}$ \\
\hline Age & $\begin{array}{c}1.06 \\
(0.05)\end{array}$ & $\begin{array}{c}1.07 \\
(0.06)\end{array}$ & $\begin{array}{c}1.07 \\
(0.06)\end{array}$ & $\begin{array}{c}1.09 \\
(0.06)\end{array}$ & $\begin{array}{l}1.25^{* * *} \\
(0.08)\end{array}$ & $\begin{array}{c}1.00^{* * *} \\
(0.00)\end{array}$ & $\begin{array}{l}1.25^{* * *} \\
(0.08)\end{array}$ & $\begin{array}{c}1.00^{* * *} \\
(0.00)\end{array}$ \\
\hline Age Squared & $\begin{array}{c}1.00 \\
(0.00)\end{array}$ & $\begin{array}{c}1.00 \\
(0.00)\end{array}$ & $\begin{array}{c}1.00 \\
(0.00)\end{array}$ & $\begin{array}{c}1.00 \\
(0.00)\end{array}$ & $\begin{array}{c}1.00^{* * *} \\
(0.00)\end{array}$ & $\begin{array}{c}1.27^{* * *} \\
(0.08)\end{array}$ & $\begin{array}{c}1.00^{* * *} \\
(0.00)\end{array}$ & $\begin{array}{c}1.26^{* * *} \\
(0.08)\end{array}$ \\
\hline$N$ & \multicolumn{4}{|c|}{4691} & \multicolumn{4}{|c|}{4030} \\
\hline & \multicolumn{8}{|c|}{ NHANES 1999-2004 } \\
\hline Black & $\begin{array}{c}4.46^{* * *} \\
(2.14)\end{array}$ & $\begin{array}{c}3.81^{* * *} \\
(1.91)\end{array}$ & $\begin{array}{c}4.37^{* * *} \\
(2.35)\end{array}$ & $\begin{array}{l}3.84^{* *} \\
(2.07)\end{array}$ & $\begin{array}{c}3.63^{* * *} \\
(1.68)\end{array}$ & $\begin{array}{c}2.17^{*} \\
(0.90)\end{array}$ & $\begin{array}{c}4.41^{* * *} \\
(2.32)\end{array}$ & $\begin{array}{l}2.71^{\text {** }} \\
(1.28)\end{array}$ \\
\hline BMI & $\begin{array}{c}1.09^{* * *} \\
(0.01)\end{array}$ & $\begin{array}{c}1.08^{* * *} \\
(0.01)\end{array}$ & $\begin{array}{c}1.05^{* * *} \\
(0.01)\end{array}$ & $\begin{array}{c}1.05^{* * *} \\
(0.01)\end{array}$ & $\begin{array}{l}1.08^{* * *} \\
(0.01)\end{array}$ & $\begin{array}{c}1.06^{* * *} \\
(0.01)\end{array}$ & $\begin{array}{c}1.06^{* * *} \\
(0.02)\end{array}$ & $\begin{array}{l}1.04^{* *} \\
(0.02)\end{array}$ \\
\hline BMI * Black & $\begin{array}{l}0.97^{* *} \\
(0.01)\end{array}$ & $\begin{array}{l}0.98^{* *} \\
(0.01)\end{array}$ & $\begin{array}{l}0.98^{*} \\
(0.01)\end{array}$ & $\begin{array}{l}0.98^{*} \\
(0.01)\end{array}$ & $\begin{array}{l}0.97^{* *} \\
(0.01)\end{array}$ & $\begin{array}{c}0.98 \\
(0.01)\end{array}$ & $\begin{array}{l}0.97^{* *} \\
(0.01)\end{array}$ & $\begin{array}{c}0.98^{*} \\
(0.01)\end{array}$ \\
\hline Body Fat Percentage & & & $\begin{array}{c}1.06^{* * *} \\
(0.01)\end{array}$ & $\begin{array}{c}1.05^{* * *} \\
(0.01)\end{array}$ & & & $\begin{array}{c}1.03 \\
(0.03)\end{array}$ & $\begin{array}{c}1.04 \\
(0.03)\end{array}$ \\
\hline Age & $\begin{array}{c}1.16^{* * *} \\
(0.06)\end{array}$ & $\begin{array}{c}1.00^{* * *} \\
(0.00)\end{array}$ & $\begin{array}{c}1.16^{* * *} \\
(0.06)\end{array}$ & $\begin{array}{c}1.00^{* * *} \\
(0.00)\end{array}$ & $\begin{array}{c}1.14^{* * *} \\
(0.05)\end{array}$ & $\begin{array}{c}1.18^{* * *} \\
(0.05)\end{array}$ & $\begin{array}{c}1.14^{* * *} \\
(0.05)\end{array}$ & $\begin{array}{c}1.18^{* * *} \\
(0.05)\end{array}$ \\
\hline Age Squared & $\begin{array}{l}1.00^{*} \\
(0.00)\end{array}$ & $\begin{array}{c}1.21^{* * *} \\
(0.06)\end{array}$ & $\begin{array}{l}1.00^{* *} \\
(0.00)\end{array}$ & $\begin{array}{c}1.21^{* * *} \\
(0.06)\end{array}$ & $\begin{array}{l}1.00^{*} \\
(0.00)\end{array}$ & $\begin{array}{c}1.00^{* * *} \\
(0.00)\end{array}$ & $\begin{array}{l}1.00^{*} \\
(0.00)\end{array}$ & $\begin{array}{c}1.00^{* * *} \\
(0.00)\end{array}$ \\
\hline$N$ & \multicolumn{4}{|c|}{3614} & \multicolumn{4}{|c|}{3345} \\
\hline
\end{tabular}


Table 20: Hypertension, Poisson Regressions, NHANES III and 1999-2004, Age 25-74

\begin{tabular}{|c|c|c|c|c|c|c|c|c|}
\hline & & & & & & & & \\
\hline & $(1)$ & (2) & (3) & (4) & $(1)$ & $(2)$ & (3) & (4) \\
\hline & & & & NH & S III & & & \\
\hline Black & $3.19^{* * *}$ & $3.10^{* * *}$ & $3.27^{* * *}$ & $3.10^{* * *}$ & $1.92^{* *}$ & $1.93^{* *}$ & $2.28^{* * *}$ & $2.18^{* * *}$ \\
\hline & $(0.59)$ & $(0.45)$ & $(0.52)$ & $(0.47)$ & $(0.51)$ & $(0.51)$ & $(0.55)$ & $(0.53)$ \\
\hline BMI & $1.07^{* * *}$ & $1.06^{* * *}$ & $1.05^{* * *}$ & $1.05^{* * *}$ & $1.06^{* * *}$ & $1.06^{* * *}$ & $1.05^{* * *}$ & $1.05^{* * *}$ \\
\hline & $(0.00)$ & $(0.00)$ & $(0.00)$ & $(0.01)$ & $(0.01)$ & $(0.01)$ & $(0.01)$ & $(0.01)$ \\
\hline BMI $*$ Black & $0.97^{* * *}$ & $0.97^{* * *}$ & $0.97^{* * *}$ & $0.97^{* * *}$ & 0.99 & $0.98^{*}$ & $0.98^{* *}$ & $0.98^{* *}$ \\
\hline & $(0.01)$ & $(0.00)$ & $(0.00)$ & $(0.00)$ & $(0.01)$ & $(0.01)$ & $(0.01)$ & $(0.01)$ \\
\hline Bodyfat Percentage & & & $1.02^{* * *}$ & $1.02^{* * *}$ & & & $1.03^{* * *}$ & $1.03^{* * *}$ \\
\hline & & & $(0.01)$ & $(0.01)$ & & & $(0.01)$ & $(0.01)$ \\
\hline Age & 1.03 & $1.05^{* *}$ & 1.04 & $1.05^{* *}$ & $1.10^{* * *}$ & $1.00^{* * *}$ & $1.10^{* * *}$ & $1.00^{* * *}$ \\
\hline & $(0.03)$ & $(0.03)$ & $(0.03)$ & $(0.03)$ & $(0.03)$ & $(0.00)$ & $(0.03)$ & $(0.00)$ \\
\hline Age Squared & 1.00 & 1.00 & 1.00 & 1.00 & $1.00^{* *}$ & $1.13^{* * *}$ & $1.00^{* * *}$ & $1.13^{* * *}$ \\
\hline & $(0.00)$ & $(0.00)$ & $(0.00)$ & $(0.00)$ & $(0.00)$ & $(0.02)$ & $(0.00)$ & $(0.02)$ \\
\hline$N$ & & & & & & & & \\
\hline & & & & NHANI & 99-2004 & & & \\
\hline Black & $3.26^{* * *}$ & $3.01^{* * *}$ & $3.25^{* * *}$ & $2.96^{* * *}$ & $1.66^{*}$ & $1.59^{*}$ & $2.00^{* *}$ & $1.86^{* *}$ \\
\hline & $(0.73)$ & $(0.69)$ & $(0.77)$ & $(0.71)$ & $(0.44)$ & $(0.41)$ & $(0.58)$ & $(0.51)$ \\
\hline BMI & $1.06^{* * *}$ & $1.05^{* * *}$ & $1.04^{* * *}$ & $1.04^{* * *}$ & $1.06^{* * *}$ & $1.05^{* * *}$ & $1.03^{* * *}$ & $1.02^{* *}$ \\
\hline & $(0.00)$ & $(0.00)$ & $(0.01)$ & $(0.01)$ & $(0.01)$ & $(0.00)$ & $(0.01)$ & $(0.01)$ \\
\hline BMI * Black & $0.97^{* * *}$ & $0.98^{* * *}$ & $0.98^{* * *}$ & $0.98^{* * *}$ & 0.99 & 0.99 & 0.99 & 0.99 \\
\hline & $(0.01)$ & $(0.01)$ & $(0.01)$ & $(0.01)$ & $(0.01)$ & $(0.01)$ & $(0.01)$ & $(0.01)$ \\
\hline Bodyfat Percentage & & & $1.03^{* * *}$ & $1.02^{* * *}$ & & & $1.04^{* * *}$ & $1.04^{* * *}$ \\
\hline & & & $(0.01)$ & $(0.01)$ & & & $(0.02)$ & $(0.02)$ \\
\hline Age & $1.09^{* * *}$ & $1.00^{* * *}$ & $1.09^{* * *}$ & $1.00^{* * *}$ & 1.03 & $1.05^{*}$ & 1.03 & $1.05^{*}$ \\
\hline & $(0.02)$ & $(0.00)$ & $(0.02)$ & $(0.00)$ & $(0.02)$ & $(0.03)$ & $(0.02)$ & $(0.03)$ \\
\hline Age Squared & $1.00^{* * *}$ & $1.10^{* * *}$ & $1.00^{* * *}$ & $1.10^{* * *}$ & 1.00 & 1.00 & 1.00 & 1.00 \\
\hline & $(0.00)$ & $(0.02)$ & $(0.00)$ & $(0.02)$ & $(0.00)$ & $(0.00)$ & $(0.00)$ & $(0.00)$ \\
\hline$N$ & & & & & & & & \\
\hline
\end{tabular}


Table 21: BMI Dissatisfaction ${ }^{a}$, Linear Regressions, BRFSS (selected years), Individuals age 25-74

\begin{tabular}{|c|c|c|}
\hline & Women & Men \\
\hline BMI & $\begin{array}{c}0.637^{* * *} \\
(0.004)\end{array}$ & $\begin{array}{c}0.497^{* * *} \\
(0.007)\end{array}$ \\
\hline Age & $\begin{array}{c}0.028^{* * *} \\
(0.002)\end{array}$ & $\begin{array}{c}0.068^{* * *} \\
(0.003)\end{array}$ \\
\hline Age Squared & $\begin{array}{c}-0.001^{* * *} \\
(0.000)\end{array}$ & $\begin{array}{c}-0.001^{* * *} \\
(0.000)\end{array}$ \\
\hline Black & $\begin{array}{c}\mathbf{- 1 . 0 4 0}^{* * *} \\
(0.026)\end{array}$ & $\begin{array}{c}\mathbf{- 0 . 5 3 4}^{* * *} \\
(0.026)\end{array}$ \\
\hline 1994 & $\begin{array}{c}-0.158^{* * *} \\
(0.026)\end{array}$ & $\begin{array}{c}-0.550^{* * *} \\
(0.035)\end{array}$ \\
\hline 1996 & $\begin{array}{c}-0.190^{* * *} \\
(0.025)\end{array}$ & $\begin{array}{c}-0.597^{* * *} \\
(0.034)\end{array}$ \\
\hline 1998 & $\begin{array}{c}-0.251^{\text {**** }} \\
(0.026)\end{array}$ & $\begin{array}{c}-0.660^{* * *} \\
(0.034)\end{array}$ \\
\hline 2000 & $\begin{array}{c}-0.236^{* * *} \\
(0.026)\end{array}$ & $\begin{array}{c}-0.650^{* * *} \\
(0.034)\end{array}$ \\
\hline High School & $\begin{array}{c}0.188^{* * *} \\
(0.024)\end{array}$ & $\begin{array}{l}-0.016 \\
(0.029)\end{array}$ \\
\hline Some College & $\begin{array}{c}0.196^{* * *} \\
(0.027)\end{array}$ & $\begin{array}{c}0.147^{* * *} \\
(0.029)\end{array}$ \\
\hline Married & $\begin{array}{c}0.013 \\
(0.013)\end{array}$ & $\begin{array}{c}-0.077^{* * *} \\
(0.016)\end{array}$ \\
\hline Smoker & $\begin{array}{c}0.135^{* * *} \\
(0.012)\end{array}$ & $\begin{array}{l}0.023^{*} \\
(0.015)\end{array}$ \\
\hline
\end{tabular}


Table 22: Weight Perceptions, NHANES III, Multinomial Logit Regressions, Age 25-74

\begin{tabular}{|c|c|c|c|c|}
\hline & \multicolumn{2}{|c|}{ Women } & \multicolumn{2}{|c|}{ Men } \\
\hline & "Underweight" & "Overweight" & "Underweight" & "Overweight" \\
\hline \multirow[t]{2}{*}{ Black } & $3.52^{* * *}$ & $\mathbf{0 . 3 3} 3^{* * *}$ & $1.50^{* *}$ & $0.48^{* * *}$ \\
\hline & $(0.92)$ & $(0.04)$ & $(0.31)$ & $(0.07)$ \\
\hline \multirow[t]{2}{*}{ Hispanic } & $2.61^{* * *}$ & $0.41^{* * *}$ & 0.93 & $0.78^{*}$ \\
\hline & $(0.80)$ & $(0.07)$ & $(0.25)$ & $(0.11)$ \\
\hline \multirow[t]{2}{*}{ Other } & $1.97^{* *}$ & $0.49^{* * *}$ & 1.73 & 0.74 \\
\hline & $(0.64)$ & $(0.10)$ & $(0.72)$ & $(0.15)$ \\
\hline \multirow[t]{2}{*}{ BMI } & $0.54^{* * *}$ & $1.65^{* * *}$ & $0.60^{* * *}$ & $1.59^{* * *}$ \\
\hline & $(0.04)$ & $(0.04)$ & $(0.04)$ & $(0.05)$ \\
\hline \multirow[t]{2}{*}{ Age } & $1.02^{* *}$ & $0.97^{* * *}$ & 0.99 & $0.99^{* * *}$ \\
\hline & $(0.01)$ & $(0.00)$ & $(0.01)$ & $(0.00)$ \\
\hline \multirow[t]{2}{*}{ High School } & $0.53^{* *}$ & $1.76^{* * *}$ & 0.86 & 1.34 \\
\hline & $(0.14)$ & $(0.22)$ & $(0.26)$ & $(0.24)$ \\
\hline \multirow[t]{2}{*}{ Some College (or above) } & $0.43^{* * *}$ & $1.72^{* * *}$ & 0.90 & $1.84^{* * *}$ \\
\hline & $(0.13)$ & $(0.24)$ & $(0.29)$ & $(0.35)$ \\
\hline \multirow[t]{2}{*}{ Middle Income } & 1.11 & $1.39^{*}$ & 1.12 & $1.52^{* * *}$ \\
\hline & $(0.36)$ & $(0.24)$ & $(0.27)$ & $(0.18)$ \\
\hline \multirow[t]{2}{*}{ High Income } & 0.56 & 1.23 & 0.76 & $1.53^{* *}$ \\
\hline & $(0.21)$ & $(0.21)$ & $(0.20)$ & $(0.27)$ \\
\hline \multirow[t]{2}{*}{ Married or Cohabiting } & 1.40 & 1.33 & 0.87 & 1.21 \\
\hline & $(0.54)$ & $(0.26)$ & $(0.22)$ & $(0.19)$ \\
\hline \multirow[t]{2}{*}{ Formerly Married } & 1.17 & 1.34 & 1.28 & 1.30 \\
\hline & $(0.47)$ & $(0.29)$ & $(0.53)$ & $(0.31)$ \\
\hline$N$ & \multicolumn{2}{|c|}{6131} & \multicolumn{2}{|c|}{5516} \\
\hline
\end{tabular}

Notes: Coefficients represent relative risk ratios. Base category is normal weight ("about right"). Standard errors are reported in parentheses. ${ }^{*}$ Statistically significant at the .10 level; ${ }^{* *}$ at the .05 level; ${ }^{* * *}$ at the .01 level. 
Table 23: Weight Perceptions, NHANES 1999-2004 Multinomial Logit Regressions, Age 25-74

\begin{tabular}{lcccc}
\hline & \multicolumn{2}{c}{ Women } & \multicolumn{2}{c}{ Men } \\
& "Underweight" & "Overweight" & "Underweight" & "Overweight" \\
\hline \multirow{3}{*}{ Black } & $\mathbf{3 . 2 2}^{* * *}$ & $\mathbf{0 . 3 3}^{* * *}$ & $\mathbf{1 . 1 5}$ & $\mathbf{0 . 3 5}^{* * *}$ \\
BMI & $(1.44)$ & $(0.04)$ & $(0.23)$ & $(0.05)$ \\
& $0.48^{* * *}$ & $1.57^{* * *}$ & $0.63^{* * *}$ & $1.57^{* * *}$ \\
Age & $(0.08)$ & $(0.03)$ & $(0.03)$ & $(0.04)$ \\
& 1.02 & 0.99 & $0.99^{*}$ & 1.01 \\
High School & $(0.01)$ & $(0.00)$ & $(0.01)$ & $(0.00)$ \\
& 0.66 & $1.86^{* *}$ & 1.13 & 1.18 \\
Some College (or above) & $(0.27)$ & $(0.55)$ & $(0.30)$ & $(0.26)$ \\
& $0.35^{* *}$ & $1.69^{* * *}$ & 1.06 & $1.68^{* * *}$ \\
Middle Income & $(0.15)$ & $(0.32)$ & $(0.26)$ & $(0.30)$ \\
& $0.52^{*}$ & $1.53^{* *}$ & 0.68 & $1.32^{*}$ \\
High Income & $(0.17)$ & $(0.28)$ & $(0.17)$ & $(0.20)$ \\
& $0.37^{* *}$ & $1.74^{* * *}$ & $0.35^{* * *}$ & $1.37^{* *}$ \\
Married or Cohabiting & $(0.15)$ & $(0.31)$ & $(0.09)$ & $(0.18)$ \\
Formerly Married & 0.75 & $1.64^{* *}$ & 0.96 & $1.53^{*}$ \\
& $(0.32)$ & $(0.37)$ & $(0.24)$ & $(0.38)$ \\
$N$ & 0.96 & 1.20 & 0.91 & 1.30 \\
& $(0.46)$ & $(0.24)$ & $(0.35)$ & $(0.32)$ \\
\hline
\end{tabular}

Notes: Coefficients represent relative risk ratios. Base category is normal weight ("about right"). Standard errors are reported in parentheses. ${ }^{*}$ Statistically significant at the .10 level; ${ }^{* *}$ at the .05 level; ${ }^{* * *}$ at the .01 level. 
Table 24: Magazines Arranged by Mean Body Shape Rating ${ }^{\mathrm{a}}$

\begin{tabular}{|c|c|c|c|c|c|}
\hline Magazine Title & Mean Body Shape Rating & Images & Magazine Title & Mean Body Shape Rating & Images \\
\hline Teen & 1.86 & 6 & Good Housekeeping & 2.85 & 8 \\
\hline Rolling Stone & 2.00 & 2 & Cosmopolitan & 2.92 & 16 \\
\hline Allure & 2.29 & 13 & Redbook & 2.92 & 7 \\
\hline YM (Young \& Modern) & 2.41 & 11 & Shape & 2.99 & 8 \\
\hline Mademoiselle & 2.49 & 6 & Prevention & 3.00 & 1 \\
\hline Newsweek & 2.50 & 1 & Glamour & 3.02 & 16 \\
\hline Health & 2.50 & 3 & McCalls & 3.17 & 8 \\
\hline Self & 2.52 & 7 & Seventeen & 3.19 & 7 \\
\hline Vogue & 2.54 & 26 & Family Circle & 3.32 & 14 \\
\hline Ebony & 2.55 & 7 & Sports Illustrated & 3.38 & 2 \\
\hline Entertainment Weekly & 2.64 & 26 & Woman's Day & 3.41 & 18 \\
\hline Details & 2.65 & 5 & Ladies' Home Journal & 3.62 & 13 \\
\hline Elle & 2.70 & 4 & People & 3.79 & 7 \\
\hline New Woman & 2.72 & 6 & Essence & 4.00 & 4 \\
\hline Fitness & 2.84 & 23 & & & \\
\hline
\end{tabular}

